\title{
Investigating insulin resistance in human obesity with transcriptomics
}

Citation for published version (APA):

Kalafati, M. (2021). Investigating insulin resistance in human obesity with transcriptomics: towards precision-based strategies. [Doctoral Thesis, Maastricht University]. Maastricht University. https://doi.org/10.26481/dis.20211112mk

Document status and date:

Published: 01/01/2021

DOI:

10.26481/dis.20211112mk

Document Version:

Publisher's PDF, also known as Version of record

\section{Please check the document version of this publication:}

- A submitted manuscript is the version of the article upon submission and before peer-review. There can be important differences between the submitted version and the official published version of record.

People interested in the research are advised to contact the author for the final version of the publication, or visit the DOI to the publisher's website.

- The final author version and the galley proof are versions of the publication after peer review.

- The final published version features the final layout of the paper including the volume, issue and page numbers.

Link to publication

\footnotetext{
General rights rights.

- You may freely distribute the URL identifying the publication in the public portal. please follow below link for the End User Agreement:

www.umlib.nl/taverne-license

Take down policy

If you believe that this document breaches copyright please contact us at:

repository@maastrichtuniversity.nl

providing details and we will investigate your claim.
}

Copyright and moral rights for the publications made accessible in the public portal are retained by the authors and/or other copyright owners and it is a condition of accessing publications that users recognise and abide by the legal requirements associated with these

- Users may download and print one copy of any publication from the public portal for the purpose of private study or research.

- You may not further distribute the material or use it for any profit-making activity or commercial gain

If the publication is distributed under the terms of Article $25 \mathrm{fa}$ of the Dutch Copyright Act, indicated by the "Taverne" license above, 


\section{Investigating insulin resistance in human obesity with transcriptomics:}

Towards precision-based strategies

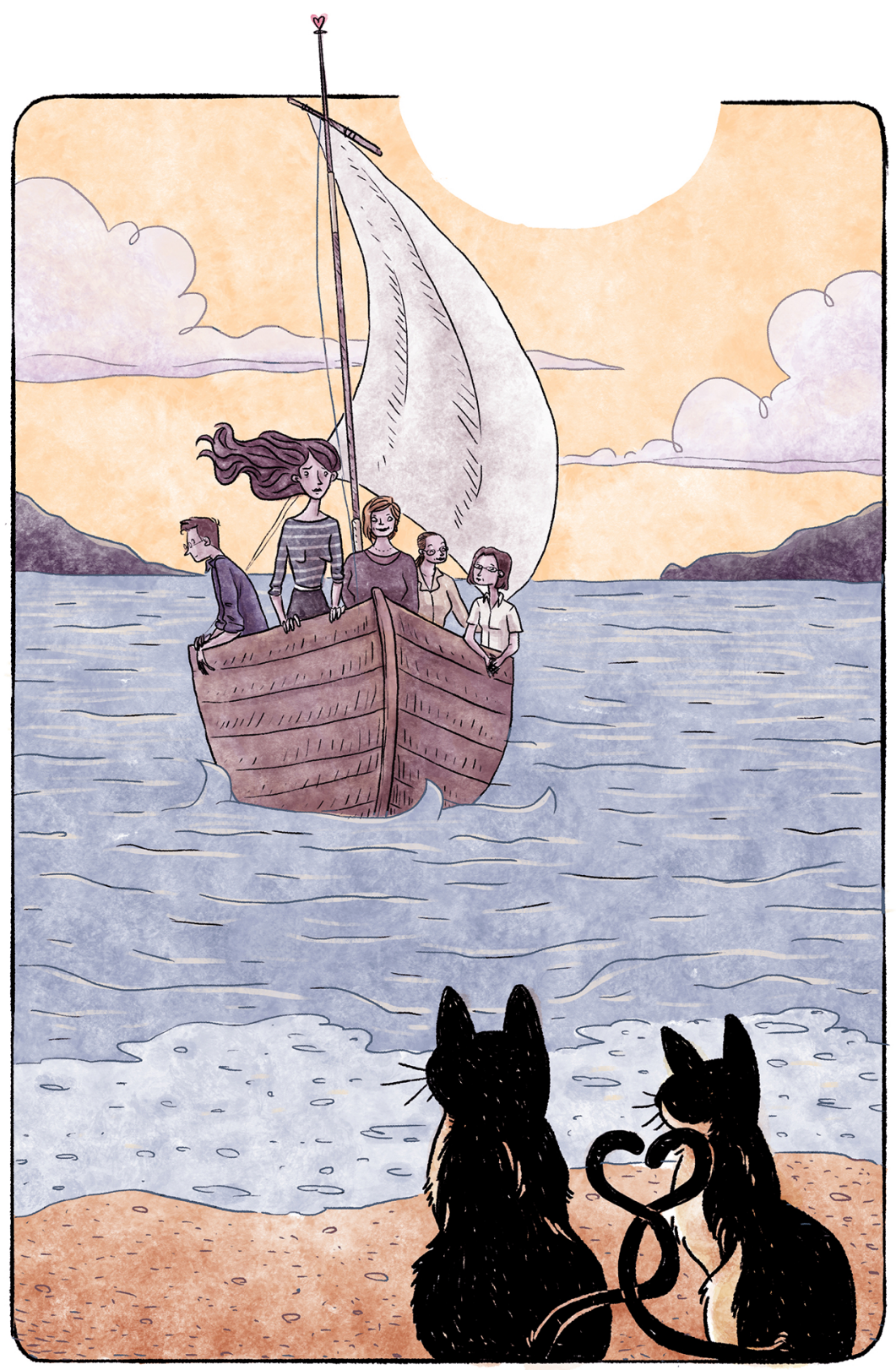

Marianthi Kalafati 


\section{Investigating insulin resistance in human obesity with transcriptomics:}

Towards precision-based strategies 


\section{Investigating insulin resistance in human obesity with transcriptomics:}

Towards precision-based strategies

DISSERTATION

Author: Marianthi Kalafati

Cover design: Efi Theodorakopoulou

Layout: Ilse Modder, www.ilsemodder.nl

Printing by: Gildeprint, www.gildepint.nl

ISBN: 978-94-6419-346-6

to obtain the degree of Doctor at the Maastricht University,

on the authority of the Rector Magnificus,

$$
\text { Prof. dr. Rianne M. Letschert }
$$

in accordance with the decision of the Board of Deans, to be defended in public

on Friday 12th November 2021, at 10.00 hours 
Supervisor

Prof. dr. Ellen E. Blaak

Co-supervisors

Dr. Marleen M.J. van Greevenbroek

Dr. Martina Summer-Kutmon

Dr. ir. Michiel E. Adriaens

Assessment committee

Prof. dr. E.C.M. Mariman (Chair)

Prof. dr. R. Shiri-Sverdlov

Dr. K. Wouters

Prof. dr.ir. J.A.P. Willems van Dijk, Leiden University Medical Center

Dr.ir. P.D. Moerland, Amsterdam UMC 
As you set out for Ithaka

hope your road is a long one,

full of adventure, full of discovery.

Laistrygonians, Cyclops,

angry Poseidon-don't be afraid of them:

you'll never find things like that on your way

as long as you keep your thoughts raised high,

as long as a rare excitement

stirs your spirit and your body.

Laistrygonians, Cyclops,

wild Poseidon-you won't encounter them

unless you bring them along inside your soul,

unless your soul sets them up in front of you.

Hope your road is a long one.

May there be many summer mornings when, with what pleasure, what joy,

you enter harbors you're seeing for the first time; may you stop at Phoenician trading stations to buy fine things,

mother of pearl and coral, amber and ebony, sensual perfume of every kind-

as many sensual perfumes as you can;

and may you visit many Egyptian cities

to learn and go on learning from their scholars.
Keep Ithaka always in your mind.

Arriving there is what you're destined for.

But don't hurry the journey at all.

Better if it lasts for years,

so you're old by the time you reach the island,

wealthy with all you've gained on the way,

not expecting Ithaka to make you rich.

Ithaka gave you the marvelous journey.

Without her you wouldn't have set out.

She has nothing left to give you now.

And if you find her poor, Ithaka won't have fooled you.

Wise as you will have become, so full of experience, you'll have understood by then what these Ithakas mean.

"Ithaka" C. P. Cavafy, "The City” from C.P. Cavafy: Collected Poems. Translated by Edmund Keeley and Philip Sherrard. Translation Copyright @ 1975, 1992 by Edmund Keeley and Philip Sherrard. Reproduced with permission of Princeton University Press. Source: C.P. Cavafy: Collected Poems (Princeton University Press, 1975) 


\section{Table of contents}

Chapter 1 General Introduction

Chapter 2

hapter 3

Chapter 4

hapter 5

hapter 6

Appendices
Subcutaneous adipose tissue and systemic inflammation are associated with peripheral but not hepatic insulin resistance in humans

Metabolic features and adipose tissue gene expression analysis in individuals discordant for adipose tissue and muscle insulin resistance

Assessing the contribution of relative macrophage frequencies to subcutaneous adipose tissue

An interferon related signature characterizes the whole blood transcriptome profile of insulin resistant individuals - The CODAM study

General Discussion

Impact paragraph

Acknowledgments

About the author

List of publications 


\section{Obesity epidemic and insulin resistance}

The World Health Organization (WHO) defines obesity and overweight as abnormal or excessive fat accumulation, an energy imbalance, driven by increased intake of energydense foods and decreased physical activity. Worldwide obesity (body mass index (BMI) $\geq 30 \mathrm{~kg} / \mathrm{m}^{2}$ ), has nearly tripled since 1975 and is expected to affect 1.12 billion persons by 2030, while overweight (BMI $\geq 25 \mathrm{~kg} / \mathrm{m}^{2}$ ) is expected to reach 2.16 billion (1). Obesity is characterised as a major global health and socio-economic problem that has grown to epidemic proportions (2). The underlying causes of obesity are complicated, including genetic, biological, social and cultural reasons (3). Several scientists consider the epidemic phenomenon of obesity a result of social globalisation where overnutrition and the reduced physical activity is associated with the industrialisation of societies (4).

Obesity and overweight have a great impact on health and well-being. Both obesity and overweight present several risks to health, as they are associated with insulin resistance (IR), which is a risk factor for the development of type 2 diabetes mellitus (T2DM) (5). Furthermore, IR is associated with metabolic and cardiovascular disorders, which may be independent risk factors for cardiovascular disease (CVD) (6). On top of that, obesity can greatly affect mental health, as obese persons commonly face social stigma (7). Taking all of these into consideration, obesity is officially recognised as a disease (8) and there is a significant amount of effort from the scientific community to find novel ways in combatting the obesity epidemic. On that note, there are several ways to address obesity, from nutritional interventions to surgery (9).

Nutritional interventions, including personalised advice based on conventional recommendations for a healthy diet and physical activity that are aiming at weight loss, are effective short-term. Several studies have shown that weight loss (even a moderate one) reduces the incidence of $\mathrm{T} 2 \mathrm{DM}$ and improves cardiometabolic risk profile (10-13). Unfortunately, maintaining that weight (and therefore not regaining it) can be extremely difficult, as several individuals do not respond or adhere to the nutritional interventions $(14,15)$.

Thus, current interventions and therapies that are aiming to reverse obesity and related cardiometabolic complications are not effective for the majority of the overweight and obese individuals, which emphasises the need for more targeted strategies. In the prevention of obesity-related health risks, besides adipose tissue mass, adipose tissue function and distribution of body fat must be taken into account, as they are among the most important contributing factors determining the individual risk to develop obesityassociated cardiometabolic diseases, IR and T2DM (16-19). It is therefore apparent, that in order to define more targeted prevention and treatment for patients with IR, T2DM and cardiometabolic diseases, we need to improve our understanding of the underlying mechanisms associated with obesity to IR. This way, we will improve our knowledge of the IR and T2DM pathogenesis, propose novel targets for precision-based strategies and determine whether these strategies are effective in the long-term in the prevention or treatment of obesity-associated health risks.

\section{Insulin and insulin resistance}

Insulin was the first peptide hormone to be discovered by Sir Frederick Banting, Charles Best and John Macleod at the University of Toronto in 1921 and James Collip subsequently purified it. Insulin is produced by the beta cells of the pancreatic islets and regulates the metabolism of carbohydrates, fats and protein by promoting the absorption of glucose from the circulation into metabolic organs such as adipose tissue, skeletal muscle, and liver.

Insulin is activated in response to increased glucose levels (e.g. when food is consumed), but it may be increased or decreased in response to other stimuli, such as circulating free fatty acids (FFA), amino acids or hormones (e.g. incretins and leptin) (20). Insulin plays an important role in nutrient partitioning within the body and the regulation of energy homeostasis (21). Beta cells respond to the increase in blood glucose levels by secreting insulin into the circulation. Blood glucose reduces, while insulin increases by increasing glucose uptake in peripheral tissues (e.g. skeletal muscle, subcutaneous adipose tissue) and suppressing the endogenous glucose production (EGP). Insulin promotes glucose uptake into the skeletal muscle (80-90\%) while the liver greatly contributes to EGP (22). Finally, insulin promotes glucose uptake into the adipose tissue (10-20\%)(22) and efficiently represses adipose tissue lipolysis (23).

However sometimes, cells are resistant to the effects of insulin on glucose uptake, metabolism or storage, a pathological condition called IR. Whole-body IR is indicative of impaired tissue (e.g. adipose tissue, skeletal muscle, liver) insulin action. Insulin sensitivity therefore describes how sensitive the body is to the effects of insulin. In the course of everyday life, fluctuations in insulin sensitivity can occur and in fact, IR has been observed in certain life periods, such as puberty, pregnancy and aging (24). On the other hand, lifestyle factors (e.g. increased or decreased physical activity, eating habits) greatly modulate insulin sensitivity (24).

IR plays an important role in hyperglycemia, dyslipidemia, and ectopic fat (lipid) accumulation, which together greatly contribute to type 2 diabetes $(25,26)$. In addition, IR may develop in different organs at a different rate or degree, resulting in substantial diversity in cardiometabolic risk among obese individuals. There is evidence reporting distinct metabolome (27) and lipidome (28) profiles associated with liver and muscle IR. 
Recently, Song et al. reported that there are adults discordant for measures of adipose tissue IR and whole-body IR, which in fact have unique metabolic features (29). Finally, there is growing evidence that shows that different tissues respond differently to nutritional and pharmacological interventions that aim to increase insulin sensitivity. For instance, in individuals with liver insulin, metformin and a low-fat, high complex carbohydrate diet might be a more effective treatment, whereas in individuals with muscle IR a Mediterranean or Palaeolithic diet may enhance muscle insulin sensitivity (30-32). Therefore, it is important to recognise the tissue-specific effects (and defects) of insulin, as this knowledge might enhance developments towards more precision-based strategies.

\section{Obesity, insulin resistance and adipose tissue dysfunction}

Besides increased adipose tissue mass, adipose tissue dysfunction and ectopic lipotoxicity greatly contribute to obesity-associated IR (16-18), which are characterised by reduced capacity of subcutaneous adipose tissue (SAT) to store the excess fat, ectopic fat deposition and adipocyte hypertrophy, and increased low-grade inflammation (16-18).

In fact, low-grade inflammation is considered one of the hallmarks in the development of many metabolic disturbances in obesity (18), which is characterised by production and secretion of pro-inflammatory factors (e.g. cytokines, chemokines) by adipocytes and other immune cells (33). On that note, research performed by Xu et al. (34) and Weisberg et al. (35) showed that obesity and obesity-induced IR was associated with significant increase in the numbers of macrophages in adipose tissue, combined with changes in their location and inflammatory phenotype (36). In obese persons, monocytes infiltrate the adipose tissue and become adipose tissue macrophages. They surround dead adipocytes forming crownlike structures, secreting pro-inflammatory cytokines, and affect adipocytes and other immune cells, thereby increasing local and systemic inflammation and promoting IR (37).

It is apparent that the pathophysiology of IR is very complex, implicating many cellular mechanisms and there is no unifying mechanism linking IR to the associated metabolic defects. Research performed in the last decades has increased the understanding of how tissues communicate by secreting factors (e.g. proteins, lipids, metabolites, non-coding RNAs) and influencing the local functions of a tissue but also the biological processes in other tissues via the systemic circulation. Hence, gaining more knowledge into the interorgan crosstalk between adipose tissue, liver and skeletal muscle, is important for the regulation of whole-body energy homeostasis. Additionally, it could help to elucidate the complex systems contributing to obesity and IR.

\section{Ectopic fat deposition, organ crosstalk and insulin resistance}

Among the traditional roles of insulation and energy storage, the adipose tissue has very important roles in energy metabolism, and it is recognised as an endocrine organ, regulating processes such as insulin sensitivity and inflammation. In humans, the adipose tissue is located under the skin (SAT), around internal organs (visceral adipose tissue; VAT) and other areas (e.g. bone marrow, breast, intermuscular).

During obesity, the SAT expands in response to an excessive caloric intake. SAT expansion occurs either via an increase in adipocyte numbers (hyperplasia) or via enlargement of the adipocyte size (hypertrophy). Hyperplasia usually associates with healthy adipose tissue expansion (adipogenesis), whereas hypertrophy usually associates with unhealthy adipose tissue expansion $(16,18)$. In fact, during an unhealthy expansion and impaired adipogenesis, the adipose tissue might become dysfunctional, resulting in inability to store the energy surplus. When the capacity of the SAT is reached, adipose tissue lipolysis is impaired (23), and adipose tissue IR results in increased circulating FFAs (38). This caloric overload results to ectopic fat deposition (e.g. in liver, skeletal muscle) and IR (lipotoxicity)(38).

The skeletal muscle is an insulin-sensitive tissue, comprising a large percentage of the body mass $(40 \%-50 \%)$. It is responsible for $30 \%$ of resting oxygen consumption and $80 \%$ of total body glucose uptake $(39,40)$. Skeletal muscle IR frequently describes the impaired insulin regulation of glucose homeostasis, which might contribute to the development of other metabolic abnormalities (22). Besides the increased lipid supply from the adipose tissue and liver, mitochondrial dysfunction might also lead to increased lipid accumulation (41). Furthermore, the liver is very important for energy storage and has a central role in glucose and lipid metabolism. During obesity, the excess of FFAs and inflammatory factors that is released from adipose tissue into the circulation, promotes ectopic fat in the liver (also known as "portal hypothesis"), which is associated with hepatic IR (42). 


\section{Investigating insulin resistance in human obesity with transcriptomics data}

The way we make clinical decisions has been transformed; from measuring a biological sample (e.g. blood sample from a patient) to measuring large amount of omics data (e.g. DNA, RNA, protein, metabolites) from different tissues and technologies. With this plethora of information at hand, analysing, and integrating this information in a meaningful way became a great challenge. In fact, the fields of bioinformatics and systems biology provided solutions in this great challenge with the use of omics technologies. In general, omics technologies refer to high-throughput biochemical assays that measure efficiently and concurrently molecules from a biological sample (43). The most commonly used technology is transcriptomics, due to its affordability, comprehensiveness and technical matureness. In this thesis, we used transcriptomics (microarrays and RNA sequencing) data, and in one chapter, we used DNA methylation data to estimate cell-type composition to enable a cell-type independent transcriptome analysis.

Transcriptomics is the study of the transcriptome, which refers to the complete set of RNA transcripts that are produced by the genome, under certain conditions in an individual cell, tissue or organism. Transcriptomics refers to all types of transcripts (e.g. messenger RNAs (mRNAs)) and includes information on transcription, function, locations, trafficking and degradation of an organism. Present-day transcriptomics employ high-throughput technologies to analyse the expression of multiple transcripts in different physiological or pathological conditions. Some of the most commonly used technologies are microarrays and RNA sequencing, which aim to broaden our understanding of the relation between the transcriptome and the phenotype over different biological samples.

In addition to analysis of the lipidome (28) or the metabolome (27), analysis of gene expression in adipose tissue may help elucidate the pathways and mechanisms that link adipose tissue function to IR, and identify distinct IR transcriptome profiles that may provide leads for more personalized prevention of cardiometabolic diseases. Previous studies have shown significant dysregulation in the SAT transcriptome in obesity and IR (44). For instance, Elbein et al. (45) found that SAT inflammatory and cell cycle-regulatory pathways were upregulated in individuals with whole-body IR compared to insulin sensitive BMI-matched individuals, while lipid metabolism pathways were downregulated. Furthermore, Soronen et al. (46) observed upregulation of inflammatory pathways and downregulation of mitochondrial respiratory and lipid metabolism pathways in obese women with whole-body IR. Finally, recent transcriptome analyses of abdominal SAT during weight loss in individuals from the Diet, Obesity, and Genes (DiOGenes) study highlighted the link between lipid metabolism pathways and glycemic improvement (47).
Estimating cell-type composition computationally, using transcriptomics and DNA methylation data in the context of obesity and insulin resistance

Biological tissue samples are characterized by heterogeneous and varying cellular composition, e.g. with several cell types present in each samples. Bulk gene expression or RNA sequencing methods measure average behaviour and not changes in cell states, which makes it difficult to identify the precise gene expression levels for each cell. Particularly when identifying gene expression changes (e.g. in different conditions), changes in cell type composition might provide misleading and difficult to interpret results (48-50). Subsequently, apart from experimental methods (e.g. immunochemistry), the generation of computational deconvolution methods, provided with cell-type specific information from genomic profiles of mixture samples $(48,51,52)$.

Furthermore, an alternative data source for the estimation of cell-type composition is DNA methylation data. Briefly, epigenomics is the study of the epigenome, which is the complete set of epigenetic modifications in the genetic material of a cell. Two of the most known epigenetic modifications are DNA methylation and histone modification. DNA methylation regulates gene expression regulation and chromosomal stability (53). In fact, it is accepted that each cell-type has a different DNA-methylation pattern (epigenetic make-up), which can be used to identify specific cell types $(54,55)$.

Besides changes in macrophage numbers, location and phenotype, studies performed in human and mouse have shown that accumulation of T-cells precedes macrophage accumulation in obese adipose tissue (61) and that numerous changes in their subpopulations are also linked to the development of obesity and IR in animal models (62). In this thesis, I have used transcriptomics to estimate cell-type composition in adipose tissue. Furthermore, I have used DNA methylation data to estimate cell-type composition in whole blood, to enable a cell-type independent transcriptome analysis. Defining cell subpopulations in these tissues can be beneficial when studying IR, diabetes and obesity.

\section{Transcriptomics data visualization and interpretation}

The output of transcriptomics data analysis can be very complex and difficult to grasp. Therefore, several methods (e.g. graphs, pathways, videos, animations) can be used to illustrate this information in an intuitive way. For the purposes of this thesis, I have used pathway diagrams and networks, briefly introduced in the next paragraphs.

A biological pathway is a schematic illustration of a series of events between molecules of a cell aiming to better understand a biological process that leads to a certain product or a change in the cell. They are widely used by researchers and are commonly drawn with pathway editors. These pathway editors are linked to online databases that 
provide important information regarding the pathway elements and their interactions. Furthermore, they enable integration and visualization of high-throughput biological data on a pathway.

Network biology is based on well-defined principles of graph theory and network science, which are commonly used in the field of computer science. They became more extensively used when Barabási and Albert showed that certain network properties (scalefree network properties) emerges in biological systems (e.g. metabolic networks, proteinprotein interaction networks) (56). Hence, network biology is the study and application of graph theory, aiming to integrate and visualize high-throughput biological, while a biological network refers to any network describing a biological system. For example, a pathway can be transformed to a network, allowing for data visualization and network analysis (57), or several pathways can be combined into a network, enabling genepathway associations. Such networks can be integrated with regulatory interactions (e.g. microRNA, transcription factor and/or drug target interactions)(58), or with co-expression information for uncovering group of genes regulated or targeted together (59).

\section{Thesis objectives and study design}

It is becoming more apparent that sub-typing obese individuals based on IR phenotype or metabolic health may lead to a better understanding of the relationship between IR and cardiometabolic risk. This may give leads to optimize prevention and treatment towards precision-based strategies. The primary goal of this thesis was to investigate IR subphenotypes in human obesity with transcriptomic data from the adipose tissue and whole blood. For the purposes of this thesis, we applied data driven computational approaches, such as differential gene expression analysis, biological pathway and network analysis.

\section{Thesis outline}

Analysis of gene expression in SAT may help to elucidate the pathways and mechanisms that link adipose tissue function to adipose to tissue-specific insulin resistance. To obtain possible targets for personalized intervention and treatment strategies, we need more information on these distinct phenotypes. In Chapter 2, we study the SAT transcriptome of overweight and obese participants without diabetes from the DiOGenes study (6o), a large European multicentre dietary intervention study. We analysed baseline RNA sequencing data in abdominal subcutaneous adipose tissue from 368 individuals and identified gene clusters that were associated with muscle or hepatic insulin resistance. Subsequently, we investigate whether we could confirm mechanisms suggested by subcutaneous adipose tissue transcriptome findings by performing complementary analyses on systemic inflammatory profiles in two independent human cohorts, namely, CODAM (Cohort on Diabetes and Atherosclerosis Maastricht) (61) and the Maastricht Study (62). In Chapter 3, in the DiOGenes study, we investigate the presence and proportion of individuals who are discordant for IR in adipose tissue and in muscle and we characterize their clinical and metabolic features as well as their subcutaneous adipose tissue transcriptome.

Understanding the contribution of immune cells to adipose tissue dysfunction and plasticity, but also the interplay with adipocytes, adipokines, adipose tissue secreted cytokines and other non-adipose tissues, can offer insights on how to control immunometabolism in health and disease. In Chapter 4, we present an approach that assesses the contribution of macrophage frequencies to the overall SAT gene expression. We used the computational algorithm TissueDecoder (51) to infer the subcutaneous adipose tissue cell-type composition from publicly available, gene expression microarray datasets. Furthermore, we divided our samples based on their relative macrophage frequencies and set out to study the relation between inter-individual differences in relative macrophage frequencies and transcriptional differences in metabolic and inflammatory pathways within the SAT. However, differential gene expression analysis performed in a tissue such as whole blood does not always take into account the potential impact from the inter-individual differences in a cell-type profile. These differences 
might represent changes on the cell-type specific level but also reflect changes in biologically relevant tissues. In Chapter 5 , we present a computational approach to investigate the whole blood transcriptome of individuals from the CODAM study (61), a prospective observational cohort that includes participants with an elevated risk of type 2 diabetes mellitus ( $\mathrm{T}_{2} \mathrm{DM}$ ) and cardiovascular disease. In this chapter, we used the computational algorithm EpiDISH (63) to infer the white blood cell profile from whole blood DNA methylation data. Next, we analysed RNA sequencing data in whole blood of the same group of participants. The objective of this chapter was to investigate the whole blood transcriptome profile of insulin resistant as compared to insulin sensitive individuals independent of inter-individual differences in their white blood cell profile. An overall evaluation of the findings can be found in the General Discussion in Chapter

\section{References}

1. Kelly T, Yang W, Chen CS, Reynolds K, He J. Global burden of obesity in 2005 and projections to 2030 Int J Obes (Lond). 2008;32(9):1431-7.

2. Tremmel M, Gerdtham UG, Nilsson PM, Saha S. Economic Burden of Obesity: A Systematic Literature Review. Int J Environ Res Public Health. 2017;14(4).

3. Albuquerque D, Nobrega C, Manco L, Padez C. The contribution of genetics and environment to obesity. Br Med Bull. 2017;123(1):159-73.

4. Goryakin Y, Lobstein T, James WP, Suhrcke M. The impact of economic, political and social globalization on overweight and obesity in the 56 low and middle income countries. Soc Sci Med. 2015;133:67-76.

5. Reaven GM. Banting lecture 1988. Role of insulin resistance in human disease. Diabetes. 1988;37(12):1595-607.

6. DeFronzo RA. Insulin resistance, lipotoxicity, type 2 diabetes and atherosclerosis: the missing links. The Claude Bernard Lecture 2009. Diabetologia. 2010;53(7):1270-87.

7. Puhl RM, Heuer CA. Obesity stigma: important considerations for public health. Am J Public Health. 2010;100(6):1019-28.

8. Society CotO. Obesity as a disease: the Obesity Society Council resolution. Obesity. 2008;16(6):1151-

9. Schaecher KL. The role of managed care organizations in obesity management. Am J Manag Care. 2016;22(7 Suppl):S197-208.

10. Ahmad Zamri L, Appannah G, Zahari Sham SY, Mansor F, Ambak R, Mohd Nor NS, et al. Weight Change and Its Association with Cardiometabolic Risk Markers in Overweight and Obese Women. Obes. 2020;2020:3198326.

11. Dow CA, Thomson CA, Flatt SW, Sherwood NE, Pakiz B, Rock CL. Predictors of improvement in cardiometabolic risk factors with weight loss in women. J Am Heart Assoc. 2013;2(6):eooo152.

12. den Boer AT, Herraets IJ, Stegen J, Roumen C, Corpeleijn E, Schaper NC, et al. Prevention of the metabolic syndrome in IGT subjects in a lifestyle intervention: results from the SLIM study. Nutr Metab Cardiovasc Dis. 2013;23(11):1147-53.

13. Lindstrom J, Louheranta A, Mannelin M, Rastas M, Salminen V, Eriksson J, et al. The Finnish Diabetes Prevention Study (DPS): Lifestyle intervention and 3-year results on diet and physical activity. Diabetes Care. 2003;26(12):3230-6.

14. van Baak MA, Mariman ECM. Mechanisms of weight regain after weight loss - the role of adipose tissue. Nat Rev Endocrinol. 2019;15(5):274-87.

15. Anderson JW, Konz EC, Frederich RC, Wood CL. Long-term weight-loss maintenance: a meta-analysis of US studies. Am J Clin Nutr. 2001;74(5):579-84.

16. Bluher M. Adipose tissue dysfunction in obesity. Exp Clin Endocrinol Diabetes. 2009;117(6):241-50.

Bluher M.Adipose tissue dysfunction contributes to obesity related metabolic diseases. Best Pract

Res Clin Endocrinol Metab. 2013;27(2):163-77.

18. Goossens GH. The role of adipose tissue dysfunction in the pathogenesis of obesity-related insulin resistance. Physiol Behav. 2008;94(2):206-18.

19. Goossens GH. The Metabolic Phenotype in Obesity: Fat Mass, Body Fat Distribution, and Adipose Tissue Function. Obes Facts. 2017;10(3):207-15.

20. FuZ Gilbert ER, Liu D. Regulation of insulin synthesis and secretion and pancreatic Beta-cell dysfunction in diabetes. Curr Diabetes Rev. 2013;9(1):25-53.

21. Rask-Madsen C, Kahn CR. Tissue-specific insulin signaling, metabolic syndrome, and cardiovascular disease. Arterioscler Thromb Vasc Biol. 2012;32(9):2052-9.

22. DeFronzo RA, Tripathy D. Skeletal muscle insulin resistance is the primary defect in type 2 diabetes. Diabetes Care. 2009;32 Suppl 2:S157-63.

23. Groop LC, Bonadonna RC, DelPrato S, Ratheiser K, Zyck K, Ferrannini E, et al. Glucose and free fatty acid metabolism in non-insulin-dependent diabetes mellitus. Evidence for multiple sites of insulin resistance. J Clin Invest. 1989;84(1):205-13.

作 diabetes. Nature. 2006;444(7121):840-6.

25. Shulman GI. Ectopic fat in insulin resistance, dyslipidemia, and cardiometabolic disease. N Engl 
Med. 2014;371(23):2237-8

In Instinct Insulin Resistant Phenotypes; Targets for Personalized Nutritional Interventions. Front Nutr. 2018;5:77.

27. Vogelzangs N, van der Kallen CJH, van Greevenbroek MMJ, van der Kolk BW, Jocken JWE, Goossens , et al. Metabolic profiling of tissue-specific insulin resistance in human obesity: results from the Dloges study and the Maastricht Study. Int J Obes (Lond). 2020;44(6):1376-86

28. Van der Kolk BW, Vogelzangs N, Jocken JWE, Valsesia A, Hankemeier T, Astrup A, et al. Plasma lipid profiling of tissue-specific insulin resistance in human obesity. Int J Obes (Lond). 2019;43(5):989-98.

Song Y, Sondergaad E, Jensen MD.Unique Metabolic Fetur Insulin Resistance. J Clin Endocrinol Metab. 2020;105(8).

30. Zheng J, Woo SL, Hu X, Botchlett R, Chen L, Huo Y, et al. Metformin and metabolic diseases: a focus on hepatic aspects. Front Med. 2015;9(2):173-86.

31. Blanco-Rojo R, Alcala-Diaz JF, Wopereis S, Perez-Martinez P, Quintana-Navarro GM, Marin C, et al. The insulin resistance phenotype (muscle or liver) interacts with the type of diet to determine changes in disposition index after 2 years of intervention: the CORDIOPREV-DIAB randomised clinical trial. Diabetologia. 2016;59(1):67-76.

32. Otten J, Stomby A, Waling M, Isaksson A, Soderstrom I, Ryberg M, et al. A heterogeneous respons of liver and skeletal muscle fat to the combination of a Paleolithic diet and exercise in obese individuals with type 2 diabetes: a randomised controlled trial. Diabetologia. 2018;61(7):1548-59.

33. Hotamisligil GS, Shargill NS, Spiegelman BM. Adipose expression of tumor necrosis factor-alpha: direct role in obesity-linked insulin resistance. Science. 1993;259(5091):87-91.

34. Xu H, Barnes GI, Yang Q, Tan G, Yang D, Chou C, et al. Chronic inflammation in fat plays a crucia role in the development of obesity-related insulin resistance. J Clin Invest. 2003;112(12):1821-30.

35. Weisberg SP, McCann D, Desai M, Rosenbaum M, Leibel RL, Ferrante AW. Obesity is associated with macrophage accumulation in adipose tissue. The Journal of clinical investigation. 2003;112(12):1796808.

36. Lumeng CN, Deyoung SM, Bodzin JL, Saltiel AR. Increased inflammatory properties of adipose tissue macrophages recruited during diet-induced obesity. Diabetes. 2007;56(1):16-23.

37. Lumeng CN, Saltiel AR. Inflammatory links between obesity and metabolic disease. The Journal of clinical investigation. 2011;121(6):2111-7.

38. Ferrannini E, Barrett EJ, Bevilacqua S, DeFronzo RA. Effect of fatty acids on glucose production and utilization in man. J Clin Invest. 1983;72(5):1737-47.

39. Abdul-Ghani MA, DeFronzo RA. Pathogenesis of insulin resistance in skeletal muscle. J Biomed Biotechnol. 2010;2010:476279.

40. Stump CS, Henriksen EJ, Wei Y, Sowers JR. The metabolic syndrome: role of skeletal muscle metabolism. Ann Med. 2006;38(6):389-402.

41. Affourtit C. Mitochondrial involvement in skeletal muscle insulin resistance: A case of imbalanced bioenergetics. Biochim Biophys Acta. 2016;1857(10):1678-93.

42. Meex RCR, Watt MJ. Hepatokines: linking nonalcoholic fatty liver disease and insulin resistance. Nat Rev Endocrinol. 2017;13(9):509-20.

43. Conesa A, Beck S. Making multi-omics data accessible to researchers. Sci Data. 2019;6(1):251.

44. Keller MP, Attie AD. Physiological insights gained from gene expression analysis in obesity and diabetes. Annu Rev Nutr. 2010;30:341-64.

45. Elbein SC, Kern PA, Rasouli N, Yao-Borengasser A, Sharma NK, Das SK. Global gene expression profiles of subcutaneous adipose and muscle from glucose-tolerant, insulin-sensitive, and insulin-resistant individuals matched for BMI. Diabetes. 2011;60(3):1019-29.

46. Soronen J, Laurila PP, Naukkarinen J, Surakka I, Ripatti S, Jauhiainen M, et al. Adipose tissue gene expression analysis reveals changes in inflammatory, mitochondrial respiratory and lipid metabolic pathways in obese insulin-resistant subjects. BMC Med Genomics. 2012;5:9.

47. Armenise C, Lefebvre G, Carayol J, Bonnel S, Bolton J, Di Cara A, et al. Transcriptome profiling from adipose tissue during a low-calorie diet reveals predictors of weight and glycemic outcomes in obese, nondiabetic subjects. Am J Clin Nutr. 2017;106(3):736-46.

48. Shen-Orr SS, Gaujoux R. Computational deconvolution: extracting cell type-specific information from heterogeneous samples. Curr Opin Immunol. 2013;25(5):571-8.

49. Repsilber D, Kern S, Telaar A, Walzl G, Black GF, Selbig J, et al. Biomarker discovery in heterogeneous tissue samples -taking the in-silico deconfounding approach. BMC Bioinformatics. 2010:11:27.

50. Mohammadi S, Zuckerman N, Goldsmith A, Grama A A critical survey of deconvolution methods for separating cell types in complex tissues. Proceedings of the IEEE. 2016;105(2):340-66.

Meeters RLM, de Kok TM. Ertaylan G. Adipose tissue in health and disease through the lens of its building blocks. Sci Rep. 2020;10(1):10433.

52. Newman AM, Alizadeh AA. High-throughput genomic profiling of tumor-infiltrating leukocytes. Curr Opin Immunol. 2016;41:77-84

53. Khavari DA, Sen GL, Rinn IL. DNA methylation and epigenetic control of cellular differentiation. Cell Cycle. 2010;9(19):3880-3.

54. Baron U, Turbachova I, Hellwag A, Eckhardt F, Berlin K, Hoffmüller U, et al. DNA Methylation Analysis as a Tool for Cell Typing. Epigenetics. 2006; $1(1): 56-61$.

55. Houseman EA, Accomando WP, Koestler DC, Christensen BC, Marsit CJ, Nelson HH, et al. DN methylation arrays 2012;13:86.

56. Barabasi AL, Albert R. Emergence of scaling in random networks. Science. 1999;286(5439):509-12.

57. Kutmon M, Lotia S, Evelo CT, Pico AR. WikiPathways App for Cytoscape: Making biological pathways amenable to network analysis and visualization. F10ooRes. 2014;3:152.

58. Kutmon M, Kelder T, Mandaviya P, Evelo CT, Coort SL. CyTargetLinker: a cytoscape app to integrate regulatory interactions in network analysis. PLoS One. 2013;8(12):e82160.

59. Langfelder P, Horvath S. WGCNA: an R package for weighted correlation network analysis. BMC Bioinformatics. 2008;9:559.

6o. Larsen TM, Dalskov S, van Baak M, Jebb S, Kafatos A, Pfeiffer A, et al. The Diet, Obesity and Genes (Diogenes) Dietary Study in eight European countries - a comprehensive design for long-term intervention. Obes Rev. 2010;11(1):76-91.

61. Hertle E, van Greevenbroek MM, Arts IC, van der Kallen CJ, Geijselaers SL, Feskens EJ, et al. Distinct associations of complement $\mathrm{C}_{3}$ and its precursor $\mathrm{C}_{3}$ with atherosclerosis and cardiovascula disease. The CODAM study. Thromb Haemost. 2014;111(6):1102-11

62. Schram MT, Sep SJ, van der Kallen CJ, Dagnelie PC, Koster A, Schaper N, et al. The Maastricht Study: an extensive phenotyping study on determinants of type 2 diabetes, its complications and its comorbidities. Eur J Epidemiol. 2014;29(6):439-51.

63. Teschendorff AE, Breeze CE, Zheng SC, Beck S. A comparison of reference-based algorithms for correcting cell-type heterogeneity in Epigenome-Wide Association Studies. BMC Bioinformatic 2017;18(1):105. 


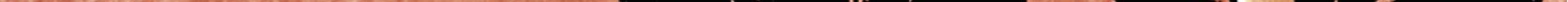

\section{Subcutaneous adipose tissue and systemic inflammation are associated with peripheral but not hepatic insulin resistance in humans}

Birgitta W. van der Kolk ${ }^{\prime \prime}$, Marianthi Kalafati ${ }^{2,3}$, Michiel Adriaens ${ }^{3}$, Marleen M.J. van Greevenbroek ${ }^{4}$, Nicole Vogelzangs ${ }^{3,10}$, Wim H.M. Saris ${ }^{1}$, Arne Astrup 5 , Armand Valsesia ${ }^{6}$, Dominique Langin ${ }^{7,89}$, Carla J.H. van der Kallen ${ }^{4}$, Simone J.P.M. Eussen ${ }^{10}$, Casper G. Schalkwijk ${ }^{4}$, Coen D.A. Stehouwer ${ }^{4}$, Gijs. H. Goossens ${ }^{1}$, Ilja C.W. Arts ${ }^{3,10}$, Johan W.E. Jocken ${ }^{1}$, Chris T. Evelo ${ }^{2,3 \S}$, Ellen E. Blaak ${ }^{1 \$}$

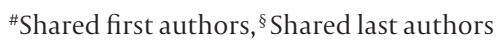

Corresponding author

${ }^{1}$ Department of Human Biology, NUTRIM School of Nutrition and Translational Research in Metabolism, Maastricht University, Maastricht, The Netherlands

2 Department of Bioinformatics-BiGCaT, NUTRIM School of Nutrition and Translational Research in Metabolism, Maastricht University, Maastricht, The Netherlands

${ }^{3}$ Maastricht Centre for Systems Biology (MaCSBio), Maastricht University, The Netherlands

${ }^{4}$ Department of Internal Medicine, CARIM School for Cardiovascular Diseases, Maastricht University, The

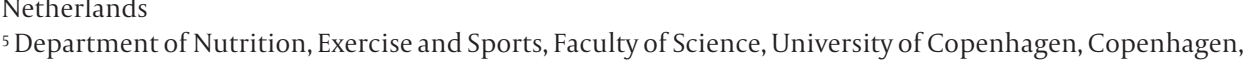
Denmark

${ }^{6}$ Nestlé Institute of Health Sciences, Lausanne, Switzerland

${ }^{7}$ Institut National de la Santé et de la Recherche Médicale (Inserm), UMR1048, Institute of Metabolic and Cardiovascular Diseases, Toulouse, France

${ }^{8}$ University of Toulouse, UMR1048, Institute of Metabolic and Cardiovascular Diseases, Paul Sabatier University, Toulouse, France

${ }^{9}$ Toulouse University Hospitals, Laboratory of Clinical Biochemistry, Toulouse, France

10 Department of Epidemiology, CARIM School for Cardiovascular Diseases, Maastricht University, The Netherlands

Modified from Diabetes (2019) 68:2247-2258 


\section{Abstract}

Obesity-related insulin resistance (IR) may develop in multiple organs, representing different etiologies towards cardiometabolic diseases. We identified abdominal subcutaneous adipose tissue (ScAT) transcriptome profiles in relation to liver or muscle IR by means of RNA sequencing in overweight/obese participants of the DiOGenes cohort $(\mathrm{n}=368)$. Tissue-specific IR phenotypes were derived from a 5-point oral glucose tolerance test. Hepatic and muscle IR were characterized by distinct abdominal ScAT transcriptome profiles. Genes related to extracellular remodeling were upregulated in individuals with primarily hepatic IR, whilst genes related to inflammation were upregulated in individuals with primarily muscle IR. In line with this, in two independent cohorts, CODAM ( $\mathrm{n}=325)$ and the Maastricht Study ( $\mathrm{n}=685$ ), an increased systemic low-grade inflammation profile was specifically related to muscle IR, but not to liver IR. We propose that increased ScAT inflammatory gene expression may translate into an increased systemic inflammatory profile, linking ScAT inflammation to the muscle IR phenotype. These distinct IR phenotypes may provide leads for more personalized prevention of cardiometabolic diseases. DiOGenes was registered at clinicaltrials.gov as NCTo039o637

\section{Introduction}

Worldwide over 2.1 billion people were overweight or obese in 2013 (1). Overweight and obesity are major risk factors for type 2 diabetes $(2,3)$. Adipose tissue dysfunction, rather than excess fat mass per se, is frequently associated with the progression towards skeletal muscle, liver and whole-body insulin resistance (IR) $(4,5)$.

Adipose tissue dysfunction is characterized by increased adipocyte size (hypertrophy) rather than increased adipocyte number (hyperplasia) (6) and this seems to be associated with impairments in adipose tissue lipid buffering capacity (7). In addition, expanded adipose tissue mass is accompanied by an increased production and secretion of proinflammatory cytokines, chemokines and adipokines $(8,9)$. Both systemic lipid overflow and low-grade inflammation are thought to contribute to the development of IR in skeletal muscle and liver (10).

Whole-body IR reflects defective insulin action in major metabolic organs, such as skeletal muscle, liver, brain and adipose tissue, and has long been known to precede the development of cardiometabolic diseases (10). IR can develop simultaneously in multiple organs, but the severity may vary between organs. For instance, impaired fasting glucose and impaired glucose tolerance may represent distinct prediabetic phenotypes, which are characterized by more pronounced hepatic or muscle insulin resistance, respectively (11). In line, altered skeletal muscle fatty acid handling as well as more pronounced peripheral IR have been observed in impaired glucose tolerance as compared to impaired fasting glucose individuals $(12,13)$. Moreover, the severity of IR at the tissue level may contribute to the differential response to lifestyle and pharmacological interventions. Indeed, physical activity has been shown to mainly target skeletal muscle insulin sensitivity (14), while metformin treatment might have more pronounced effects on hepatic insulin sensitivity (15). Moreover, a low-fat, high complex carbohydrate diet may result in a more pronounced increase in the disposition index in prediabetic individuals with hepatic IR, while a Mediterranean diet may have more beneficial effects in individuals with muscle IR (16).

Analysis of gene expression in subcutaneous adipose tissue (ScAT) may help to elucidate the pathways and mechanisms that link adipose tissue function to tissue-specific IR. Previous studies have shown significant dysregulation in the ScAT transcriptome in obesity and IR (17). For instance, Elbein et al. found that ScAT inflammatory and cell-cycle regulatory pathways were upregulated in individuals with whole-body IR compared to insulin-sensitive BMI-matched individuals, while lipid metabolism pathways were downregulated (18). In addition, Soronen et al. observed an upregulation of inflammatory and a downregulation of mitochondrial respiratory and lipid metabolism pathways in obese women with whole-body IR (19). In addition, recent DiOGenes transcriptome 
analyses of abdominal ScAT during weight loss highlighted the link between lipid metabolism pathways and glycemic improvement (20).

Studies that focus on detailed characterization of tissue-specific IR phenotypes are scarce, and it is currently not known whether differential ScAT transcriptome profiles are related to either more pronounced muscle or hepatic IR. Identification and quantification of metabolic anomalies in different IR phenotypes may provide directions for more personalized lifestyle or pharmacological interventions in the prevention and control of cardiometabolic diseases. In this report, we studied the ScAT transcriptome of overweight and obese, nondiabetic participants, from the DiOGenes study (21), a large European multicenter dietary intervention study. We analyzed baseline RNA sequencing (RNA-seq) data in abdominal ScAT from 368 individuals and identified gene clusters that were associated with muscle or hepatic IR. Subsequently, we investigated whether we could confirm mechanisms suggested by ScAT transcriptome findings by performing complementary analyses on systemic inflammatory profiles in two independent human cohorts, namely the CODAM study (22) and the Maastricht Study (23).

\section{Materials and Methods}

\section{Study Design}

DiOGenes is a multicenter, randomized, controlled dietary intervention study that involved 8 European countries. Briefly, 938 overweight or obese, nondiabetic adults [age $18-65$ years, BMI $27-45 \mathrm{~kg} / \mathrm{m}^{2}$ and blood fasting glucose concentrations $\left.<6.1 \mathrm{mmol} / \mathrm{L}\right]$ were included. More details on this study have been described previously (21). For current analyses, baseline data were used of 368 participants for whom abdominal ScAT RNA sequencing and oral glucose tolerance test (OGTT) data were available.

The Cohort on Diabetes and Atherosclerosis Maastricht (CODAM) is a prospective, observational study on, among others, the natural progression of IR and glucose tolerance. A total of 574 individuals (age $>40$ years) were included from a large population-based cohort as described in detail elsewhere (22). The Maastricht Study is a large populationbased cohort (age 40-75 years) that is enriched with type 2 diabetes participants which focuses on the etiology of type 2 diabetes, its classic complications and its emerging comorbidities (23). The analyses described here include baseline data of 325 (CODAM; BMI $>25 \mathrm{~kg} / \mathrm{m}^{2}$ ) and 685 (Maastricht Study; BMI $>27 \mathrm{~kg} / \mathrm{m}^{2}$ ) overweight/obese non-diabetic participants for whom data on OGTT and systemic low-grade inflammation were available. Local ethics committees approved all three studies and all participants gave written informed consent. These studies were carried out in accordance with the principles of the Declaration of Helsinki.

\section{Estimates of tissue-specific IR and classification of IR subgroups}

DiOGenes participants underwent a 5-point OGTT at baseline. In short, after an overnight fast, venous blood was sampled at baseline and after a $75 \mathrm{~g}$ flavored glucose load was ingested. Blood samples were taken at $\mathrm{t}=\mathrm{O}, 30,60,90$ and 120 minutes and plasma was stored at $-80^{\circ} \mathrm{C}$ until analysis to determine glucose and insulin concentrations. CODAM participants underwent a 4-point OGTT with blood samples taken at $\mathrm{t}=\mathrm{O}, 30,6 \mathrm{o}$ and 120 minutes. The Maastricht Study participants underwent a 7-point OGTT with blood samples taken at $\mathrm{t}=\mathrm{O}, 15,30,45,60,90$ and 120 minutes. Muscle insulin sensitivity and hepatic IR were estimated using the methods of Abdul-Ghani et al. (24).

The muscle insulin sensitivity index (MISI) was calculated according to the following formula: MISI= (dG/dt)/ mean plasma insulin concentration during OGTT. Here, dG/dt is the rate of decay of plasma glucose concentration during the OGTT, calculated as the slope of the least square fit to the decline in plasma glucose concentration from peak to nadir (24). The decline in plasma glucose concentration in the second part of the OGTT primarily reflects glucose uptake by peripheral tissues, mainly skeletal muscle. This index has been developed and validated against measures of peripheral insulin sensitivity as assessed 
The hepatic IR index (HIRI) was calculated using the square root of the product of the area under curves (AUCs) for glucose and insulin during the first 30 minutes of the OGTT - i.e., SQRT (glucoseo-30 [AUC in mg/d*h] * insulino-30 [AUC in $\mu \mathrm{U} / \mathrm{mL}^{*} \mathrm{~h}$ ]). This index has been developed and validated against the product of fasting plasma insulin and endogenous glucose production during a hyperinsulinemic euglycemic clamp using a stable isotope glucose tracer (24).

DiOGenes, CODAM and Maastricht Study participants were each divided into four groups. This was based on the tertiles of the HIRI and MISI scores of each cohort (16). The lowest tertile of MISI represented individuals with muscle IR; the highest tertile of HIRI represented individuals with hepatic IR. Accordingly, participants were categorized in one of four groups: i) no-IR, ii) IR primarily in muscle (muscle-IR), iii) IR primarily in liver (liver-IR) and iv) IR in both muscle and liver (muscle/liver-IR).

\section{Adipose tissue biopsy, RNA preparation and RNA sequencing}

In DiOGenes, abdominal ScAT needle biopsies were collected 6-8 $\mathrm{cm}$ lateral from the umbilicus under local anesthesia by needle biopsy and were snap-frozen in liquid nitrogen and stored at $-80{ }^{\circ} \mathrm{C}$ until further analysis. Total RNA was extracted from abdominal ScAT needle biopsies as previously described (25). For each sample, the number of reads mapping onto 53,343 genes (GRCh37 assembly) was retrieved by using GenomicAlignments. Only reads with both ends mapping onto a single gene were considered. RNA expression data are available from the Gene Expression Omnibus under accession GSE95640 (20).

\section{Statistical analyses}

\section{Participants' characteristics}

In DiOGenes, CODAM and Maastricht Study descriptive variables with a skewed distribution were $\log _{\mathrm{e}}$-transformed before further analyses. The phenotypic differences between tissue-specific IR groups were assessed using one-way ANOVA for continuous variables with Bonferroni post hoc tests, adjusted for sex, and $\chi^{2}$-test for categorical variables. The threshold for statistical significance was set at $\mathrm{p}<0.05$.

\section{Differential RNA expression analyses}

In DiOGenes, after alignment and transcript abundance, estimation raw count data for 53,343 genes and 368 samples was further analyzed in RStudio (version 3.2). Differential expression analysis was performed in the DESeq2 package (version 1.12.4) using default settings (26). Pre-filtering of genes with low counts was applied by removing genes with a total of o or 1 reads. The standard differential expression analysis steps are wrapped into a single function, DESeq (26). The differential expression analysis in DESeq2 implements a negative binomial generalized linear model (A) with the tissue-specific IR phenotypes (muscle-IR, liver-IR and no-IR), study center, sex, BMI and waist-to-hip ratio as covariates. Due to a low number of men $(\mathrm{n}=12)$ in the muscle-IR group, we were not able to stratify our results for sex. The DESeq2 model internally corrects for library size; no additional data normalization was applied. The result tables were generated using the function results comparing the tissue-specific IR phenotypes (liver-IR vs no-IR and muscle-IR vs no-IR). Furthermore, the method fpkm was used from DESeq2 to calculate relative expression of transcripts. The transcript lengths were obtained, using the Biostrings $\mathrm{R}$ package. The GRange transcript lengths were added to the DESeq object with the rowRanges method. Then the fpkm method extracted the FPKM values.

In an additional analysis, including all participants, MISI and HIRI were simultaneously included as continuous independent variables in the model with gene expression as the dependent variable to assess their independent effects. To allow for direct comparison of the effect sizes, we additionally standardized beta coefficients by calculating their z-scores. Study center, sex, BMI and waist-to-hip ratio were included as other covariates in the model.

\section{Gene ontology analysis}

Gene ontology (GO) analysis was performed using GOrilla (27). Applied settings were i) organism: Homo Sapiens, ii) running mode: two unranked list of genes (target and background lists) iii) ontology: process and iv) $\mathrm{p}<0.05$. All significant genes (nominal $\mathrm{p}<0.05$ ) were included (Table S1 and S2), divided into up- and downregulated genes to provide direction for the involved biological processes and this gave four different set of results. For each result, based on Benjamini \& Hochberg FDR p-values, the top five biological processes were selected.

\section{Pathway analysis}

Pathway analysis was performed with PathVisio 3.2.1. The curated human pathway collection was obtained from WikiPathways (version 20171116) (28), containing 344 pathways. An overrepresentation analysis was performed with the RNA sequencing data set. The pathways were then ranked based on a standardized difference score (z-score). Pathways were considered significantly changed when i) Z-score $>1.96$, ii) permuted $p<0.05$ and iii) the number of significantly different genes (nominal $p<0.05$ ) in the pathway is $\geq 3$.

\section{Association with low grade inflammation score}

In CODAM and Maastricht Study, linear regression analyses were performed with a lowgrade inflammation score as the independent variable and HIRI or MISI (continuous variables) as dependent variable, i.e. model 1. Skewed variables were $\log _{e}$-transformed. The low-grade inflammation score was calculated by averaging the Z-scores of eight inflammatory markers in CODAM (C-reactive protein (CRP), interleukin-6 (IL-6), 
interleukin-8 (IL-8), serum amyloid A (SAA), soluble intercellular adhesion molecule 1 (sICAM-1), tumor necrosis factor- $\alpha$ (TNF- $\alpha$ ), ceruloplasmin and haptoglobin) and 6 markers in the Maastricht Study (CRP, IL-6, IL-8, SAA, sICAM-1, TNF- $\alpha$ ). Averaging these markers of low-grade inflammation produces a robust estimate of the overall inflammatory state with minimization of random error (29). To allow for direct comparison of the effect sizes, we additionally standardized HIRI and MISI by calculating their Z-scores. In model 2a, HIRI was included as a covariate in analyses on MISI, and vice versa, to assess the independent effects of tissue-specific IR and in model 2b, age, sex, BMI and waist-to-hip ratio were included as covariates. Finally, in model 3 , the covariates of model $2 a$ and $2 b$ were combined. All data were analyzed using SPSS for Mac version 24.o (SPSS, Chicago, IL, USA) and R statistical programming language (version 3.3.3).

\section{Results}

Characteristics of DiOGenes population

Table 2.1 shows the demographic and metabolic characteristics of the DiOGenes participants according to their tissue-specific IR phenotype. Compared to the no-IR group (68\% women), participants with liver-IR were more often men (47\% women, $\mathrm{p}=0.006)$ while participants with muscle-IR were more often women $(82 \%, \mathrm{p}=0.027)$. Comparison of other characteristics between groups were adjusted for sex. Muscle/liver-IR group had significantly greater waist circumference and waist-to-hip ratio than those with no-IR. The muscle/liver-IR group also showed significantly greater waist circumference, waistto-hip ratio and systolic blood pressure compared to the muscle-IR group. Plasma TAG concentrations were significantly higher in liver-IR and muscle/liver-IR groups than in those with no-IR. Cholesterol concentrations were highest in participants in the liver-IR group, while HDL-cholesterol was lowest in muscle/liver-IR group compared with noIR group. Concentrations of the inflammatory marker CRP were significantly higher in muscle/liver-IR groups than in those with no-IR. Insulin concentrations were significantly higher in all groups compared to no-IR. Previous studies have shown similar characteristics for the different tissue-specific IR groups (16).

Table 2.1. Participants' characteristics of DiOGenes

\begin{tabular}{|c|c|c|c|c|c|}
\hline & $\begin{array}{c}\text { No-IR } \\
(n=186)\end{array}$ & $\begin{array}{c}\text { Muscle-IR } \\
(\mathbf{n}=69)\end{array}$ & $\begin{array}{l}\text { Liver-IR } \\
(\mathbf{n}=53)\end{array}$ & $\begin{array}{c}\text { Muscle/liver-IR } \\
(\mathrm{n}=60)\end{array}$ & $p$ \\
\hline Female sex (\%) & 68 & 82 & 47 & 61 & $<0.001$ \\
\hline & $42 \pm 7$ & $41 \pm 6$ & $42 \pm 6$ & $41 \pm 6$ & 0.684 \\
\hline $\operatorname{BMI}\left(\mathrm{kg} / \mathrm{m}^{2}\right)$ & $33.9 \pm 4.6$ & $35.0 \pm 4.3$ & $34.7 \pm 4.8$ & $35.7 \pm 4.4^{*}$ & 0.029 \\
\hline Waist $(\mathrm{cm})$ & $104.9 \pm 12.2$ & $105.6 \pm 11.5$ & $111.3 \pm 11.4$ & $112.6 \pm 14.1^{\circ}$ & 0.001 \\
\hline hip ratio & $\begin{array}{l}0.91 \pm 0.09 \\
0.912\end{array}$ & $0.90 \pm 0.08$ & $0.96 \pm 0.08$ & $0.96 \pm 0.10^{* \#}$ & 0.018 \\
\hline & $123 \pm 15$ & $123 \pm 12$ & $128 \pm 14$ & $130 \pm 11^{*}$ & 0.004 \\
\hline $\mathrm{DBP}(\mathrm{m}$ & $76 \pm 11$ & $77 \pm 10$ & $80 \pm 9$ & $79 \pm 11$ & 0.340 \\
\hline ss $(\mathrm{kg})$ & $57.9 \pm 13.7$ & $56.3 \pm 10.8$ & $66.3 \pm 13.9^{*}$ & $61.8 \pm 10.8$ & 0.019 \\
\hline Body & $\begin{array}{l}39.1 \pm 8.8 \\
39.1 \pm 13.1\end{array}$ & $42.0 \pm 6.3$ & $36.3 \pm 8.1$ & $39.9 \pm 8.0$ & 0.153 \\
\hline TAG $(\mathrm{m}$ & $1.2 \pm 0.5$ & $1.4 \pm 0.6$ & $1.6 \pm 0.7^{\circ}$ & $1.5 \pm 0.6^{*}$ & $<0.001$ \\
\hline $\mathrm{nmol} / \mathrm{L}$ ) & $4.8 \pm 1.0$ & $4.8 \pm$ & $5.2 \pm 1.0$ & $0 \pm 0.9$ & 0.096 \\
\hline HDL ( & $1.3 \pm 0.3$ & $1.2 \pm$ & $1.2 \pm 0.2$ & $1.1 \pm 0.3^{*}$ & 0.003 \\
\hline & $3.0 \pm 0$ & $2.9 \pm$ & $3.3 \pm$ & & 0.165 \\
\hline $\mathrm{ol} / \mathrm{L}$ ) & $656 \pm 3$ & $739 \pm$ & $734=$ & $657 \pm 318$ & 0.201 \\
\hline $\mathrm{CRP}(\mathrm{mg} / \mathrm{L})$ & $2.6[1.3-5.5 .1]$ & $3.8[2.3-5.9]$ & $2.9[1.3-5.0]$ & $4.7[2.4-7.1]^{*}$ & \\
\hline Glucose $(\mathrm{mmol} / \mathrm{L})$ & $5.0 \pm 0.6$ & $5.0 \pm 0.6$ & $5.3 \pm 0.5$ & $\begin{array}{l}4.7[.2 \pm 0.1] \\
5.2 \pm 0.7\end{array}$ & 0.036 \\
\hline Insulin $(\mathrm{mU} / \mathrm{L})$ & $6.8[4.9-9.8]$ & $9.4\left[7.5^{-14} .0\right]^{\top}$ & $12.4[9.8-17.2]^{\top}$ & $17.1[12.1-23.5]^{\# \text { \# }}$ & $<0.001$ \\
\hline $\begin{array}{l}\text { MISI (AU) } \\
\text { (AU) }\end{array}$ & $0.07[0.05-0.11]$ & $0.02[0.00-0.03]^{\$ 8}$ & $0.05[0.04-0.08]^{\# \#}$ & $0.02[0.01-0.02]^{\S}$ & $<0.001$ \\
\hline HIRI (AU) & $26.0 \pm 5.5$ & $28.5 \pm 5.0^{\text {s }}$ & $43.2 \pm 8.7^{* \#}$ & $46.8 \pm 12.0^{\circ \# \mathrm{~S}}$ & $<0.001$ \\
\hline
\end{tabular}

Data are mean \pm SD (normally distributed variables), median [interquartile range] (skewed variables) or proportion (\%, categorical variables). $p$-values were obtained by Pearson Chi for sex, and by ANOVA adjusted for sex, for other variables. Skewed variables were $\log _{\mathrm{e}}$-transformed before analysis. In addition, Bonferroni post hoc tests were performed. $p<0.05$ vs no-IR group; ${ }^{*} p<0.05$ vs muscle-IR group; ${ }^{{ }} p<0.05$ vs liver-IR group. HDL: high-density lipoprotein; LDL: low-density lipoprotein; NEFA: non-esterified fatty acids; CRP: C-reactive protein; HOMA-IR: homeostatic model for assessment of insulin resistance; MISI: muscle insulin sensitivity index; HIRI: hepatic insulin resistance index. 
Extracellular structure organization is differentially regulated in liver-IR vs no-IR

We performed RNA sequencing on the abdominal ScAT to assess transcriptome differences in adipose tissue in individuals with liver-IR or muscle-IR. The no-IR group was used as reference and the analyses were adjusted for study center, sex, BMI and waist-to-hip ratio. To gain insight into the differentially expressed transcriptome in the tissue-specific IR phenotypes, Gene Ontology (GO) enrichment analyses were performed, focusing on biological processes. We identified 2416 genes differentially expressed in the liver-IR vs noIR comparison (nominal p<0.05) with in total 1221 upregulated and 1195 downregulated genes (Figure 2.1, Table $\mathrm{S} 1$ ). The GO classification with the strongest statistical significance in the upregulated genes was 'extracellular structure organization' (including genes related to collagens, integrins, laminins and thrombospondins (Table 2.2 and $S_{5}$ ) and 'mitotic cell cycle process' (including genes related to cell division cycle and kinesins) (Table 2.2 and $\mathrm{S}_{5}$ ). In additional analyses where the adipose tissue gene expression was the dependent variable and the continuous HIRI the independent variable, adjusted for study center, sex, BMI, waist-to-hip ratio, and MISI, similar significant associated genes (Table S9) and GO terms (Table S11) were found.

Subsequently, a pathway enrichment analysis was included using the WikiPathways human collection of curated pathways. Eight significantly different pathways were overrepresented in the liver-IR vs no-IR groups with at least one gene with |fold change| $>1.2$ and nominal $\mathrm{p}<0.05$ respectively (Table $\mathrm{S} 7$ ). Pathways related to extracellular matrix (ECM) organization (e.g. focal adhesion pathways) and mitotic cell cycle (e.g. cell cycle) were among the most significantly differing pathways in the liver-IR vs no-IR comparison (Figure 2.2 and 2.3).

In both the liver-IR and muscle-IR versus no-IR comparison the GO classification with the highest enrichment in downregulated genes was 'regulation RNA metabolic process' (Table $S_{3}$ and $S_{4}$ ), which was accompanied by enrichment of upregulated genes in the 'mitotic cell cycle process' (Table 2.2). These data might indicate gene-specific translational repression as a mean of controlling the mitotic proteome, which may complement posttranslational mechanisms for inactivating protein function (30).
A.

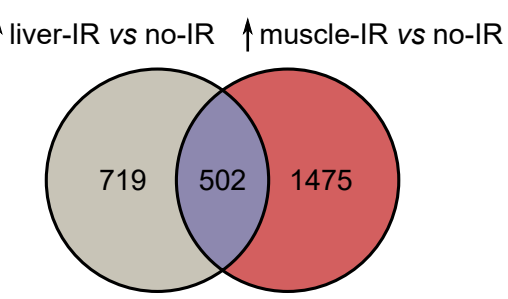

B.

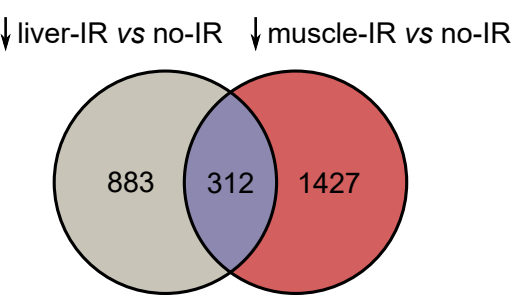

Figure 2.1. (A) Venn diagram of significantly upregulated genes (nominal $\mathrm{p}<0.05$ ) in liver-IR vs no-IR and muscle-IR vs no-IR comparisons (B) Venn diagram of significantly downregulated genes (nominal p<0.05) in liver-IR vs no-IR and muscle-IR vs no-IR comparisons.
Table 2.2. Gene Ontology analyses of differentially expressed genes in liver-IR $v s$ no-IR and muscle-IR $v s$ no-IR comparisons in DiOGenes

\begin{tabular}{|c|c|c|c|c|c|}
\hline Comparison & GO Term & Description & FDR-p & $\begin{array}{c}\text { Enrich- } \\
\text { ment }\end{array}$ & $\begin{array}{c}\text { \# Genes } \\
(\mathbf{b} / \mathbf{B})\end{array}$ \\
\hline & GO:0043062 & extracellular structure organization & $1.30 \mathrm{OE}-07$ & 3.34 & $40 / 270$ \\
\hline Liver-IR & GO:0030198 & extracellular matrix organization & $2.31 \mathrm{E}-\mathrm{O} 7$ & 3.36 & $40 / 269$ \\
\hline vs no-IR & GO:0007059 & chromosome segregation & $2.07 \mathrm{E}-06$ & 5.15 & $21 / 92$ \\
\hline \multirow[t]{4}{*}{$\uparrow$ genes } & GO:0051276 & chromosome organization & $1.27 \mathrm{E}-04$ & 2.52 & $41 / 367$ \\
\hline & GO:1903047 & mitotic cell cycle process & 1.46E-04 & 2.14 & $57 / 601$ \\
\hline & GO:0051252 & regulation of RNA metabolic process & $1.26 \mathrm{E}-11$ & 1.61 & $233 / 3442$ \\
\hline & GO:0016070 & RNA metabolic process & 1.54E-11 & 1.66 & $215 / 3072$ \\
\hline $\begin{array}{l}\text { Liver-IR } \\
v s \text { no-IR }\end{array}$ & GO:0006355 & $\begin{array}{l}\text { regulation of transcription, } \\
\text { DNA-templated }\end{array}$ & $1.80 \mathrm{E}-11$ & 1.62 & $222 / 3245$ \\
\hline \multirow[t]{2}{*}{$\downarrow$ genes } & $\begin{array}{l}\text { GO:2001141 } \\
\text { GO:1903506 }\end{array}$ & $\begin{array}{l}\text { regulation of RNA biosynthetic process } \\
\text { regulation of nucleic acid-templated } \\
\text { transcription }\end{array}$ & $\begin{array}{l}2.56 \mathrm{E}-11 \\
2.60 \mathrm{E}-11\end{array}$ & $\begin{array}{l}1.61 \\
1.62\end{array}$ & $\begin{array}{l}222 / 3270 \\
222 / 3264\end{array}$ \\
\hline & GO:1903047 & mitotic cell cycle process & 4.04E-14 & 2.36 & $111 / 601$ \\
\hline \multirow{5}{*}{$\begin{array}{l}\text { Muscle-IR vs } \\
\text { no-IR } \\
\uparrow \text { genes }\end{array}$} & GO:0002376 & immune system process & $4.73 \mathrm{E}-14$ & 1.73 & $236 / 1747$ \\
\hline & GO:0019882 & antigen processing and presentation & 3.73E-12 & 3.68 & $48 / 167$ \\
\hline & GO:0022402 & cell cycle process & $5.00 \mathrm{E}-12$ & 1.95 & $145 / 949$ \\
\hline & GO:0002478 & $\begin{array}{l}\text { antigen processing and presentation of } \\
\text { exogenous peptide antigen }\end{array}$ & $2.72 \mathrm{E}-11$ & 3.91 & $41 / 134$ \\
\hline & GO:0032774 & RNA biosynthetic process & $1.29 \mathrm{E}-15$ & 1.73 & $251 / 2349$ \\
\hline \multirow{4}{*}{$\begin{array}{l}\text { Muscle-IR vs } \\
\text { no-IR } \\
\downarrow \text { genes }\end{array}$} & GO:0044260 & cellular macromolecule metabolic process & $1.76 \mathrm{E}-15$ & 1.36 & $518 / 6161$ \\
\hline & GO:0097659 & nucleic acid-templated transcription & 2.89E-15 & 1.74 & $234 / 2170$ \\
\hline & GO:0oo6351 & transcription, DNA-templated & 3.64E-15 & 1.74 & $234 / 2169$ \\
\hline & GO:0051252 & regulation of RNA metabolic process & $7.35 \mathrm{E}-15$ & 1.54 & $328 / 3442$ \\
\hline \multicolumn{6}{|c|}{$\begin{array}{l}\text { The top five most significant and biologically relevant Gene Ontology (GO): Biological processes are listed for } \\
\text { the genes identified in Figure1A and } 1 \mathrm{~B} \text {. FDR-p-values are presented for the GO analysis. Enrichment is defined } \\
\text { as follows: (b/n)/(B/N). N - is total number of identified genes; B - is total number of genes associated with a } \\
\text { specific GO term; } \mathrm{n} \text { - is number of significant genes added to the GO analysis; b - is number of significant genes } \\
\text { in a specific GO term. The number of genes (\# Genes) represent the number of significant genes in a specific } \\
\text { GO term (b) compared to the total number of genes associated with a specific } G O \text { term (B). }\end{array}$} \\
\hline
\end{tabular}

Inflammatory pathways are differentially regulated in muscle-IR vs no-IR

For the muscle-IR vs no-IR comparison, 3716 genes were differentially expressed (nominal $\mathrm{p}<0.05$ ) with 1977 upregulated and 1739 downregulated genes (Figure 2.1 and Table S2). ScAT of muscle IR individuals was characterized by a higher expression of inflammatory genes. The GO terms with the highest enrichment with upregulated genes in ScAT was 'mitotic cell cycle process' (including genes related to cell division cycle and kinesins) (Table 2.2) and 'immune system response' (including genes related to several complement factors and chemokine) (Table 2.2 and $\mathrm{S}_{4}$ ). 'Antigen processing and presentation' was highly statistically significant as well (including genes related to proteasome degradation and lysosomal cathepsins) (Table 2.2 and $\mathrm{S}_{4}$ ). Like the GO enrichment analyses, WikiPathwaysrelated inflammatory pathways were predominant in the comparison of the muscle-IR vs no-IR group (pathways e.g. Microglia pathogen phagocytosis, IL-1 and megakaryocytes in obesity pathway and Complement activation pathway) (Figure 2.2 and 2.3, Table S8). In additional analyses where the adipose tissue gene expression was the dependent variable 
and the continuous MISI the independent variable, adjusted for study center, sex, BMI, waist-to-hip ratio, and HIRI, similar significantly associated genes (Table S10) and GO terms were found (Table S11). Thus, ScAT of muscle IR individuals is characterized by an increased expression of genes involved in chemotaxis, complement activation and immune cell function related to lysosomal (e.g. cathepsins) and ubiquitin-proteasomal degradation.
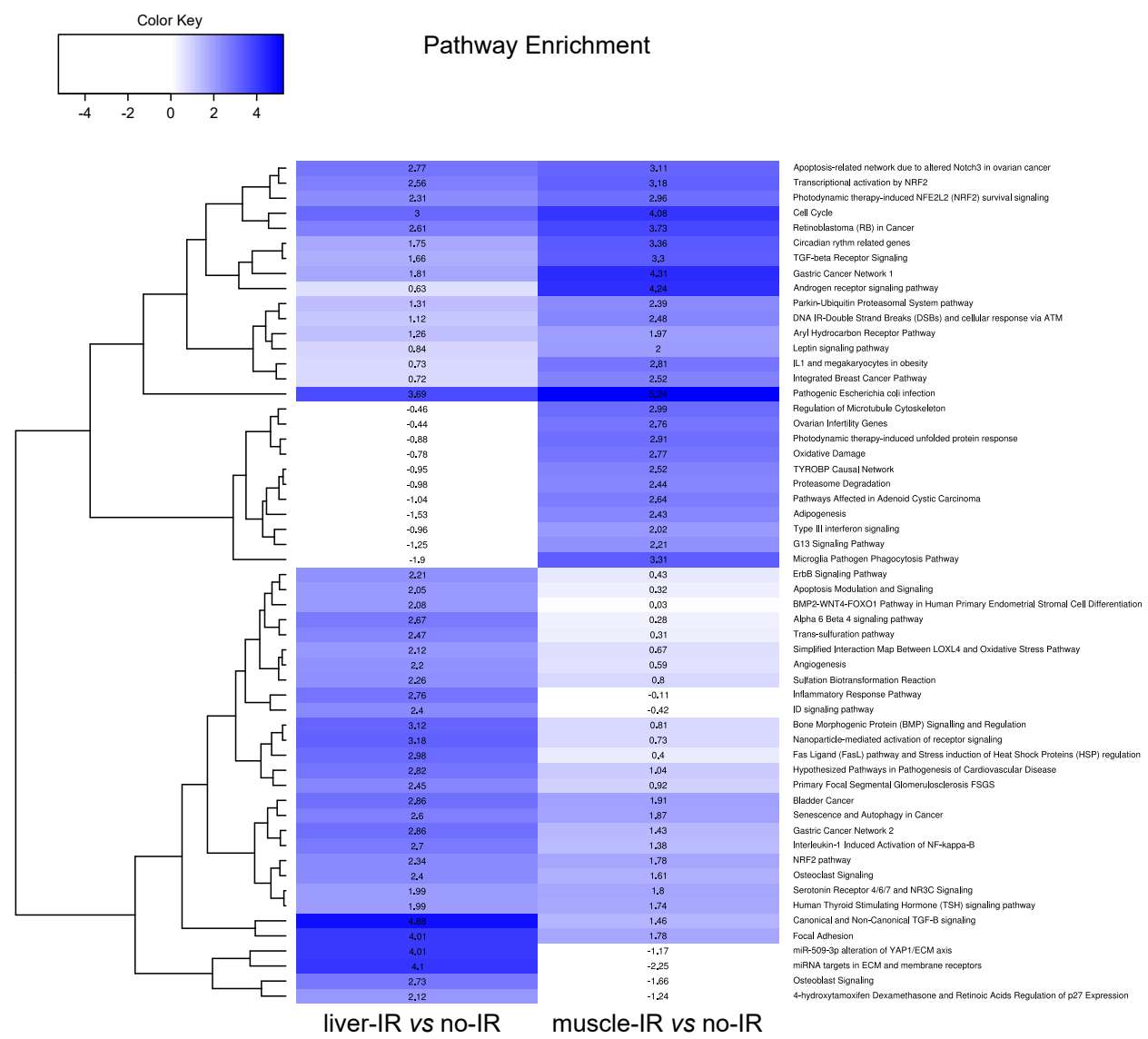
Figure 2.2. A heatmap representing the pathway enrichment analysis using the WikiPathways score (Z-score). Z-scores $>0$ are indicative of enrichment for significantly different genes, indicated by gradients of a blue color. Z-scores $<0$ are indicative of absence of enrichment for significantly different genes, indicated by a white color Pathways were considered significantly different when i) Zscore $>1.96$,ii) permuted $p<0.05$ and iii) the number of significantly different genes (nominal $\mathrm{p}<$ 0.05 ) in the pathway $\geq 3$.
A.
liver-IR vs no-IR

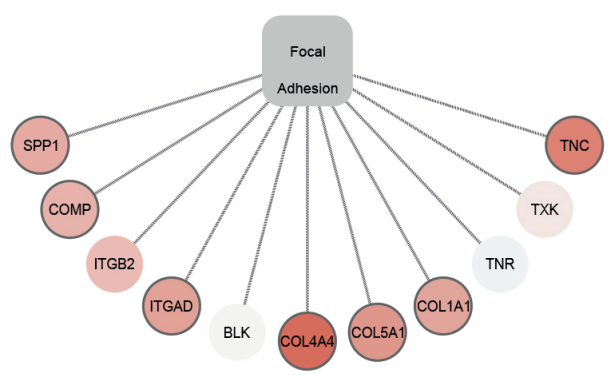

C.

liver-IR vs no-IR

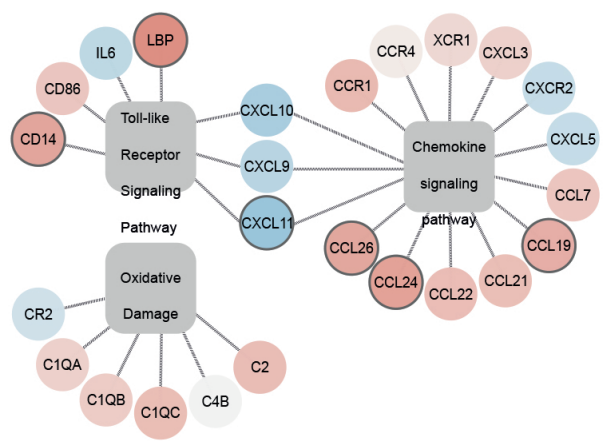

muscle-IR vs no-IR
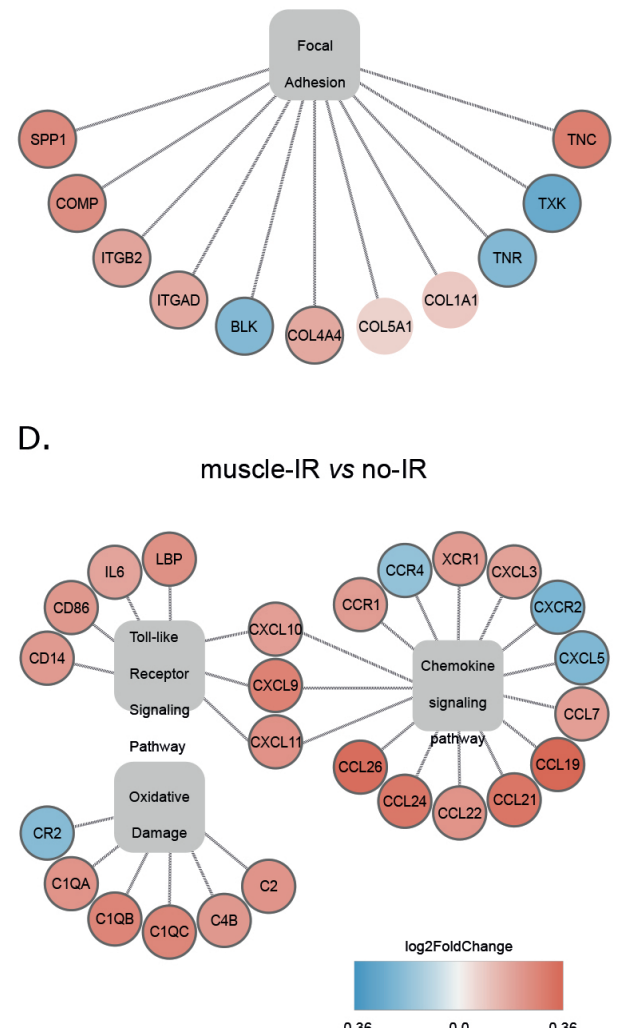

Figure 2.3. Fourlarge pathways from the WikiPathways human curated collection with comprehensive information on inflammation and ECM remodeling were selected and integrated into two networks. IR comparison: two diagrams representing ECM remodeling processes in the comparison between liver-IR vs no-IR (A) and muscle-IR vs no-IR (B); two diagrams representing inflammatory processes in the comparison between liver-IR vs no-IR (C) and muscle-IR vs no-IR (D). Only genes with ffold changel $>11$ and nominal $p<0.05$ for the liver-IR vs no-IR and/or muscle-IR vs no-IR comparison were included. Pathway nodes are visulized as rounded rectangles and genes as circles colored based

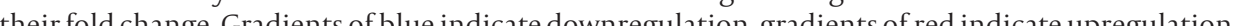
the color white is usecte visulized by agrayline around he circlerepresenting the respetive gene. 


\section{Systemic low-grade inflammation is associated with muscle IR in CODAM and}

\section{Maastricht Study}

Following up on the transcriptome analyses, we hypothesized that an increased ScAT inflammatory gene expression, as observed in the muscle-IR group, may lead to the secretion of pro-inflammatory adipokines in the circulation. Subsequently, a systemic proinflammatory profile may induce peripheral insulin sensitivity. As systemic inflammation markers were not available in DiOGenes, we studied the relationship between systemic inflammation and either muscle or liver IR in two independent cohorts, namely the CODAM and Maastricht Study $(22,23)$. In these cohorts, data on systemic low-grade inflammation and tissue-specific IR are available for 325 and 685 overweight/obese nondiabetic individuals, respectively (Table S12 and S13). In general, CODAM and Maastricht Study participants had similar risks profiles for cardiometabolic diseases as DiOGenes, but were less often women, slightly older and less obese (Table S14).

A combined score of several plasma markers of low-grade inflammation (which includes adipose tissue derived factors including, among others, IL-6, IL-8, TNFa, SAA, sICAM, CRP) was inversely associated with MISI in a linear regression analysis that was adjusted for HIRI (CODAM: standardized (std) ß: -0.107; $\mathrm{p}=0.028$ and Maastricht Study: $\operatorname{std} ß:-0.131 ; \mathrm{p}<0.001$ ) (Table 2.3, model 2a). Notably, the low-grade inflammation score was not significantly associated with HIRI, in a linear regression analysis that was adjusted for MISI (CODAM: stdß: $0.065, p=0.184$ and the Maastricht Study: $\operatorname{std} ß$ : $0.000, p=0.995$ ) (Table 2.3, model 2a). After additional adjustments for age, sex, BMI and waist-to-hip ratio, the association between low-grade inflammation and MISI was maintained (CODAM: $\operatorname{std}$ : $-0.051, \mathrm{p}=0.317$ and the Maastricht Study: stdß: -0.091, $\mathrm{p}=0.008$ ) (Table 2.3, model 3). No significant sex interactions were observed for the associations between the low-grade inflammation score and MISI ( $\left.\mathrm{p}_{\text {interaction }}=0.639\right)$ or HIRI $\left(\mathrm{p}_{\text {interaction }}=0.982\right)$. Therefore, associations between low-grade inflammation and MISI/HIRI were assessed in men and women combined.

Finally, additional analyses in DiOGenes showed that in adipose tissue the RNA expression levels of 7 out of the 8 inflammatory genes that are included in the inflammation score were indeed higher in those with the muscle-IR compared to those with no-IR (Table S15). For three individual genes (IL-6, s-ICAM, Haptoglobin) these differences were statistically significant. Such consistent upregulation of the inflammatory marker genes was not observed in adipose tissue of those with liver-IR.
Table 2.3. Associations plasma low-grade inflammation with MISI and HIRI

\begin{tabular}{|c|c|c|c|c|c|c|c|}
\hline & \multirow[b]{3}{*}{ Model } & \multicolumn{3}{|c|}{$\begin{array}{c}\text { CODAM } \\
\text { BMI >25 kg/m } \\
(\mathrm{N}=325)\end{array}$} & \multicolumn{3}{|c|}{$\begin{array}{c}\text { The Maastricht Study } \\
\text { BMI >27 kg/m } \\
(\mathrm{N}=685)\end{array}$} \\
\hline & & & $\mathrm{LGI}^{\circ}$ & & & LGI $^{\#}$ & \\
\hline & & $\beta$ & $95 \% \mathrm{Cl}$ & $p$ & $\beta$ & $95 \% \mathrm{CI}$ & $p$ \\
\hline \multirow[t]{4}{*}{ MISI } & 1 & -.180 & $-.291 ;-.073$ & $<.001$ & -183 & $-.257 ;-109$ & $<.001$ \\
\hline & $2 \mathrm{a}$ & -.107 & $-.205 ;-.011$ & .028 & -.131 & -193;-.068 & $<.001$ \\
\hline & $2 \mathrm{~b}$ & -.071 & -.182;.039 & .202 & -.108 & 年.-186;-.030 & .007 \\
\hline & 3 & -.051 & $-.153 ; .050$ & .317 & -.091 & 作-.159;-.024 & .008 \\
\hline \multirow[t]{4}{*}{ HIRI } & 1 & .138 & $.031 ; .244$ & .012 & .099 & $.024 ; .174$ & .010 \\
\hline & $2 \mathrm{a}$ & .065 & $-.032 ; .165$ & . 184 & .000 & $-.064 ; .064$ & .995 \\
\hline & $2 \mathrm{~b}$ & .046 & $-.059 ; .150$ & .394 & .031 & $-.045 ; .107$ & .418 \\
\hline & 3 & .021 & $-.078 ; .120$ & .678 & -.022 & -.088;.043 & .504 \\
\hline
\end{tabular}

$B$ values are standardized regression coefficients and represent the change in MISI and HIRI according to the low-grade inflammation score (LGI). Model 1: crude associations. Model za: only mutually adjusted for HIRI or MISI, respectively. Model 2b: only adjusted for age, sex, BMI, waist-to-hip ratio. Model 3: model 2b + adjustment for HIRI or MISI, respectively. ' LGI score with 8 markers: IL-6, IL-8, TNFa, SAA, sICAM, CRP, Haptoglobin, Ceruloplasmin." "LGI score with 6 markers: IL-6, IL-8, TNFa, SAA, SICAM, CRP 


\section{Discussion}

Here, we demonstrated distinct adipose tissue transcriptome profiles in tissue-specific IR. We show that an altered ECM gene expression profile in abdominal ScAT was present in overweight and obese individuals with pronounced hepatic IR. Furthermore, an inflammatory gene expression profile was particularly present in individuals with pronounced muscle IR and not with hepatic IR. We propose that an increased systemic inflammatory profile is a mechanism linking the increased expression of inflammatory genes in abdominal ScAT to muscle IR. In line, in two independent human cohorts, we show a relation between the combined score of plasma markers of low-grade inflammation and muscle IR, but not liver IR. Although the relationship between adipose tissue inflammation and insulin resistance has been posed previously (8), the findings in the present study extend these previous observations by indicating the tissue-specific nature of this relationship.

Increased abdominal ScAT inflammation appeared to be a predominant phenotype in muscle-IR individuals. This was mainly determined by upregulation of genes involved in chemotaxis, complement activation and immune cell function related to lysosomes (e.g. cathepsins) and ubiquitin-proteasome. In recent years, several chemokines have been reported to be of importance in the etiology of obesity-associated inflammation and IR (31). Chemokines are crucial for the attraction of leukocytes from the circulation into tissues, including macrophages and T-cells. For instance, it is known that higher total leukocyte counts precede and predict the incident risk of type 2 diabetes (32). Additionally, overrepresentation of T-cell-recruiting and activating genes is of interest, given the recent implication of T-cell recruitment in obesity-related adipose tissue inflammation and IR in animal models (33) and humans (34) although T-cell infiltration in humans is much less characterized (35)

Furthermore, the upregulation of lysosomal genes such as cathepsins, and genes in the ubiquitin-proteasome pathway by which many intracellular proteins are degraded, is in line with previous studies, and may point towards an increased removal of apoptotic adipocytes (36). Moreover, complement factors (e.g. $\mathrm{C}_{1} \mathrm{Q}$ ) are known to enhance phagocytosis by linking apoptotic cells and phagocytes, and contribute to the rapid clearance of dead cells (37). Notably, cell death is associated with an increased immune cell infiltration (e.g. macrophages) and local tissue inflammation (38). Strong upregulation of ScAT C1Q is consistent with previous reports on ScAT gene expression in humans (19,39-42). C1Qa knockout mice were protected from high-fat diet-induced adipose tissue inflammation, systemic glucose intolerance and hepatic IR (43). In addition, obesity-related adipocyte death was slightly increased in C10 a knockout mice, implying that a reduction in the efficacy of clearing dead adipocytes may reduce macrophage inflammatory activation (43).
Although ScAT inflammation has been posed previously as a central factor in the development of IR, ourdata show for the first time thata ScATinflammatorygeneexpression profile is most pronounced in the muscle-IR phenotype. Secretion media derived from ScAT explants of obese individuals have been show to impair insulin signaling in both human myotubes $(44,45)$ and hepatocytes $(44)$. Furthermore, intracellular organelles like inflammasomes and autophagosomes in ScAT have been recognized in organ crosstalk and insulin resistance, albeit in an indirect and yet incompletely understood ways (46). The fact that we only found a relationship between ScAT inflammatory gene expression and muscle IR, but not liver IR, might be related to a differential in vivo blood supply to both tissues. The liver may be more strongly affected by portal vein supply and factors derived from the visceral adipose tissue and the gut, while peripheral tissues like skeletal muscle might be more affected by the peripheral circulation. Indeed, as ScAT drains more systemically, this could affect skeletal muscle IR more than hepatic IR.

We hypothesized that an increased ScAT inflammatory gene expression, as observed in the muscle-IR group, may lead to the secretion of pro-inflammatory adipokines in the circulation and a systemic pro-inflammatory profile inducing subsequently peripheral insulin sensitivity. In line with the adipose tissue transcriptome data, in two comparable cohorts, the CODAM and Maastricht Study, we showed that low-grade inflammation scores of plasma inflammatory markers, were inversely associated with muscle insulin sensitivity (MISI), while we did not observe an association between the systemic low-grade inflammation score and hepatic IR (HIRI). These data provide support for the hypothesis that the link between an inflammatory ScAT gene expression profile as found in DiOGenes, may translate into an increased systemic inflammatory profile, thereby explaining the link with peripheral insulin sensitivity.

In liver-IR individuals, increased ECM remodeling in the abdominal ScAT was a predominant phenotype in the present study. The upregulation of genes related to ECM organization in ScAT is in line with the previously reported increased accumulation of ECM components in dysfunctional adipose tissue in obesity, which may decrease ECM flexibility and reduce adipose tissue plasticity by triggering adipocyte necrosis (47). In general, abnormal collagen deposition is tightly associated with increased local inflammation, characterized by infiltration of macrophages and other immune cells (48). Nevertheless, we did not observe a significant upregulation of ScAT inflammatory genes in liver-IR individuals when compared to no-IR individuals. One explanation may be that our ScAT transcriptome data might reflect simultaneous processes related to ECM remodeling and fibrosis in the liver, which could in turn contribute to hepatic IR. Indeed, it has been shown that hepatic IR is also closely associated with an increased ECM remodeling and fibrosis in the liver (49) 
In the present study, we had the possibility to include large independent human data sets from DiOGenes and cohort studies (CODAM, the Maastricht Study). This included adipose tissue transcriptome analysis by RNA sequencing as well as detailed human phenotyping. The data from the multiple 5-7 points OGTT with glucose and insulin concentrations available made it feasible to derive tissue-specific IR phenotypes as validated and used previously $(16,24,50)$. The estimated MISI and HIRI from an OGTT have been validated against gold standard hyperinsulinaemic-euglycaemic clamp studies (24) and have been used previously in large cohort and intervention studies $(16,50)$. Nevertheless, contrary to the standardized clamp-derived insulin sensitivity measures, MISI and HIRI may also be determined to some extent by other biological processes such as the rate of glucose absorption as well as the incretin response. In addition, our data are adjusted for sex and body composition and they show robust and consistent associations between tissuespecific IR, adipose tissue transcriptome profiles and systemic low-grade inflammation. Finally, a limitation of the present study is that we do not have data regarding visceral adipose tissue gene expression as previous studies have reported strong associations between hepatic IR and visceral adipose tissue (5).

To our knowledge, this study is the first to link the adipose tissue transcriptome with tissuespecific insulin resistance in a large population of overweight and obese individuals. The present data open new exciting avenues showing distinct tissue-specific IR prediabetic phenotypes in overweight and obese individuals in the development of type 2 diabetes and cardiovascular disease. Our findings of differential adipose tissue transcriptome and systemic inflammatory profiles in tissue-specific IR may provide targets and/ or biomarkers for more tailored nutritional or pharmacological interventions in the prevention or treatment of cardiometabolic disease. Indeed, there is evidence from posthoc analyses that the response to nutritional intervention may depend on IR phenotype, e.g. being more insulin resistant at the level of the liver or skeletal muscle (16). Future studies are urgently warranted to obtain detailed insight into these differential metabolic phenotypes as well as related biomarkers.

\section{Data and Resource Availability}

RNA expression data are available from the Gene Expression Omnibus under accession GSE95640 (20). Other data are unsuitable for public deposition due to ethical restriction and privacy of participant data. Data are available from the corresponding author for any interested researcher who meets the criteria for access to confidential data and upon reasonable request.

\section{References}

1. Ng M, Fleming T, Robinson M, Thomson B, Graetz N, Margono C, et al. Global, regional, and national prevalence of overweight and obesity in children and adults during 1980-2013: a systematic analysis for the Global Burden of Disease Study 2013. Lancet. 2014 Aug 30;34(9945):766-81.

2. Van Gaal LF, Mertens IL, De Block CE. Mechanisms linking obesity with cardiovascular disease. Nature. 2006 Dec 14;444(7121):875-80.

3. Kahn SE, Hull RL, Utzschneider KM. Mechanisms linking obesity to insulin resistance and type 2 diabetes. Nature. 2006 Dec 14;444(7121):840-6.

4. Goossens GH. The Metabolic Phenotype in Obesity: Fat Mass, Body Fat Distribution, and Adipose Tissue Function. Obes Facts. 2017 Jun 1;10(3):207-15.

5löting N, Blüher M. Adipocyte dysfunction, inflammation and metabolic syndrome. Rev Endocr Metab Disord. 2014 Oct 26;15(4):277-87.

6. Hoffstedt J, Arner E, Wahrenberg H, Andersson DP, Qvisth V, Löfgren P, et al. Regional impact of adipose tissue morphology on the metabolic profile in morbid obesity. Diabetologia. 2010 Sep 10;53(12):2496503.

7. Goossens GH, Blaak EE. Adipose Tissue Dysfunction and Impaired Metabolic Health in Human Obesity: A Matter of Oxygen? Front Endocrinol (Lausanne). 2015 Apr 24;6:1-5.

8. Kwon H, Pessin JE. Adipokines Mediate Inflammation and Insulin Resistance. Front Endocrinol (Lausanne). 2013;4:1-13.

9. McArdle MA, Finucane OM, Connaughton RM, McMorrow AM, Roche HM. Mechanisms of ObesityInduced Inflammation and Insulin Resistance: Insights into the Emerging Role of Nutritional Strategies. Front Endocrinol (Lausanne). 2013;4:1-23.

10. Stinkens R, Goossens GH, Jocken JWE, Blaak EE. Targeting fatty acid metabolism to improve glucose metabolism. Obes Rev. 2015 Jul 16;16(9):715-57.

11. Stefan N, Fritsche A, Schick F, Häring H-U. Phenotypes of prediabetes and stratification of cardiometabolic risk. Lancet Diabetes Endocrinol. 2016 Sep;4(9):789-98.

12. Blaak EE. Characterisation of fatty acid metabolism in different insulin-resistant phenotypes by means of stable isotopes. Proc Nutr Soc. 2017 Jan 19;:1-7.

13. Goossens G, Moors C, Jocken J, van der Zijl N, Jans A, Konings E, et al. Altered Skeletal Muscle Fatty Acid Handling in Subjects with Impaired Glucose Tolerance as Compared to Impaired Fasting Glucose. Nutrients. 2016 Mar;8(3):164-15.

14. Bird SR, Hawley JA. Update on the effects of physical activity on insulin sensitivity in humans. BMJ Open Sport Exerc Med. 2016;2(1):eooo143.

15. Zheng J, Woo S-L, Hu X, Botchlett R, Chen L, Huo Y, et al. Metformin and metabolic diseases: a focus on hepatic aspects. Front Med. 2015 Feb 12;9(2):173-86.

16. Blanco-Rojo R, Alcala-Diaz JF, Wopereis S, Perez-Martinez P, Quintana-Navarro GM, Marin C, et al. The insulin resistance phenotype (muscle or liver) interacts with the type of diet to determine changes in disposition index after 2 years of intervention: the CORDIOPREV-DIAB randomised clinical trial. Diabetologia. 2016 Jan 1;59(1):67-76.

17. Keller MP, Attie AD. Physiological Insights Gained from Gene Expression Analysis in Obesity and Diabetes. Annu Rev Nutr. 2010 Jul;30(1):341-64.

18. Elbein SC, Kern PA, Rasouli N, Yao-Borengasser A, Sharma NK, Das SK. Global gene expression profiles of subcutaneous adipose and muscle from glucose-tolerant, insulin-sensitive, and insulin-resistant individuals matched for BMI. Diabetes. 2011 Mar;60(3):1019-29.

19. Soronen J, Laurila P-P, Naukkarinen J, Surakka I, Ripatti S, Jauhiainen M, et al. Adipose tissue gene expression analysis reveals changes in inflammatory, mitochondrial respiratory and lipid metabolic pathways in obese insulin-resistant subjects. BMC Med Genomics. 2012;5(1):9.

20. Armenise C, Lefebvre G, Carayol J, Bonnel S, Bolton J, Di Cara A, et al. Transcriptome profiling from adipose tissue during a low-calorie diet reveals predictors of weight and glycemic outcomes in obese, nondiabetic subjects. Am J Clin Nutr. 2017 Sep;106(3):736-46.

21. Larsen TM, Dalskov S-M, van Baak M, Jebb SA, Papadaki A, Pfeiffer AFH, et al. Diets with high or low protein content and glycemic index for weight-loss maintenance. N Engl J Med. 2010 Nov 25;363(22):2102-13. 
22. Hertle E, van Greevenbroek MM, Arts IC, van der Kallen CJ, Geijselaers SL, Feskens EJ, et al. Distinct associations of complement $\mathrm{C}_{3}$ and its precursor $\mathrm{C}_{3}$ with atherosclerosis and cardiovascular disease. The CODAM study. Thromb Haemost. 2014 Jun;111(6):1102-11.

23. Schram MT, Sep SIS, van der Kallen C], Dagnelie PC, Koster A, Schaper N, et al. The Maastricht Study an extensive phenotyping study on determinants of type 2 diabetes, its complications and its comorbidities. Eur J Epidemiol. 2014 Apr 23;29(6):439-51.

24. Abdul-Ghani MA, Matsuda M, Balas B, DeFronzo RA. Muscle and liver insulin resistance indexes derived from the oral glucose tolerance test. Diabetes Care. 2007 Jan;30(1):89-94

Determinants of Human Adipose Tissue Gene Expression. Impact of Diet, Sex, Metabolic Status, and Cis Genetic Regulation. Gibson G, editor. Plos Genet. 2012 Sep 27,8(9).eno $2959^{-14}$

26. Love MI, Huber W, Anders S. Moderated estimation of fold change and dispersion for RNA-seq data with DESeq2. Genome Biol. 2014 Dec 5;15(12):31-21.

27. Eden E, Navon R, Steinfeld I, Lipson D, Yakhini Z. GOrilla: a tool for discovery and visualization of enriched GO terms in ranked gene lists. BMC Bioinformatics. 2009;10(1):48-7.

28. Slenter DN, Kutmon M, Hanspers K, Riutta A, Windsor J, Nunes N, et al. WikiPathways: a multifaceted pathway database bridging metabolomics to other omics research. Nucleic Acids Res. 2017 Nov 10;46(D1):D661-7.

29. Wlazlo N, van Greevenbroek MMJ, Ferreira I, Feskens EJM, van der Kallen CJH, Schalkwijk CG, et al. Complement factor 3 is associated with insulin resistance and with incident type 2 diabetes over a 7-year follow-up period: the CODAM Study. Diabetes Care. 2014 Jul;37(7):1900-9.

30. Tanenbaum ME, Stern-Ginossar N, Weissman JS, Vale RD. Regulation of mRNA translation during mitosis. Elife. 2015 Aug 25;4:1834.

31. Tourniaire F, Romier-Crouzet B, Lee JH, Marcotorchino J, Gouranton E, Salles J, et al. Chemokine Expression in Inflamed Adipose Tissue Is Mainly Mediated by NF- B. Xu H, editor. PLoS ONE. 2013 Jun 18;8(6):e66515-9.

32. Vozarova B, Weyer C, Lindsay RS, Pratley RE, Bogardus C, Tataranni PA. High white blood cell count is associated with a worsening of insulin sensitivity and predicts the development of type 2 diabetes. Diabetes. 2002 Feb;51(2):455-61.

33. Guzik TJ, Skiba DS, Touyz RM, Harrison DG. The role of infiltrating immune cells in dysfunctional adipose tissue. Cardiovasc Res. 2017 Jul 1;113(9):1009-23.

34. Goossens GH, Blaak EE, Theunissen R, Duijvestijn AM, Clement K, Tervaert J-WC, et al. Expression of NLRP3 inflammasome and T cell population markers in adipose tissue are associated with insulin resistance and impaired glucose metabolism in humans. Mol Immunol. 2012 Mar;50(3):142-9.

35. Travers RL, Motta AC, Betts JA, eacute AB, Thompson D. The impact of adiposity on adipose tissueresident lymphocyte activation in humans. Int J Obes (Lond). 2014 Dec 23;39(5):762-9.

Trouw LA, Blom AM, Gasque P. Role of complement and complement regulators in the removal of apoptotic cells. Mol Immunol. 2008 Mar;45(5):1199-207.

3. Kuroda M, Sakaue H. Adipocyte Death and Chronic Inflammation in Obesity. J Med Invest. 2017;64(3.4):193-6

39. Pietiläinen KH, Naukkarinen J, Rissanen A, Saharinen J, Ellonen P, Keränen H, et al. Global transcript profiles of fat in monozygotic twins discordant for BMI: pathways behind acquired obesity. Groop LC, editor. PLoS Med. 2008 Mar 11;5(3)::51.

40. van Greevenbroek MMJ, Ghosh S, van der Kallen CJH, Brouwers MCGJ, Schalkwijk CG, Stehouwer CDA. Up-Regulation of the Complement System in Subcutaneous Adipocytes from Nonobese, Hypertriglyceridemic Subjects Is Associated with Adipocyte Insulin Resistance. I Clin Endocrinol Metab. 2012 Dec;97(12):4742-52.

41. Das SK, Ma L, Sharma NK. Adipose tissue gene expression and metabolic health of obese adults. Int J Obes (Lond). 2015 Jan 13;39(5):869-73.

42. Wiklund P, Zhang X, Pekkala S, Autio R, Kong L, Yang Y, et al. Insulin resistance is associated with altered amino acid metabolism and adipose tissue dysfunction in normoglycemic women. Sci Rep. 2016 Apr 15;6(1):24540.

43. Hillian AD, McMullen MR, Sebastian BM, Roychowdhury S, Rowchowdhury S, Kashyap SR, et al. Mice lacking C1q are protected from high fat diet-induced hepatic insulin resistance and impaired glucose homeostasis. J Biol Chem. 2013 Aug 2;288(31):22565-75

44. Kranendonk MEG, Visseren FL, van Herwaarden JA, Nolte-'t Hoen ENM, de Jager W, Wauben MHM, et al. Effect of extracellular vesicles of human adipose tissue on insulin signaling in liver and muscle cells. Obesity. 2014 Jul 17;22(10):2216-23.

作 Adipose Tissue Secretions from Extremely Obese Men and Women both Acutely Suppress Muscle Insulin Signaling. Int I Mol Sci. 2017 May:18(5):959-7.

46. Indrakusuma I Sell H, Eckel I Novel Mediators of Adipose Tissue and Muscle Crosstalk. Curr Obes Rep. $2015 \operatorname{Sep} 8 ; 4(4): 411-7$

47. Sun K, Tordjman J, Clement K, Scherer PE. Fibrosis and Adipose Tissue Dysfunction. Cell Metab. 2013 Oct 1;18(4):470-7.

48. Lin D, Chun T-H, Kang L. Adipose extracellular matrix remodelling in obesity and insulin resistance. Biochem Pharmacol. 2016 Nov 1;119:8-16.

49. Koyama Y, Brenner DA. Liver inflammation and fibrosis. J Clin Invest. 2017 Jan 3;127(1):55-64

50. van der Kolk BW, Vogelzangs N, Jocken JWE, Valsesia A, Hankemeier T, Astrup A, et al. Plasma lipid profiling of tissue-specific insulin resistance in human obesity. Int J Obes. 2018 Sep 21;384:766-10. 



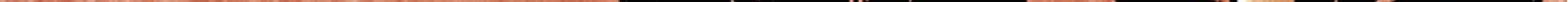

\section{Assessing the contribution of \\ relative macrophage frequencies to \\ subcutaneous adipose tissue}

Marianthi Kalafati', Michael Lenz', ${ }^{2,6,7}$, Gökhan Ertaylann ${ }^{2,8}$, Ilja CW Arts',3,

Chris T Evelo ${ }^{2,4}$, Marleen MJ van Greevenbroek ${ }^{5}$, Ellen E Blaak ${ }^{1}$, Michiel Adriaens ${ }^{2,}$, and Martina Kutmon $2,4^{*} \dagger$

\section{†These authors have contributed equally to this work}

*Corresponding authors

'Deparment of Human Biology, NUTRIM School of Translational Research in Metabolism, Maastricht University, Maastricht, the Netherlands

2Maastricht Centre for Systems Biology (MaCSBio), Maastricht University, Maastricht, the Netherlands 3Department of Epidemiology, CARIM School for Cardiovascular Diseases, Maastricht University, the Netherlands

${ }^{4}$ Department of Bioinformatics-BiGCaT, NUTRIM School of Translational Research in Metabolism, Maastricht University, Maastricht, the Netherlands

sDepartment of Internal Medicine, CARIM School for Cardiovascular Diseases, Maastricht University, Maastricht, the Netherlands

'Institute of Organismic and Molecular Evolution, Johannes Gutenberg University Mainz, Mainz, Germany

PPreventive Cardiology and Preventive Medicine - Center for Cardiology, University Medical Center of the Johannes Gutenberg-University Mainz, Mainz, Germany

${ }_{8}^{8}$ Unit Health, Flemish Institute for Technological Research (VITO), Mol, Belgium

Modified from Frontiers in Nutrition and Metabolism (2021)

https://doi.org/10.3389/fnut.2021.675935 


\section{Abstract}

\section{Background}

Macrophages play an important role in regulating adipose tissue function, while their frequencies in adipose tissue vary between individuals. Adipose tissue infiltration by high frequencies of macrophages has been linked to changes in adipokine levels and low-grade inflammation, frequently associated with the progression of obesity. The objective of this project was to assess the contribution of relative macrophage frequencies to the overall subcutaneous adipose tissue gene expression using publicly available datasets.

\section{Methods}

Seven publicly available microarray gene expression datasets from human subcutaneous adipose tissue biopsies $(\mathrm{n}=519)$ were used together with TissueDecoder to determine the adipose tissue cell type composition of each sample. We divided the subjects in four groups based on their relative macrophage frequencies. Differential gene expression analysis between the high and low relative macrophage frequencies groups was performed, adjusting for sex and study. Finally, biological processes were identified using pathway enrichment and network analysis.

\section{Results}

We observed lower frequencies of adipocytes and higher frequencies of adipose stem cells in individuals characterised by high macrophage frequencies. We additionally studied whether, within subcutaneous adipose tissue, inter-individual differences in the relative frequencies of macrophages were reflected in transcriptional differences in metabolic and inflammatory pathways. Adipose tissue of individuals with high macrophage frequencies had a higher expression of genes involved in complement activation, chemotaxis, focal adhesion and oxidative stress. Similarly, we observed a lower expression of genes involved in lipid metabolism, fatty acid synthesis and oxidation and mitochondrial respiration.

\section{Conclusion}

We present an approach that combines publiclyavailable subcutaneous adipose tissuegene expression datasets with a deconvolution algorithm to calculate subcutaneous adipose tissue cell-type composition. The results showed the expected increased inflammation gene expression profile accompanied by decreased gene expression in pathways related to lipid metabolism and mitochondrial respiration in subcutaneous adipose tissue in individuals characterised by high macrophage frequencies. This approach demonstrates the hidden strength of reusing publicly available data to gain cell-type specific insights into adipose tissue function.

\section{Introduction}

The adipose tissue is an endocrine and immunologically active organ, that combined with its insulative and dynamic energy storage functions affects the regulation of systemic energy and inflammatory homeostasis (1). It consists of two main components, a heterogeneous cellular population and an extracellular matrix (2). The most abundant cell type in adipose tissue is the adipocyte. Other cell types are also present including preadipocytes, mesenchymal stem cells, fibroblasts, endothelial cells, and many immune cells, including adipose tissue macrophages (ATMs) (3).

In adipose tissue, there are resident macrophages and monocyte-derived macrophages, which collectively are called adipose tissue macrophages (ATMs). In general, macrophages are phagocytes that preserve tissue homeostasis by finding and removing cell debris, pathogens, apoptotic or necrotic cells. ATMs are present in lean and obese adipose tissues, involved in the regulation of adipogenesis and angiogenesis (4). Macrophages in lean humans constitute around $5 \%$ of the cells in adipose tissue, whereas during obesity they constitute up to $50 \%$ of all adipose tissue cells (5). Chronic metabolic diseases promote macrophage infiltration often leading to adipose tissue inflammation (4-7), characterized by increased secretion of adipokines and cytokines into the systemic circulation, which may be associated with hepatic and peripheral insulin resistance (8).

The area of immunometabolism aims to understand how changes in intracellular metabolic pathways in immune cells alter their function and, how immune cells employ tissue metabolism in adaptation to environmental changes. Understanding therefore the contribution of macrophages and other immune cells to adipose tissue dysfunction and plasticity, but also the interplay with adipocytes, adipokines, adipose tissue secreted cytokines and other non-adipose tissues, can offer insights on how to control immunometabolism in health and disease. Describing therefore adipose tissue cell-type composition is particularly important. In general, tissue cell-type composition can be estimated with common experimental methods (e.g. flow cytometry) or computational deconvolution (e.g. CIBERSORT (9)). Experimental methods can be costly and are often logistically impractical for large human cohort studies. Researchers can overcome these limitations by using computational methods to estimate cell type composition of complex tissues from their gene expression profiles (9).

In this paper, our analysis assesses the contribution of macrophage frequencies to the overall SAT gene expression. We used the computational algorithm TissueDecoder (10) to infer the SAT cell-type composition from publicly available, gene expression microarray datasets. Furthermore, we divided our samples based on their relative macrophage frequencies and set out to study the relation between inter-individual differences in 
relative macrophage frequencies and transcriptional differences in metabolic and inflammatory pathways within the SAT.

\section{Materials and Methods}

Deconvolution of adipose tissue cell types by TissueDecoder

The TissueDecoder (10) framework uses CIBERSORT (9) to estimate the cellular composition of adipose tissue samples from their whole tissue gene expression profiles. TissueDecoder provides a novel signature matrix (AT21) that includes highly relevant celltypes for adipose tissue, based on publicly available data from the Affymetrix Human U1333 Plus 2.0 microarray. Briefly, the AT21 reference dataset is generated using single cell-type gene expression data from 21 different cell types from 204 samples that were collected from publicly available datasets in the Gene Expression Omnibus (GEO) (11) and ArrayExpress (12) databases. The raw data (CEL files) were pre-processed with the Affymetrix Power Tools using the robust multi-array average normalization method as described in the original publication by Lenz et al. (10). CIBERSORT together with the AT21 matrix were used to deconvolute the 779 samples, thus determining the relative frequencies of 21 cell types. Additional information on the probe selection criteria can be found in the original publication (10).

In our analysis, we initially included 616 human subcutaneous adipose tissue (SAT) samples from eight studies (GSE27916 (13), GSE20950 (14), GSE27657 (15), GSE41168 (16), GSE66159 (17), E-MTAB-1895 (18), GSE26637 (19), GSE27949 (20)), combined into one SAT dataset. As we wanted to adjust for sex in the linear regression models, samples without sex information were excluded, thus 583 samples and 7 studies remained in our analysis (GSE27949 was excluded, as 33 samples did not have sex information). Furthermore, 64 samples from studies with multiple time points, e.g. samples after intervention, were excluded (54 samples from GSE41168 and 10 samples from GSE66159). Finally, 519 SAT samples and 7 studies remained.

\section{Filtering on absolute expression level}

The seven studies with the 529 SAT samples comprised 54,675 probes. Firstly, 11,953 probes without gene identifiers were removed, thus 42,722 remained. The probes with the duplicated gene identifiers (19,622 probes) were summarised into one unique gene identifier (per duplicated probe) calculating the medians across samples. The probes with the highest median expression were kept resulting in 23,100 unique genes. Furthermore, the median expression of the $\mathrm{Y}$ chromosome genes in female subjects was defined as the gene expression detection threshold. Y chromosome genes are not expressed in female subjects and hence provide a measure of background noise. Genes with a median expression below the computed threshold ( $3.1 \mathrm{on}$ a $\log _{2}$ scale) were removed. Finally, from 23,100 unique genes, 4,056 genes were expressed below background level and therefore removed, resulting in 19,043 unique genes considered for downstream analysis. The probe identifiers were additionally mapped to the Homo sapiens GRCh38 assembly in Ensembl 
(21) through the BioMart (22) library in R (v3.6.3).

\section{Grouping subjects based on relative macrophage amount}

The SAT dataset individuals were divided into 4 groups based on their relative adipose tissue macrophage frequencies. Individuals with no detectable frequencies of macrophages were defined as Mo group. The remaining subjects were divided into tertiles, defined as M1 (\% o to 1 ), $\mathrm{M}_{2}$ (\% 1 to 2 ) and $\mathrm{M}_{3}$ (\% 2 to 25 ).

\section{Statistical analysis}

\section{Participant characteristics}

We assessed the differences in the cell-type frequencies between groups using a Wilcoxon rank sum test. Multiple testing correction was performed by applying the Benjamini and Hochberg method on the p-values, to control the false discovery rate (FDR). The threshold for statistical significance for nominal and FDR $p$-values was set at $p<0.05$.

\section{Differential gene expression analysis}

We focussed our analysis on the extremes ( $\left.\mathrm{M}_{3} v s \mathrm{Mo}\right)$. Differential gene expression analysis was implemented using limma (v3.42.2) (23). To assess the effect of adjusting for cell-type composition, two linear models were implemented for the differential gene expression analysis, i) adjusting for sex and study (model 1) and ii) additionally adjusting for differences in cell-type composition (20 cell types excluding macrophages). All significant genes (nominal $\mathrm{p}<0.05$ ) were divided into up- (nominal $\mathrm{p}<0.05 \& \log _{2}$ fold change $>0.26$ ) and downregulated (nominal $p<0.05 \& \log$ fold change $<-0.26$ )

\section{Gene Ontology analysis}

Gene Ontology (GO) analysis was performed using clusterProfiler (v3.14.3) (24). All upregulated and downregulated genes were included separately to provide direction for the involved biological processes. The organism Homo sapiens and the ontology biological process were used. The gene-mapping database was set to 'ENSEMBL'. Finally, the over-representation results were simplified using the function simplify filtering on FDR-p $<0.05$ and similarity cut-off 0.7

\section{Pathway analysis}

Pathway analysis was performed with rWikiPathways (v1.6.1) (25). We used the curated human pathway collection (20200610). An overrepresentation analysis was performed with the microarray dataset. Pathways were significantly changed and considered for the analysis when FDR-p<0.05

\section{Network analysis}

The top 10 GO biological processes for the up- and downregulated genes were exported as a process-gene network using the function cnetplot from clusterProfiler. The nodes in the networks represented genes and biological processes. They were connected by an edge when a gene was involved in the process. The networks were imported in Cytoscape (v3.8.o)

(26) with the function createNetworkFromIgraph via the RCy3 (v2.6.3) (27). Only the relevant differentially expressed genes for the enriched processes were shown in the networks. The pie chart visualization for the process nodes showed how many genes were associated with the biological process in total and their overall expression patterns. The differential gene expression was visualised using a colour gradient for the node fill colour in the networks.

\section{Sensitivity analysis}

We performed a sensitivity analysis excluding study GSE27916 (with 375 participants) to check whether the results we obtained were mainly driven by this dataset, as a large proportion of the samples were included in our SAT dataset. Likewise, we performed an additional sensitivity analysis excluding study E-MTAB-1895 (with 52 participants) which consisted of twins to evaluate if our results were driven by the non-independence of these participants. Differential gene expression and GO analysis was performed as described in the Methods section above. 


\section{Results}

\section{Dataset characteristics}

The human SAT dataset was comprised of 519 samples and 7 studies, all publicly available. Briefly, study GSE20950 (14) contained expression data from BMI-matched obese cohort individuals that were either insulin sensitive or insulin resistant. Study GSE26637 (19) contained expression data from obese insulin sensitive and insulin resistant females. Study GSE27657 (15) expression data of individuals undergoing surgery in the thyroid region. Study GSE27916 (13) contained expression data from the Swedish Obese Subjects Sib-Pair offspring cohort. Furthermore, study GSE41168 (16) contained expression data from non-obese individuals with normal glucose tolerance. Study GSE66159 (17) contained expression data from overweight or obese females at moderately increased risk of breast cancer. Finally, the E-MTAB-1895 (18) contained expression data from young adult obesitydiscordant monozygotic twin pairs.

\section{Participant Characteristics}

The SAT dataset individuals were divided into 4 groups based on their relative adipose tissue macrophage frequencies. Individuals with no detectable frequencies of macrophages were defined as Mo group. The remaining subjects were divided into tertiles according to the percentage (frequency) of macrophages in the tissue, defined as $\mathrm{M} 1 \%$ o to 1 ), $\mathrm{M}_{2}$ (\% 1 to 2 ) and $\mathrm{M}_{3}$ (\% 2 to 25 ). Since the studies included in our analysis were publicly available, only a limited amount of phenotypic information was available. Briefly, in Mo there were 115 participants ( 82 women), in M1 were 135 participants (106 women), in M2 were 135 participants ( 94 women), in M3 were 134 participants (9o women) (Table S1). Thus, the groups did not differ with respect to female/male distribution, and in all groups, females were more prevalent. Additionally, from Mo to M3 group, based on the available characteristics, obesity and insulin resistance seems to worsen (Figure S1 and Figure S2). Detailed phenotypic participant characteristics are reported separately for each group and study in Table $\mathrm{S} 1$.

High macrophage frequencies are associated with higher adipose stem cell and lower subcutaneous adipocyte frequencies in SAT

We focused our analysis on the extremes ( $\mathrm{M}_{3} v s \mathrm{Mo}$ ). Compared to the Mo group, individuals in $M_{3}$ had higher relative frequencies of eight cell-types, namely macrophages, adipose stem cells, B-cells, CD8T-cells, monocytes, plasmacytoid dendritic cells, platelets and smooth muscle cells (Figure 4.1A). Six cell-types had lower relative frequencies in the $\mathrm{M}_{3}$ group compared to the Mo group. Those were the subcutaneous adipocytes, CD4T-cells, eosinophils, fibroblasts, neutrophils, and NK-cells (Figure 4.1B). Finally, for seven cell-types there were no significant differences between the Mo and $\mathrm{M}_{3}$ group (Figure 4.1C). Those were the chondrocytes, endothelial cells, erythroblasts, mesenchymal stromal cells, myeloid dendritic cells, osteoblasts and pericardial adipocytes. Information on cell-type composition and differences (p-values) for the M1 and M2 group comparisons is provided in Table S2.

\section{${ }^{\oplus} \mathbf{M 0}{ }^{\oplus} \mathbf{M}$}

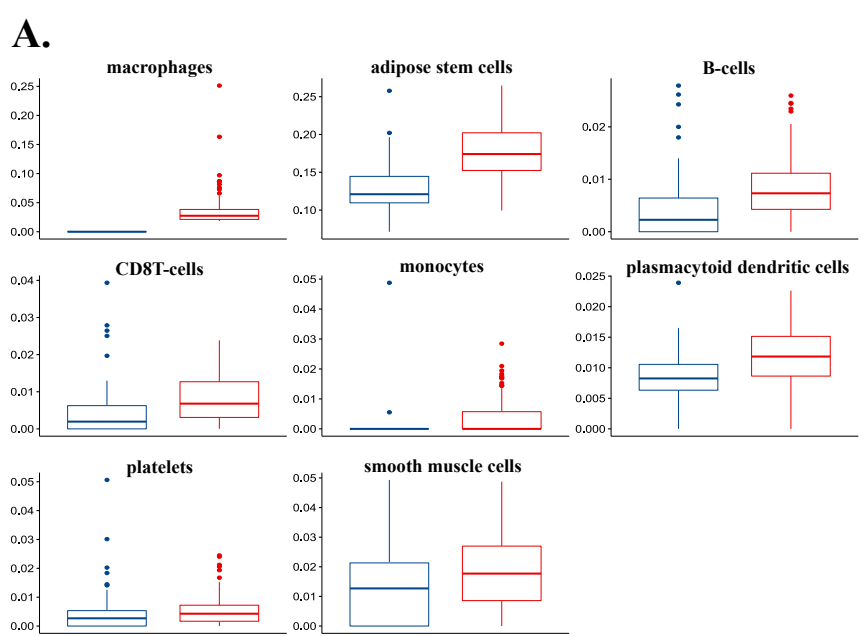

B.
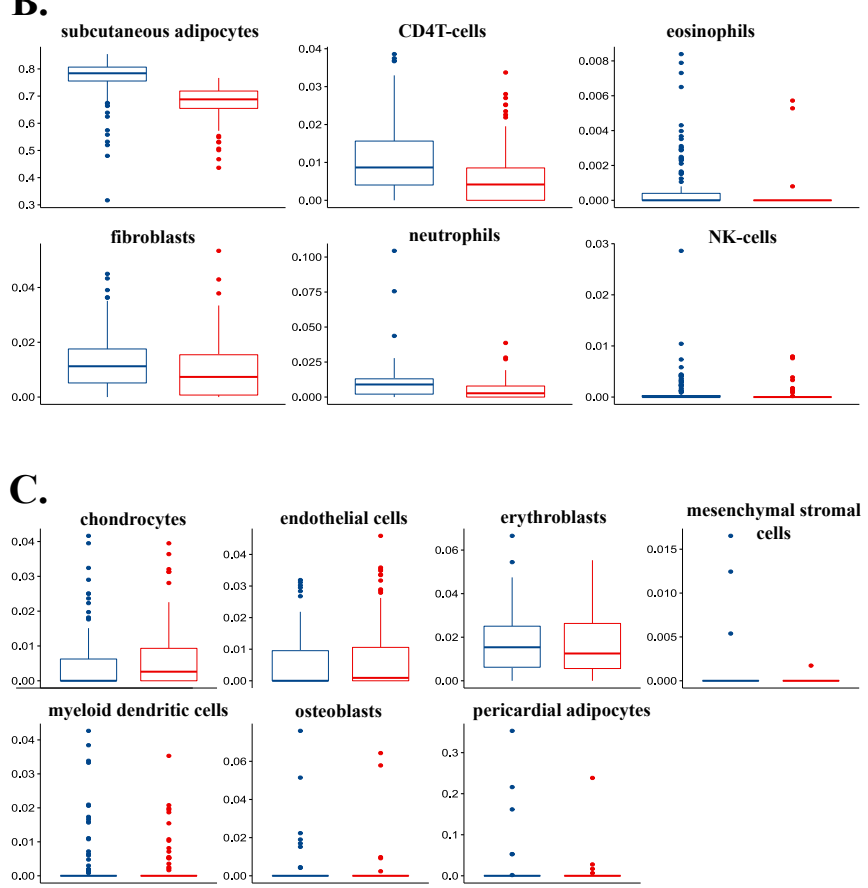

Figure 4.1. Cell-type composition and differences between the Mo and $\mathrm{M}_{3}$ groups of the 21 cell-types estimated by TissueDecoder in the SAT dataset. Compared to the Mo group, individuals in $\mathrm{M}_{3}$ had higher relative frequencies of eight cell-types (A), lower relative frequencies of six cell-types (B) and for seven celltypes there were no significant differences (C) 
SAT transcriptome differences between groups with high and low macrophage frequencies

Next, we assessed the SAT transcriptome for the M3 vs Mo group comparison. The Mo group was used as a reference. We identified 2,210 upregulated (nominal $\mathrm{p}<0.05 \& \log$, fold change $>0.26$ ) genes after adjusting for sex and study (model 1 ) and 842 after additionally adjusting for differences in cell-type composition (model 2) (Figure 4.2A \& Table $\mathrm{S}_{3}$ ). We identified 1,057 downregulated (nominal $\mathrm{p}<0.05 \& \log 2$ fold change $<-0.26$ ) genes in model 1 and 252 in model 2 (Figure 4.2B \& Table S4).

A.

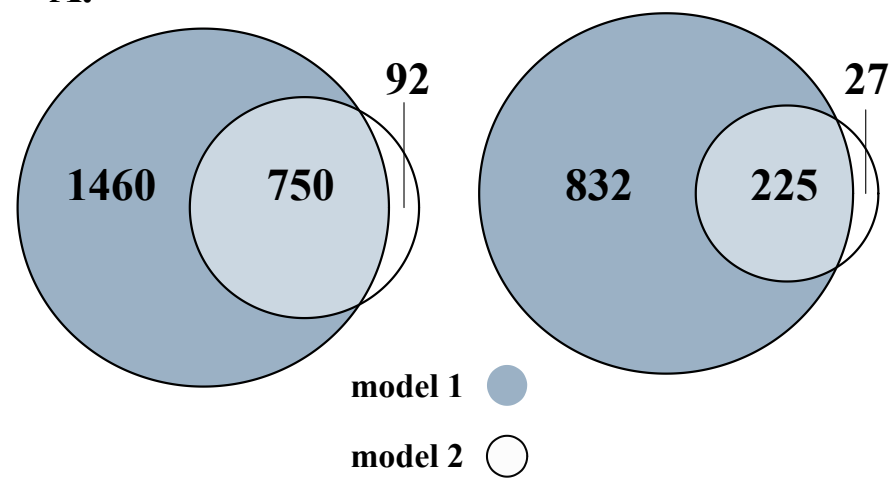

Figure 4.2. Venn diagram of the numbers of the upregulated (A) and downregulated (B) genes, for the $M_{3}$ vs Mo group comparison. Two models were used: adjusted for sex and (model 1) and additionally adjusted

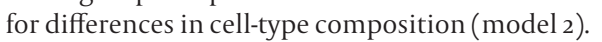

\section{GO enrichment analysis between high and low M groups}

To gain further insight into the differentially expressed SAT transcriptome after adjusting for sex and study (model1) and additionally adjusting for cell-type composition differences (model 2), GO analysis was performed for the $\mathrm{M}_{3} v s$ Mo comparison for the upregulated and downregulated genes, separately, to provide direction of the biological processes. All 2,210 upregulated and 1,057 downregulated genes from model 1 and all 842 upregulated and 252 downregulated genes from model 2 were used. The analysis resulted in 252 significant biological processes for the upregulated genes (Table $S_{5}$ ) and 85 for the downregulated genes (Table S6) for model 1 and in 248 significant biological processes for the upregulated genes (Table 57 ) and 46 for the downregulated genes (Table S8) for model 2. Additionally adjusting for differences in cell-type composition did not materially alter the results, therefore the analysis was continued with model 1 (adjusting for sex and study).
Increased inflammatory SAT gene expression associated with high macrophage frequencies

The top 10 enriched biological processes (FDR-p<0.05) for the upregulated genes were selected and combined into a network (Figure 4.3). The network illustrates a gene-process network in which the nodes represent upregulated genes and enriched processes, and they are connected by edges which show that the genes are directly involved in the biological process. The overall expression patterns are shown in the pie chart visualization of the process nodes. Only the 472 upregulated genes in the top 10 processes are added in the network visualization. In additional analyses, we performed a pathway overrepresentation analysis with all upregulated genes for the $M_{3} v s$ Mo group comparison. The analysis identified 55 significantly changed pathways (FDR-p<0.05) (Table S9). Among those pathways were the "Human Complement System (WP2806)", "Regulation of toll-like receptor signaling pathway (WP1449)", "Chemokine Signaling Pathway (WP3929)", "Type II interferon signaling (IFNG) (WP619)", "Focal adhesion (WP4172)", "Oxidative damage (WP3941)", "AGE/RAGE pathway (WP2324)", and "VEGFA-VEGFR2 Signaling Pathway (WP3888)". SAT of individuals with high numbers of macrophages was characterized by higher expression of key genes involved in complement activation (e.g. $\mathrm{C}_{1} \mathrm{QA}_{\mathrm{A}}, \mathrm{C}_{1} \mathrm{QB}$, and $\mathrm{C}_{1} \mathrm{QC}$ ), chemotaxis (e.g. $C \mathrm{CL}_{2}, \mathrm{CCL}_{3}$, and $C \mathrm{CL}_{5}$ ) and adhesion molecules (e.g. ITGB2, VCAM1, and ICAM1); major histocompatibility complex (MHC) class I (e.g. HLA-A and HLA-B) and II (e.g. HLA-DPA1, HLA-DRB1 and HLA-DQA1). Furthermore, it was characterized by higher expression of genes involved in extracellular matrix (ECM) organization (e.g. collagens, metalloproteinase domain-containing protein (ADAMs), matrix metalloproteases (MMPs), and tissue inhibitor of metalloproteinases (TIMPs)), angiogenesis (e.g. VEGFB, SERPINE1, ANGPTL4) and oxidative stress (e.g. CYBB and CYBA). These data reveal activation of inflammatory pathways and an overrepresentation of inflammatory GO biological processes, indicating that high macrophage frequencies in the SAT associates with increased SAT inflammatory gene expression.

Dysfunctional lipid and glucose metabolism, mitochondrial respiration and BCAA catabolism associated with high macrophage frequencies in SAT

The top 10 enriched biological processes (FDR-p<0.05) for the downregulated genes were selected and combined into a network (Figure 4.4). The network illustrates a gene-process network in which the nodes represent downregulated genes and enriched processes, and they are connected by edges which show that the genes are directly involved in the biological process. The overall expression patterns are shown in the pie chart visualization of the process nodes. Only the 157 downregulated genes in the top 10 processes are added in the network visualization. Following the GO analysis, we performed pathway analysis. The analysis revealed 12 significantly changed pathways (Table S10). Among those pathways were, "Fatty Acid Biosynthesis (WP357)", "Amino Acid metabolism (WP3925)" and "Adipogenesis (WP236)". Key genes involved in lipid and glucose metabolism 
(glucose transporters e.g. SLC27A2 (also known as FATP2), IRS1 and IRS2, LPIN1), fatty acid metabolism (e.g. ACACA, FASN) and fatty acid oxidation (e.g. PPARA, PPARG), lipogenesis (e.g. ACLY, ELOVL6, FADS1, FADS2), adipogenesis (e.g. KLF15, FOXO1, IGF1, TWIST1) and angiogenesis (e.g. VEGFA, FGF2) were significantly downregulated in individuals with high macrophage frequencies. Furthermore, key genes involved in mitochondrial respiration (e.g. PPARG and PGC1A (also known as PPARGC1A), COX7C and COX14, NDUFA8, NDUFB5 and NDUFS 4 , ATP11B and ATP8A2) were significantly downregulated in individuals with high macrophage frequencies. On the same direction, key genes involved in degradation of all BCAAs, namely isoleucine, leucine and valine (e.g. $B C K D H B$ ), and those specific to isoleucine (e.g. PCCA and PCCB), leucine (e.g. AUH) and valine (e.g. HIBADH and ALDH6A1) were significantly downregulated in the individuals with high macrophage frequencies. Collectively these data reveal a decreased lipid and glucose metabolism, mitochondrial respiration and BCAA catabolism associated with high macrophage frequencies in SAT.

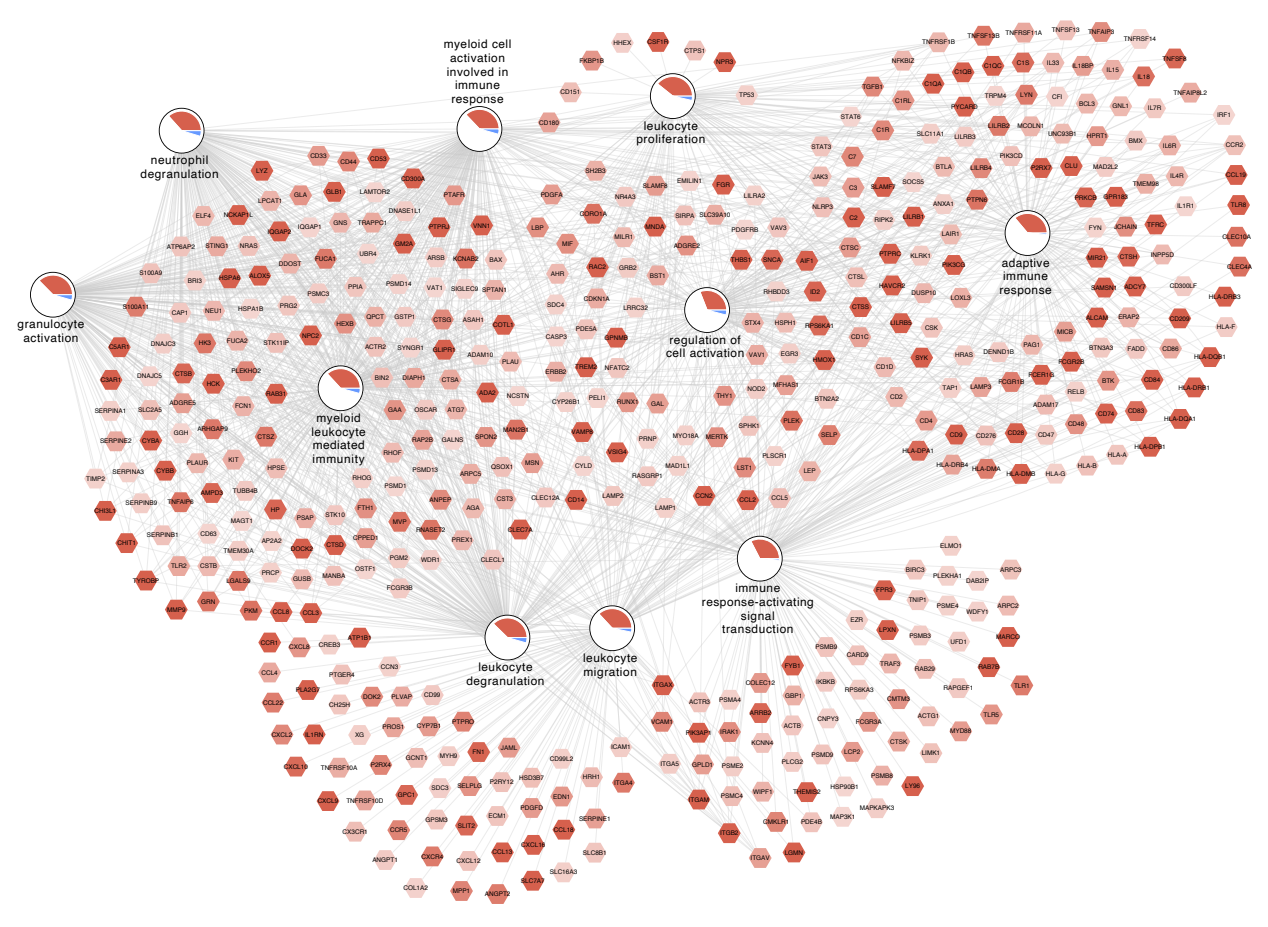

Figure 4.3. Increased inflammation associated with high macrophage frequencies in SAT. The geneprocess network illustrates the top $10 \mathrm{GO}$ biological processes enriched for upregulated genes for the $\mathrm{M}_{3}$ vs Mo group comparison. Gene nodes are visualized as hexagons and process nodes as circles. The edges in the network show the involvement of genes in biological processes to which they are connected to. The differential gene expression is visualized on the gene nodes using a colour gradient from blue (downregulated) over white (not changed) to red (up-regulated).The overall distribution of gene expression changes for genes associated with a biological process is visualized using a pie chart divided into upregulated, down-regulated and not significantly changed genes.

\section{Sensitivity analysis}

We performed a sensitivity analysis excluding study GSE27916 (with 375 participants) to check whether the results we obtained were mainly driven by this dataset, as a large proportion of the samples were included in our SAT dataset. Likewise, we performed an additional sensitivity analysis excluding study E-MTAB-1895 (with 52 participants) which consisted of twins to evaluate if our results were driven by the non-independence of these participants. Differential gene expression and GO analysis was performed. Exclusion of these datasets did not materially alter the results (Tables S11-S18).

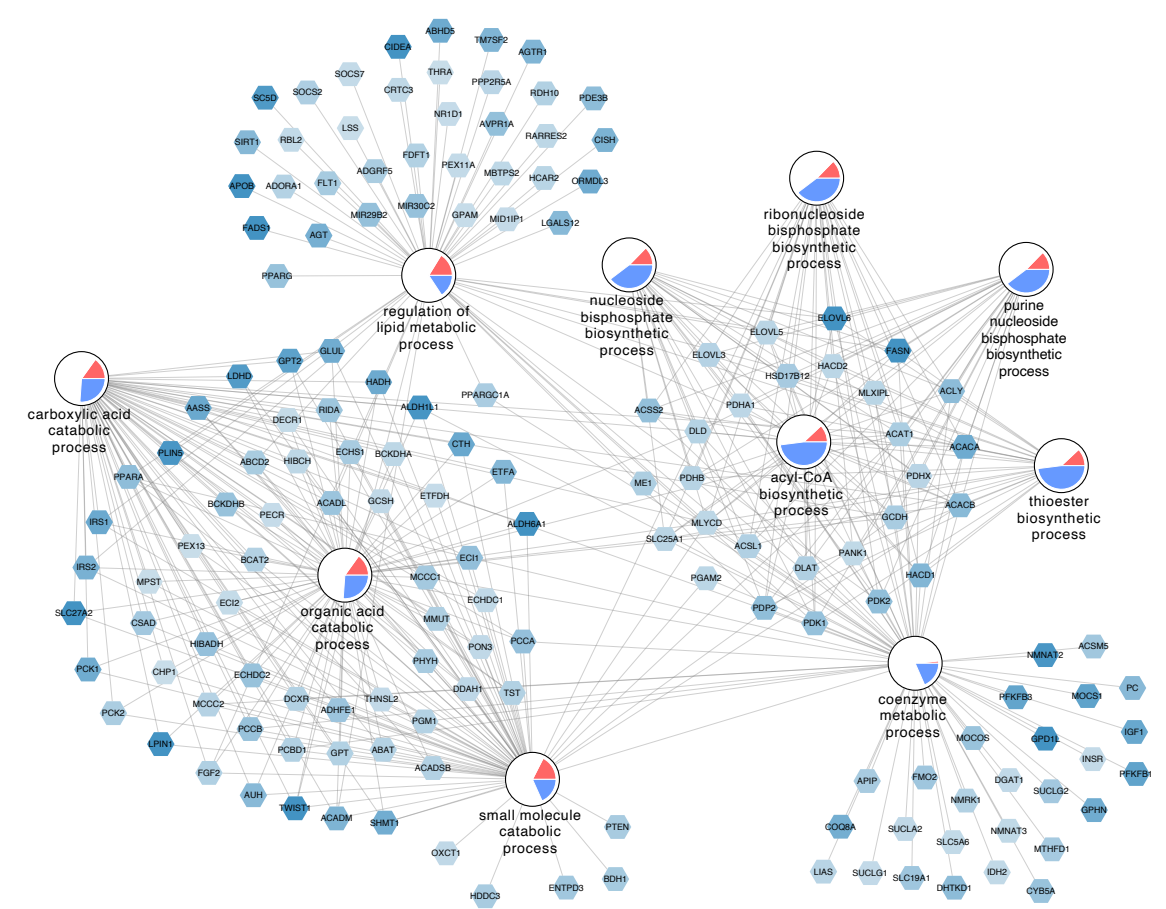

Figure 4.4. Dysfunctional lipid and glucose metabolism, mitochondrial respiration and BCAA catabolism associated with high macrophage frequencies in SAT. The gene-process network illustrates the top $10 \mathrm{GO}$ biological processes enriched for downregulated genes for the M3 vs Mo group comparison. Downregulated gene nodes are visualized as hexagons and process nodes as circles. The edges in the network show the involvement of genes in biological processes to which they are connected to. The differential gene expression is visualized on the gene nodes using a colour gradient from blue (downregulated) over white (not changed) to red (upregulated).The overall distribution of gene expression changes for genes associated with a biological process is visualized using a pie chart divided into upregulated, downregulated and not significantly changed genes. 


\section{Discussion}

Methodology and benefit of the analytic approach

Our analysis demonstrated the substantial benefit of integrating publicly available datasets in combination with the algorithm TissueDecoder, in assessing the contribution of macrophage frequencies to the overall subcutaneous adipose tissue gene expression. TissueDecoder provides a signature matrix with cell-types relevant for obesity, type 2 diabetes, insulin resistance and other metabolic abnormalities. We used the inferred celltype composition from SAT Affymetrix microarray data to identify individuals with high and low macrophage frequencies, as macrophage content in adipose tissue predicts the risk for metabolic disease. We showed the relative frequencies of adipocytes to be lower and the relative frequencies of adipose stem cells to be higher in individuals characterised by high macrophage frequencies. Notably, TissueDecoder estimates 20 more cell-types across three additional depots (omental, epicardial and pericardial adipose tissue). The proposed approach can therefore be used in a similar manner to define other groups of interest (e.g. subcutaneous adipocytes or adipose stem cells) in investigating adipose tissue metabolism

\section{Biological implications of our findings}

We observed lower frequencies of adipocytes and increased frequencies of adipose stem cells in the individuals with high macrophage frequencies compared to those with low. Failure of adipocyte differentiation has been associated with reduced expandability of adipose tissue, contributing to adipose tissue inflammation, systemic inflammation, lipid overflow, and insulin resistance $(8,28,29)$, while low numbers of adipocytes may be associated with impaired metabolic health (30). In line, previous studies have showed that obese-derived adipose stem cells have decreased differentiation, migration and angiogenic capabilities $(31,32)$ attributed to differences in the anatomical distribution of adipose tissue (33) or decrease in adipose stem cells in obese humans (34, 35) and mice (35, 36). Based on the available phenotypic data, obesity and insulin resistance status seems to worsen, in individuals characterised by high macrophage frequencies, lower percentage of adipocytes and higher percentage of adipose stem cells. Overall, our data suggest that those individuals are characterised by an impaired pre-adipocyte differentiation and a limited capacity for hyperplasia, which may contribute to adipose tissue dysfunction, insulin resistance and a generally unfavourable metabolic profile.

We observed that adipose tissue of individuals characterised by high SAT macrophage frequencies, exhibited the expected increased inflammatory gene expression profile accompanied by decreased gene expression in pathways related to lipid metabolism, mitochondrial respiration and BCAA catabolism. In individuals characterised by high macrophage frequencies, we observed a higher expression of genes involved in inflammatory processes (e.g. chemotaxis, complement activation), ECM remodelling, oxidative stress and angiogenesis. Macrophage amount butalso change in their localization is associated with increased chemokine expression and increased inflammation in the adipose tissue $(6,37,38)$, obesity $(5,7)$ and insulin resistance $(39)$. Furthermore, increased expression of complement components has been previously associated with an increased inflammatory profile in SAT in obesity, suggesting complement involvement in the clearance of apoptotic debris in the adipose tissue (40). Next, upregulation of genes related to ECM organization in SAT has been associated with a reduced adipose tissue expansion capacity and dysfunctional adipose tissue in obesity $(41,42)$ and with hepatic insulin resistance (43). Alcala et al. suggested that oxidative stress plays an important role in ECM remodelling and therefore metabolic regulation in mice (44). On that note, van den Bossche et al. reported that oxidative stress promotes M1 macrophage polarisation (45), while a plethora of studies have corroborated that adipose tissue undergoes increased oxidative stress due to obesity induced by overnutrition $(46,47)$. Finally, the vascular endothelial growth factors (VEGFs) are key factors in angiogenesis and adipose tissue remodelling and VEGF has been reported to be a chemotactic for macrophages (48). In line with our results Lu et al. reports VEGFB upregulation was associated to VEGFA downregulation, as a compensatory mechanism that leads to brown-like white adipose tissue differentiation (49). Collectively, our data show that individuals characterised by high macrophage frequencies have higher expression of genes involved in inflammatory processes and ECM remodelling, suggesting increased SAT inflammation.

Moreover, we observed lower expression in genes involved in lipid and glucose metabolism, mitochondrial respiration and BCAA catabolism in the individuals with high macrophage composition. Similar observations have been previously reported with obesity and/or insulin resistance (19, 50-53). Especially during hyperinsulinemic conditions, the lower expression of mitochondrial pathways is an important finding as it could reflect a regulatory defect, that potentially further advances the pathogenesis of insulin resistance (19). Nilsson et al. reported genes involved in adipose tissue lipogenesis strongly downregulated in the SAT from monozygotic twins discordant for type 2 diabetes (54). During the development of obesity and insulin resistance, the adipose tissue can reach a flexing point while adipocytes reduce their ability to synthesize additional fatty acids or triglycerols, resulting in decreased lipogenesis $(55,56)$. Furthermore, we found lower expression of genes involved in amino acid metabolism. Wiklund et al. reported lower SAT expression of genes related to BCCA catabolism and mitochondrial energy metabolism along with increased expression of genes involved in inflammatory processes in insulin resistant subjects (57). Collectively, our data show that individuals characterised by high macrophage frequencies have lower expression of genes involved in lipid metabolism and mitochondrial respiration, suggesting adipose tissue dysfunction and impaired adipocyte differentiation, enhanced by the increased SAT inflammation. 


\section{Strengths, limitations, and future directions}

Our analysis exhibits the substantial benefit of combining and reusing publicly available data. Additionally, it allows assessing the contribution of macrophage frequencies to the overall SAT gene expression. Furthermore, this type of analysis allows researchers to investigate other cell types potentially involved in the dysregulation of adipose tissue metabolism. Naturally, our analysis comes with shortcomings; publicly available datasets do not provide sufficient information on phenotypic measures (e.g. BMI, HOMA-IR or age) that could be adjusted for in the linear regression analysis. Finally, a context-specific signature matrix from isolated cells from the tissue of interest could further improve the computational predictions of the cell-type composition (10). Additionally, for studying adipose tissue inflammation, identifying signatures for macrophage subtypes could be of interest.

In conclusion, we have shown the additive value of integrating publicly available datasets in combination with the useful application of cell-type composition in SAT gene expression. The contribution of macrophage frequencies and other cell-types to adipose tissue dysfunction and plasticity can offer insights in modulating human health and disease by providing targets and biomarkers for more personalized risk classification in the prevention and treatment of obesity and its complications. We hypothesised that increased macrophage and adipose stem cell percentage and the decreased percentage of adipocytes reflects adipose tissue inflammation and impaired pre-adipocyte differentiation, possibly reflective of a limited capacity for hyperplasia and adipose tissue dysfunction that contributes to an unfavourable metabolic profile. Further studies, should investigate whether classifying individuals based on their M1 or M2 macrophage profile has a similar effect in SAT gene expression profiles.

\section{References}

1. Huh JY, Park YJ, Ham M, Kim JB. Crosstalk between adipocytes and immune cells in adipose tissue inflammation and metabolic dysregulation in obesity. Mol Cells. 2014;37(5):365-71.

2. Pawlina W, Ross MH. Histology: a text and atlas: with correlated cell and molecular biology: Lippincott Williams \& Wilkins; 2018.

3. Esteve Rafols M. Adipose tissue: cell heterogeneity and functional diversity. Endocrinol Nutr. 2014;61(2):100-12.

4. Thomas D, Apovian C. Macrophage functions in lean and obese adipose tissue. Metabolism. 2017;72:12043.

Weisberg SP, McCann D, Desai M, Rosenbaum M, Leibel RL, Ferrante AW, Jr. Obesity is associated with macrophage accumulation in adipose tissue. J Clin Invest. 2003;112(12):1796-808.

6. Surmi BK, Hasty AH. Macrophage infiltration into adipose tissue: initiation, propagation and remodeling. Future Lipidol. 2008;3(5):545-56.

7. Xu H, Barnes GT, Yang Q, Tan G, Yang D, Chou C), et al. Chronic inflammation in fat plays a crucial role in the development of obesity-related insulin resistance. J Clin Invest. 2003;112(12):1821-30.

8. Stinkens R, Goossens GH, Jocken JW, Blaak EE. Targeting fatty acid metabolism to improve glucose metabolism. Obes Rev. 2015;16(9):715-57.

9. Newman AM, Steen CB, Liu CL, Gentles A], Chaudhuri AA, Scherer F, et al. Determining cell type abundance and expression from bulk tissues with digital cytometry. Nat Biotechnol. 2019;37(7):773-82.

10. Lenz M, Arts ICW, Peeters RLM, de Kok TM, Ertaylan G. Adipose tissue in health and disease through the lens of its building blocks. Sci Rep. 2020;10(1):10433.

11. Barrett T, Wilhite SE, Ledoux P, Evangelista C, Kim IF, Tomashevsky M, et al. NCBI GEO: archive for functional genomics data sets-update. Nucleic Acids Res. 2013;41(Database issue):D991-5

12. Athar A, Fullgrabe A, George N, Iqbal H, Huerta L, Ali A, et al. ArrayExpress update - from bulk to singlecell expression data. Nucleic Acids Res. 2019;47(D1):D711-D5.

13. Nookaew I, Svensson PA, Jacobson P, Jernas M, Taube M, Larsson I, et al. Adipose tissue resting energy expenditure and expression of genes involved in mitochondrial function are higher in women than in men. J Clin Endocrinol Metab. 2013;98(2):E370-8.

14. Hardy OT, Perugini RA, Nicoloro SM, Gallagher-Dorval K, Puri V, Straubhaar J, et al. Body mass indexindependent inflammation in omental adipose tissue associated with insulin resistance in morbid obesity. Surg Obes Relat Dis. 2011;7(1):60-7.

15. Svensson PA, Jernas M, Sjoholm K, Hoffmann JM, Nilsson BE, Hansson M, et al. Gene expression in human brown adipose tissue. Int J Mol Med. 2011,27(2):227-32.

16. Yoshino J, Conte C, Fontana L, Mittendorfer B, Imai S-i, Schechtman KB, et al. Resveratrol

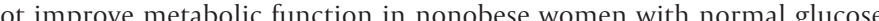
tolerance. Cell metabolism. 2012;16(5):658-64.

17. Ong KR, Sims AH, Harvie M, Chapman M, Dunn WB, Broadhurst D, et al. Biomarkers of dietary energy restriction in women at increased risk of breast cancer. Cancer Prevention Research. 2009:2(8):720-31.

18. Naukkarinen J Heinonen S, Hakkarainen A Lundbom IVuolteenaho K Sarinen L etal.Characterising metabolically healthy obesity in weight-discordant monozygotic twins. Diabetologia. 2014:57(1):16776.

19. Soronen J, Laurila PP, Naukkarinen J, Surakka I, Ripatti S, Jauhiainen M, et al. Adipose tissue gene expression analysis reveals changes in inflammatory, mitochondrial respiratory and lipid metabolic pathways in obese insulin-resistant subjects. BMC Med Genomics. 2012;5:9.

20. Keller P, Gburcik V, Petrovic N, Gallagher IJ, Nedergaard J, Cannon B, et al. Gene-chip studies of adipogenesis-regulated microRNAs in mouse primary adipocytes and human obesity. BMC Endocr Disord. 2011;11:7.

21. Yates AD, Achuthan P, Akanni W, Allen J, Allen J, Alvarez-Jarreta J, et al. Ensembl 2020. Nucleic Acids Res. 2020;48(D1):D682-D8

22. Durinck S, Spellman PT, Birney E, Huber W. Mapping identifiers for the integration of genomic datasets with the R/Bioconductor package biomaRt. Nat Protoc. 2009;4(8):1184-91.

23. Ritchie ME, Phipson B, Wu D, Hu Y, Law CW, Shi W, et al limma powers differential expression analyses for RNA-sequencing and microarray studies. Nucleic Acids Res. 2015;43(7):e47. 
24. Yu G, Wang LG, Han Y, He QY. clusterProfiler: an R package for comparing biological themes among gene clusters. OMICS. 2012;16(5):284-7.

25. Slenter DN, Kutmon M, Hanspers K, Riutta A, Windsor J, Nunes N, et al. WikiPathways: a multifaceted pathway database bridging metabolomics to other omics research. Nucleic Acids Res. 2018;46(D1):D661-D7

26. Shannon P, Markiel A, Ozier O, Baliga NS, Wang JT, Ramage D, et al. Cytoscape: a software environment for integrated models of biomolecular interaction networks. Genome Res. 2003;13(11):2498-504.

27. Gustavsen JA, Pai S, Isserlin R, Demchak B, Pico AR. RCy3: Network biology using Cytoscape from within R. F100oRes. 2019;8:1774

28. Bluher M. Metabolically Healthy Obesity. Endocr Rev. 2020;41(3).

29. Danforth E, Jr. Failure of adipocyte differentiation causes type II diabetes mellitus? Nat Genet.

30. Pasarica M, Xie H, Hymel D, Bray G, Greenway F, Ravussin E, et al. Lower total adipocyte number but no evidence for small adipocyte depletion in patients with type 2 diabetes. Diabetes Care. 2009;32(5):9002.

31. Perez LM, Bernal A, San Martin N, Galvez BG. Obese-derived ASCs show impaired migration and angiogenesis properties. Arch Physiol Biochem. 2013;119(5):195-201.

32. Perez LM, Bernal A, San Martin N, Lorenzo M, Fernandez-Veledo S, Galvez BG. Metabolic rescue of obese adipose-derived stem cells by Lin28/Let7 pathway. Diabetes. 2013;62(7):2368-79.

33. Baglioni S, Cantini G, Poli G, Francalanci M, Squecco R, Di Franco A, et al. Functional differences in visceral and subcutaneous fat pads originate from differences in the adipose stem cell. PLoS One. 2012; $7(5): 336569$.

34. Onate B, Vilahur G, Ferrer-Lorente R, Ybarra ], Diez-Caballero A, Ballesta-Lopez C, et al. The subcutaneous adipose tissue reservoir of functionally active stem cells is reduced in obese patients. FASEB J. 2012;26(10):4327-36.

35. Perez LM, Bernal A, de Lucas B, San Martin N, Mastrangelo A, Garcia A, et al. Altered metabolic and stemness capacity of adipose tissue-derived stem cells from obese mouse and human. PLoS One. 2015;10(4):e0123397.

36. Perez LM, Suarez J, Bernal A, de Lucas B, San Martin N, Galvez BG. Obesity-driven alterations in adiposederived stem cells are partially restored by weight loss. Obesity (Silver Spring). 2016;24(3):661-9.

37. Huber J, Kiefer FW, Zeyda M, Ludvik B, Silberhumer GR, Prager G, et al. CC chemokine and CC chemokine receptor profiles in visceral and subcutaneous adipose tissue are altered in human obesity. J Clin Endocrinol Metab. 2008;93(8):3215-21.

38. Tourniaire F, Romier-Crouzet B, Lee JH, Marcotorchino J, Gouranton E, Salles J, et al. Chemokine Expression in Inflamed Adipose Tissue Is Mainly Mediated by NF-kappaB. PLoS One. 2013;8(6):e66515.

39. Cinti S, Mitchell G, Barbatelli G, Murano I, Ceresi E, Faloia E, et al. Adipocyte death defines macrophage localization and function in adipose tissue of obese mice and humans. I Lipid Res. 2005;46(11):2347-55. . Kaye S, Lokki AI, Hanttu A, Nissila E, Heinonen S, Hakkarainen A, et al. Upregulation of Early and Downregulation of Terminal Pathway Complement Genes in Subcutaneous Adipose Tissue and Adipocytes in Acquired Obesity. Front Immunol. 2017;8:545.

41. Sun K, Kusminski CM, Scherer PE. Adipose tissue remodeling and obesity. JClin Invest. 2011;121(6):2094101.

42. Khan T, Muise ES, Iyengar P, Wang ZV, Chandalia M, Abate N, et al. Metabolic dysregulation and adipose tissue fibrosis: role of collagen VI. Mol Cell Biol. 2009;29(6):1575-91.

43. van der Kolk BW, Kalafati M, Adriaens M, van Greevenbroek MMJ, Vogelzangs N, Saris WHM, et al. Subcutaneous Adipose Tissue and Systemic Inflammation Are Associated With Peripheral but Not Hepatic Insulin Resistance in Humans. Diabetes. 2019;68(12):2247-58.

44. Alcala M, Sanchez-Vera I, Sevillano J, Herrero L, Serra D, Ramos MP, et al. Vitamin E reduces adipose tissue fibrosis, inflammation and oxidative stress and improves metabolic profile in obesity Obesity (Silver Spring). 2015;23(8):1598-606.

45. Van den Bossche J, Baardman J, Otto NA, van der Velden S, Neele AE, van den Berg SM, etal. Mitochondrial Dysfunction Prevents Repolarization of Inflammatory Macrophages. Cell Rep. 2016;17(3):684-96.

46. Aroor AR, DeMarco VG. Oxidative stress and obesity: the chicken or the egg? Diabetes. 2014;63(7):22168 .

47. Furukawa S, Fujita T, Shimabukuro M, Iwaki M, Yamada Y, Nakajima Y, et al. Increased oxidative stress in obesity and its impact on metabolic syndrome. J Clin Invest. 2004;114(12):1752-61

48. Barleon B, Sozzani S, Zhou D, Weich HA, Mantovani A, Marme D. Migration of human monocytes in response to vascular endothelial growth factor (VEGF) is mediated via the VEGF receptor flt-1. Blood. 1996;87(8):3336-43.

49. Lu X, Ji Y, Zhang L, Zhang Y, Zhang S, An Y, et al. Resistance to obesity by repression of VEGF gene entocinology. 2012:153(7):3123-

50. 32. and fatty acid oxidation in the subcutaneous adipose tissue of morbidly obese women. Obesity (Silver Spring). 2014;22(9):2032-8.

51. Elbein SC, Kern PA, Rasouli N, Yao-Borengasser A, Sharma NK, Das SK. Global gene expression profiles of subcutaneous adipose and muscle from glucose-tolerant, insulin-sensitive, and insulin-resistant

52. Mootha VK, Lindgren CM, Eriksson KF, Subramanian A, Sihag S, Lehar J, et al. PGC-1alpha-responsive genes involved in oxidative phosphorylation are coordinately downregulated in human diabetes. Nat Genet. 2003;34(3):267-73

53. Mustelin L, Pietilainen KH, Rissanen A, Sovijarvi AR, Piirila P, Naukkarinen J, et al. Acquired obesity and poor physical fitness impair expression of genes of mitochondrial oxidative phosphorylation in monozygotic twins discordant for obesity. Am J Physiol Endocrinol Metab. 2008;295(1):E148-54.

54. Nilsson E, Jansson PA, Perfilyev A, Volkov P, Pedersen M, Svensson MK, et al. Altered DNA methylation and differential expression of genes influencing metabolism and inflammation in adipose tissue from subjects with type 2 diabetes. Diabetes. 2014;63(9):2962-76.

55. Ortega FJ, Mayas D, Moreno-Navarrete JM, Catalan V, Gomez-Ambrosi J, Esteve E, et al. The gene expression of the main lipogenic enzymes is downregulated in visceral adipose tissue of obese subjects. Obesity (Silver Spring). 2010;18(1):13-20.

56. Poulain-Godefroy O, Lecoeur C, Pattou F, Fruhbeck G, Froguel P. Inflammation is associated with a decrease of lipogenic factors in omental fat in women. Am J Physiol Regul Integr Comp Physiol. 2008;295(1):R1-7.

57. Wiklund P, Zhang X, Pekkala S, Autio R, Kong L, Yang Y, et al. Insulin resistance is associated with altered amino acid metabolism and adipose tissue dysfunction in normoglycemic women. Sci Rep. 2016;6:24540. 

Obesity and overweight have a great impact on health and well-being. Obesity is even officially recognised as a disease (1). Both obesity and overweight present several risks to health, as they are associated with insulin resistance (IR), which is a risk factor for the development of type 2 diabetes and cardiovascular disease (2). A plethora of evidence suggests that adipose tissue mass and function and the distribution of body fat are the most important contributing factors, determining an individual's risk to develop obesityassociated IR, type 2 diabetes and cardiometabolic disease (3-11)

Importantly, IR may develop separately in multiple organs and the severity may vary between organs. Sub-typing obese individuals based on their IR phenotype, may lead to a better understanding of the relationship between IR and type 2 diabetes and cardiometabolic risk. This may give leads to precision-based prevention and treatment strategies.

The primary goal of this thesis was to investigate the adipose tissue and the whole blood transcriptome of IR phenotypes in human obesity. In Chapters 2 and 3, we have investigated abdominal subcutaneous adipose tissue (SAT) gene expression in individuals with more pronounced IR in either skeletal muscle or liver (Chapter 2) and in individuals discordant or concordant for adipose tissue and muscle IR (Chapter 3). In Chapter 4, we have investigated whether relative frequencies of macrophages in adipose tissue were reflected in transcriptional differences, using publicly available datasets. In Chapter $\mathbf{5}$ we used DNA methylation data to investigate the whole blood transcriptome of insulin resistant individuals independent of their white blood cell profile. In the final chapter (Chapter 6), I summarize and discuss the main findings of this thesis along with several methodological considerations.

\section{Employing gene expression to link adipose tissue dysfunction to insulin resistance}

Increased subcutaneous adipose tissue inflammation and adipose tissue dysfunction There is growing evidence showing that the severity of IR at the tissue level may play a role in the differential responses to lifestyle and pharmacological interventions that aim to increase insulin sensitivity (12-14). Adipose tissue dysfunction, rather than adiposity per se, is characterised by lipid overflow and low-grade inflammation and is frequently associated with the development of whole-body, adipose tissue, liver or skeletal muscle IR $(7,9-11,15,16)$. Recently, it was reported that adipose tissue IR and whole-body IR, as reflected by Homeostatic Model Assessment of Insulin Resistance (HOMA-IR), not always coincide (16), while previous studies have shown significant dysregulation in the SAT transcriptome in obesity and IR (17-20). Hence, analysis of gene expression in SAT may help to elucidate the pathways and mechanisms involved in adipose tissue dysfunction that are altered in insulin resistant individuals.

In Chapters $\mathbf{2}$ and 3, we acquired more information on the phenotypes of distinct IR phenotypes in terms of clinical, metabolic and abdominal SAT gene expression profiles. We used cross-sectional data from the DioGenes study (21), a large cohort of overweight or obese non-diabetic individuals who are at risk for developing cardiometabolic diseases. The DioGenes study is a multi-centre, randomised, controlled dietary intervention study, which involves eight European countries (21). Furthermore, in Chapter 2 we additionally included the CODAM study, a prospective observational cohort that includes participants with an elevated risk of type 2 diabetes mellitus and cardiovascular disease (22), and the Maastricht Study, a large population-based cohort that is enriched with participants with type 2 diabetes and that focuses on the etiology of type 2 diabetes, its classic complications, and its emerging comorbidities (23). These cohorts provide great benefits as they are well characterised and may therefore provide insights into factors related to tissue-specific IR and cardiometabolic diseases.

In Chapter 2, we demonstrated distinct adipose tissue transcriptome profiles in tissuespecific IR. We showed that an altered extracellular matrix (ECM) gene expression profile in SAT was present in overweight and obese individuals with pronounced hepatic IR. Furthermore, an inflammatory gene expression profile was particularly present in individuals with pronounced muscle IR. This was mainly reflected in an upregulation of genes involved in chemotaxis, complement activation and immune cell function related to lysosomes and ubiquitin-proteasome. We hypothesized that an increased SAT inflammatory gene expression, as observed in the muscle IR group, may lead to the secretion of pro-inflammatory adipokines in the circulation and a systemic proinflammatory profile inducing subsequently peripheral IR. In line with this hypothesis, 
in two cohorts with similar characteristics, the CODAM and Maastricht Study, we showed that low-grade inflammation scores of plasma inflammatory markers, were inversely associated with muscle insulin sensitivity (MISI), after adjustment for sex and body composition, while we did not observe an association between the systemic low-grade inflammation score and hepatic IR (HIRI).

In Chapter 3, also in the DiOGenes study, we investigated the presence and proportion of individuals who are discordant for IR in their adipose tissue and their muscle (i.e. in whom the adipose tissue is resistant to insulin, while muscle is not, or vice versa). Furthermore, we characterized their clinical and metabolic features, as well as their SAT transcriptome. We found that $40 \%$ of the study participants were discordant for IR in adipose tissue and muscle. Moreover, we found that adipose tissue IR was characterized by an upregulation of inflammatory and ECM genes, and a worse metabolic and inflammatory profile as compared to adipose (insulin sensitivity) IS, regardless of concurrent presence of muscle IR. On the other hand, within individuals with a relative insulin sensitive adipose tissue and no major alterations in adipose tissue gene expression and systemic metabolic profile, a considerable group of individuals developed muscle IR.

The reasons for these discordant phenotypes are not clear. Nevertheless, based on the available literature, there may be several explanations for these observations. Participants in the adipo-IS/muscle-IR compared to the adipo-IS/muscle-IS group, had slightly higher HIRI values, which might have contributed to muscle IR through several mechanisms including elevated BCAA (24) or lipid species (25) or a differential in vivo blood supply between muscle and liver tissues (Chapter 2). Moreover, intrinsic disturbances in the muscle (e.g. muscle or the mitochondrial oxidative capacity) (26-28), differences in muscle mass (29) or the genetic predisposition for mitochondrial abnormalities (e.g. in lean relatives of individuals with type 2 diabetes)(30-33) could potentially contribute to muscle IR, independent of adipose tissue function and insulin resistance. Finally, it remains to be elucidated how an increased SAT expression of ECM remodelling genes links to hepatic IR (Chapter 2). One explanation may be that our SAT transcriptome data might reflect simultaneous processes related to ECM remodelling and fibrosis in the liver, which could in turn contribute to hepatic IR. Indeed, it has been shown that hepatic IR is also closely associated with increased ECM remodelling and fibrosis in the liver (34).

Some limitations of Chapters $\mathbf{2}$ and $\mathbf{3}$ are that our data were cross-sectional, hindering causal inferences. Additionally, we did not have gene expression data for the skeletal muscle (Chapter $\mathbf{3}$ ) or visceral adipose tissue (Chapters 2 and $\mathbf{3}$ ).

Collectively, the data presented in Chapters 2 and 3, open new exciting avenues showing distinct IR phenotypes in overweight and obese individuals in the development of type 2 diabetes and cardiovascular disease. Our findings could help identify functional subgroups of obese individuals with different risk profiles, which may represent a starting point for future research aimed at identifying novel, more effective precision-based prevention and treatment strategies of obesity and its complications. 


\section{Cellular composition, insulin resistance and adipose tissue dysfunction}

Adipose tissue macrophage frequencies and altered abdominal subcutaneous adipose tissue gene expression

Obesity promotes low-grade chronic adipose tissue inflammation, and adipocytes and other immune cells produce and secrete pro-inflammatory factors (e.g. cytokines, chemokines) (35). Research has shown that obesity and obesity-related insulin resistance were associated with significant a higher number of macrophages in adipose tissue $(36,37)$ and changes in their inflammatory phenotype (38). In obese persons, monocytes circulate in the periphery, infiltrate the adipose tissue, become adipose tissue macrophages, and affect adipocytes and other immune cells, thereby greatly regulating adipose tissue function, increasing local and systemic inflammation and promoting IR (39).

In Chapter 4, using a publicly available collection of adipose tissue transcriptomics datasets and the bioinformatics tool TissueDecoder (40), we presented an approach to assess the contribution of macrophages to the overall subcutaneous adipose tissue gene expression. We used publicly available microarray gene expression datasets from human subcutaneous adipose tissue biopsies $(\mathrm{n}=519)$ together with TissueDecoder to determine the adipose tissue cell type composition of each sample. As discussed in the previous paragraph, prior research has associated macrophage infiltration with increased adipose tissue inflammation in the context of obesity and IR. Inline, we also observed that adipose tissue of individuals with high macrophage frequencies has a higher expression of genes involved in complement activation, chemotaxis, focal adhesion and oxidative stress. For the same individuals, we observed a lower expression of genes involved in lipid metabolism, fatty acid synthesis and oxidation and mitochondrial respiration, which appears to correlate with the observation of a lower number of adipocytes. We hypothesised that increased macrophage and adipose stem cell frequencies and the decreased frequencies of adipocytes reflect adipose tissue inflammation and impaired pre-adipocyte differentiation, possibly reflective of a limited capacity for hyperplasia and adipose tissue dysfunction that contributes to an unfavourable metabolic profile.

Importantly, the reference gene expression dataset used as the signature matrix for the deconvolution algorithm, used the baseline expression of isolated cell types that do not all come from adipose tissue, which is not optimal for our objective. Even though cell types in the AT21 signature matrix that do not usually occur in the adipose tissue were predicted with very low frequencies in our samples, a more context-specific signature matrix would have been preferred. Lenz et al. (40) have addressed this issue and have generated an alternative reference dataset containing solely cell types that were directly isolated from adipose tissue for evaluation and comparison to the results obtained using AT21. The resulting AT4 signature matrix is limited to four cell fractions, namely, adipocytes, stem/ stromal cells, monocytes/macrophages, and other leukocytes. In the paper of Lenz et al. only minimal differences were reported between the AT21 and AT4 signature matrices (40). As we were specifically interested in investigating the contribution of macrophages to SAT gene expression, we decided to use for our analysis in Chapter 4 the AT21 signature matrix and not the $\mathrm{AT}_{4}$, as the $\mathrm{AT}_{4}$ signature matrix groups macrophages and monocytes into one cell type. Finally, for studying adipose tissue inflammation, identifying signatures for macrophage subtypes could be of interest.

\section{White blood cell profile and whole blood transcriptome in insulin resistance}

Blood transcriptomics data can be safely stored in biobanks and reanalysed if necessary with the latest technology (41), while access to blood is less invasive compared to obtaining biopsy samples from directly affected tissues. Notably, it has been shown that the changes in the expression levels of individual genes reflect alterations in the environment of whole blood or blood cells and may also reflect organ-specific changes (42).

In Chapter 5 therefore, we used the whole blood transcriptome as a means that reflects the peripheral blood environment along with obesity and IR related organ-specific changes. More specifically, we investigated the whole blood transcriptome of insulin resistant and insulin sensitive individuals, independent of white blood cell (WBC) profile. We used the computational algorithm EpiDISH (43) and the DNA methylation data of participants of the CODAM study to infer the WBC profile. We showed the relative amount of monocytes to be significantly greater in the insulin resistant compared to the insulin sensitive participants, indicating more pronounced monocytosis, which has also been described by others $(44,45)$.

Furthermore, the observed overrepresentation of monocytes suggests a relative underrepresentation of other cell types. We anticipated that the differences in WBC profile between insulin resistant and insulin sensitive individuals would drive overall whole blood gene expression, therefore we adjusted for this. As a matter of fact, the effect of interperson differences in cellular profile and its contribution to bulk tissue gene expression has been previously reported (46-48). Indeed, the GO analysis before adjustment was overrepresented by immunological pathways, which became less apparent after adjustment. More specifically, for the upregulated genes, several genes involved in immune response processes (e.g.IFIT1,IFI6,IRF7, IRF9, IL1RN) were not differentially expressed after we adjusted for WBC profile. Similarly, several downregulated genes involved in intracellular processes (e.g. PDZK1, UST, PTGDR and CHCHD7) were not differentially expressed after we adjusted for WBC profile. Interestingly, several of the up regulated (e.g. $A D M 2, F O X P_{1}$ ) and downregulated genes (e.g. $\mathrm{CASS}_{4}, \mathrm{RHOQ}$ ) became differentially expressed after adjusting for WBC profile. 
We demonstrated a distinct blood transcriptome profile in insulin resistance, independent of WBC profile. We observed that the expression of interferon-stimulated genes (ISGs) (e.g. ISG15, OAS1 and RASD2) in the whole blood was higher in insulin resistant as compared to insulin sensitive individuals. Increased expression of type I interferon ISGs has been previously reported in PBMCs of human obese subjects (49) and type 2 diabetes subjects (50). We hypothesised that this interferon related signature might indicate increased systemic inflammation possibly due to an innate immune response and whole-body IR, and may suggest a role in the etiology of IR. We additionally observed a lower expression of genes involved in cellular differentiation (e.g. GATA2 and $S 100 B$ ) and reorganization of the actin cytoskeleton (e.g. LPAR1, RHOQ and LIMK1), in the whole blood of insulin resistant individuals. Taken together, we think that the systemic inflammation in combination with the downregulation of cellular differentiation and remodelling of actin cytoskeleton we observed in the whole blood of the insulin resistant individuals, may reflect obesity and/or insulin resistance related organ dysfunction, in organs like adipose tissue or gut. Finally, adjustment for WBC profile in the whole blood, as we did in our current differential gene expression analysis, adds a layer of information that would otherwise remain elusive and adds substantially to the biological interpretation of the data.

A limitation of this study is that we do not have absolute numbers for the WBC subtypes. Absolute numbers of cell type amounts in a tissue are important for prognosis and diagnosis in clinical applications (43). Therefore, it would be interesting for future studies to investigate the differences in adjustment for relative or absolute differences in WBC profile on blood transcriptome analysis and subsequent biological interpretation in the context of obesity/insulin resistance.

Collectively in Chapters 4 and 5, we have shown the value of integrating publicly available datasets, while we highlighted the added value of knowing/determining cell type composition in the context of human obesity and IR, in SAT (Chapter 4) and whole blood (Chapter 5). In addition to identifying functional subgroups of obese individuals with different risk profiles, the contribution of macrophage frequencies and other celltypes to organ/tissue dysfunction and plasticity can offer targets and biomarkers for novel precision-based prevention and treatment strategies of obesity and its complications.

\section{Methodological considerations}

Measurements of insulin sensitivity

Phenotyping IR individuals requires methods that precisely measure and quantify insulin sensitivity and insulin action. The gold standard for assessing insulin sensitivity in vivo is the hyperinsulinemic-euglycemic clamp method (51). The one-step clamp method primarily quantifies peripheral insulin sensitivity (e.g., skeletal muscle), while the twostep clamp method combined with a glucose tracer quantifies peripheral, hepatic and adipose tissue insulin sensitivity.

While the hyperinsulinemic-euglycemic clamp is the gold standard method, it should be kept in mind that it is not physiological to increase plasma insulin concentrations for several hours. Furthermore, it is costly, invasive and time-consuming making it difficult to implement on a large scale. For practical yet valid reasons, such as reducing costs and the challenges (e.g. they are invasive) that come with clamp techniques (52-56), surrogate measures were developed to quantify insulin sensitivity, using fasting glucose and insulin concentrations or glucose and insulin curves after oral ingestion of a glucose load (oral glucose tolerance test, OGTT).

In this thesis, in Chapter 5, we measured IR using the Homeostatic Model Assessment for Insulin Resistance (HOMA-IR) (57) broadly used as a measure of whole-body IR (22, 58), based on fasting glucose and insulin. In Chapter 3 we estimated the adipose tissue IR index (ATIRI) as the product of fasting insulin and FFA, which is a surrogate marker of IR of adipose tissue lipolysis (15, 16, 59-63). Furthermore, in Chapters $\mathbf{2}$ and $\mathbf{3}$ we additionally measured glucose and insulin with a 5-points OGTT and estimated tissue-specific IR. The muscle insulin sensitivity index (MISI) and hepatic insulin resistance index (HIRI) were estimated using the methods Abdul-Ghani et al. (64). MISI was calculated as the rate of decay of plasma glucose concentration during the OGTT, i.e. the slope of the least square fit to the decline in plasma glucose concentration from peak to nadir. The decline in plasma glucose concentration in the second part of the OGTT primarily reflects glucose uptake by peripheral tissues, mainly skeletal muscle. HIRI was calculated using the square root of the product of the areas under the curve for glucose and insulin during the first 30 min of the OGTT. HIRI and MISI have been developed and validated against the gold standard hyperinsulinemic-euglycemic clamp studies (64). The MISI and HIRI have been used in large cohort and intervention studies $(12,24,25)$. Nevertheless, contrary to standardised clamp-derived insulin sensitivity measures, MISI and HIRI may to some extent be determined by other biological processes, such as the rate of glucose absorption as well as the incretin response (This thesis, Chapter 2). 
Surrogate measures are appropriate measures for large-scale clinical and epidemiological studies with a cross-sectional design, that compensate for the loss of accuracy compared to the clamp techniques, with increased power (e.g., large sample sizes), practicality, accessibility, cost efficiency, and by being more physiological.

\section{Correcting for cell-type composition}

Gene expression profiling is used to systematically characterise a tissue state, and to identify changes in gene expression across conditions. Biological tissue samples are characterized by heterogeneous and varying cellular composition. Particularly if a researcher is primarily interested in the identification of changes in expression of genes across conditions, concomitant changes in cell type composition can hamper data interpretation $(47,65,66)$

There are several experimental cell separation techniques. Initially, single cells were identified using technologies such as Fluorescence-Activated Cell Sorting (FACS) and immunohistochemistry. However, these techniques are limited in the parameters (e.g. cell markers) that can be measured (67). Recently, next-generation sequencing techniques, such as single-cell RNA sequencing, substantially improved the depth in which cells can be identified and analysed. Nevertheless, for the time being, their usage in clinical research dealing with large cohorts has been challenging, as these techniques are timeconsuming, expensive and require specialised wet-lab and bioinformatics resources. As an alternative to the experimental cell separation techniques, tissue cell type composition can be also estimated computationally. The generation of gene expression computational deconvolution methods (in silico deconvolution) for example, provided with predicted frequencies of several cell types from gene expression profiles of mixture samples (40,47, 68).

In this thesis, we have used two reference-based computational deconvolution algorithms, In Chapter 4, we used TissueDecoder (40) to infer cell type composition from SAT Affymetrix microarray data to identify individuals with high and low macrophage frequencies. Importantly, TissueDecoder (40) estimates 20 more cell-types across three additional depots (omental, epicardial and pericardial adipose tissue). The approach we propose in Chapter 4, grouping individuals in high and low macrophage frequencies, can be used in a similar manner to define other groups of interest (e.g., high/low subcutaneous adipocytes or adipose stem cells frequencies) in investigating adipose tissue metabolism. In Chapter 5, we used algorithm EpiDISH (43) and the CODAM DNA methylation from the CODAM study (22), as an alternative to transcriptomics inferred WBC profile or FACS. EpiDISH estimates cell type composition in whole blood using DNA methylation data and cell type specific DNase hypersensitive sites (43). As we have described earlier, we investigated the whole blood transcriptome of insulin resistant and insulin sensitive individuals from the
CODAM study (22); using the DNA methylation data instead of the transcriptomics data from CODAM to infer the WBC profile enables us to perform a differential gene expression analysis without the risk of introducing bias.

The majority of the gene expression deconvolution methods depend on specialized knowledge of genes whose expression is cell type specific, called barcode genes (69). These barcode genes are commonly defined based on biological knowledge (e.g., known markers used for FACS or immunochemistry) or by determining differentially expressed genes after profiling functionally defined cell type subsets (either purified from human tissue or via in vitro differentiation) $(47,68)$. Although these barcode genes are valuable when the cell types of interest are well characterised, they are not able to determine new cell states and new cell type specific gene expression profiles, or provide cell type phenotype information of a complex tissue (70). As an example in Chapter 4, identifying signatures for macrophage subtypes could be of interest for studying adipose tissue inflammation. Similarly, in Chapter $\mathbf{5}$, identifying signatures for monocyte subtypes could be of interest for studying systemic inflammation in the context of obesity/IR. Notably, the relevance of deconvolution methods that estimate cell type gene expression profiles has been examined $(47,68)$ and recently the potential use of single-cell reference profiles for in silico tissue dissection has emerged (69, 71-73). Limitations related to the computational deconvolution algorithms are thoroughly reviewed elsewhere $(47,66,67,74)$.

\section{Reuse of publicly available data}

The "Big Data" revolution enabled the scientific community to recognise the advantages of open and reusable data, while data sharing and reuse are becoming an important part of research particularly in life sciences $(75,76)$. The scientific community has established guidelines to improve and facilitate data reusability, known as "FAIR data principles" (77). Sharing data improves statistical robustness while corroborates and reinforces study outcomes by re-analysis of existing datasets (78) and promotes the uncovering of novel findings via meta-analysis (79). In this way, data reuse is beneficial to the scientific community as it provides novel scientific discoveries, reduces costs but most importantly it enables a research community of accountability and reproducibility. Despite the benefits, data reuse is not yet globally used for various reasons (e.g., concerns for the quality and reliability of the data) $(75,76)$. Additional challenges, limitations and risks in data sharing and data management in regards to using and reusing publicly available data can be found elsewhere $(75,76)$.

In this thesis, for instance, one of the computational deconvolution algorithms that we used was TissueDecoder (Chapter 4) (40), whose development was realised solely from publicly available data reuse. In the scientific community, especially in departments that mainly use computational approaches, scientists might not have access, sufficient 
funds, or as a matter of fact expertise to use a wet-lab experimental approach. In those circumstances, publicly available datasets can tackle these hurdles and enable researchers to develop valid and useful computational deconvolution algorithms to estimate cell type composition. On that note, depositing data generated with more expensive technologies such as RNA sequencing or single-cell mRNA sequencing, apart from minimising costs, will enable more accurate strategies for estimating cell type gene expression profiles and single-cell reference profiles for in silico tissue dissection.

In Chapter 4, we have used publicly available SAT datasets, which have been downloaded from the public repository GEO (80, 81) which complies with the MIAME (Minimum Information About a Microarray Experiment) and MINSEQE (Minimum Information About a Next-generation Sequencing Experiment) guidelines which outline the minimum information that should be included when describing a microarray or sequencing study (e.g. meta-information). We observed that the adipose tissue of individuals with high macrophage frequencies had a higher expression of genes involved in complement activation, chemotaxis, focal adhesion and oxidative stress. Unfortunately, we did not have information on phenotypic measures, such as BMI and HOMA-IR, which would have helped elucidate whether the high macrophage frequencies were indeed associated with obesity or IR status, similar to prior research $(38,39)$. Characterisation of IR phenotypes, as well as characterisation of mechanisms related to the contribution of macrophage frequencies and other cell-types to adipose tissue dysfunction and plasticity, can offer targets and biomarkers for novel precision-based prevention and treatment strategies in reversing the increasing prevalence of obesity and cardiometabolic diseases.

\section{Employing Pathway, Gene Ontology and Network analysis}

Throughout this thesis, Gene Ontology (GO) enrichment, pathway and network analysis were used. Enrichment analysis methods are very popular in providing summarised information about functional characteristics of gene sets, while pathway analysis enabled us to visualise transcriptomics data on a pathway. Network analysis made it possible to integrate information either from pathway or enrichment analysis, and provided us with a powerful representation of complex biological processes. With these methods we identified and illustrated significantly changed processes and genes associated with IR and obesity.

Notably, these analyses come with limitations and challenges that can be split up into two wide groups: (i) knowledge biases and (ii) methodological challenges. GO, pathway and network analysis depend on knowledge acquired from gene or pathway databases, which contribute useful information on how genes interact with each other. Alas, the knowledge we have on existing genes and biological pathways is limited $(82,83)$. For instance, current pathway diagrams are to a great extent deduced from transcriptional relationships among genes, while there is insufficient information for several other regulatory factors (e.g., post-transcriptional modifiers, epigenetic factors and environmental triggers) (84). Furthermore, regarding methodological challenges, pathway analysis and other enrichment analyses (e.g. GO enrichment analysis), assume independence between genes, which is not the case for gene expression experiments (e.g. regulatory genes regulate the expression of other genes) (85). Despite these limitations, as long as there is growth in biological content, combined with improved technological and analysis methods, the usefulness of pathway and network analysis and trust in results will be improving. As an example, the latest WikiPathways update (86) reported a constant content growth since their last update in 2018 (87), with new pathways and revisions each year.

In the last few years, machine learning methods (e.g. deep learning) have gathered great interest in the scientific community in their promise to warrant a personalised approach to medicine, which offers refined diagnosis and prediction of discrete responses to therapy. One of their core advantages is their strong empirical classification performance and, thus prediction power. While machine learning methods hold a great promise in realising precision medicine, they were not used in this thesis. One of the main reasons why, was the need for interpretability (88). In this thesis, our goal was to characterise IR phenotypes and the mechanisms related to obesity and/or IR organ dysfunction and increase our understanding of the biology of obesity and related diseases. The black box concept of machine learning hinders the need to provide insights on the underlying mechanisms of a biological process (89) which can offer targets and biomarkers for novel precision-based prevention and treatment strategies in reversing the increasing prevalence of obesity and cardiometabolic diseases. Finally, a combination of both data-driven and knowledgedriven approaches has been suggested in personalised treatment for chronic diseases (90) and could potentially provide novel precision-based prevention and treatment strategies.

\section{Towards precision-based prevention and treatment strategies}

Interestingly, Wilkinson et al. recently argued that the current hype around personalised medicine must be contrasted with reality and suggested that a pragmatic approach to precision medicine is stratified medicine, for instance, identifying and predicting subgroups and their responses (91). Different subgroups might be of interest (e.g. dependent on the microbial composition), but in this thesis, we have emphasised the need for precision-based prevention and treatment strategies, which might depend on the IR phenotype of an individual, in order to optimise the response to dietary or other intervention, and to facilitate the maintenance of a healthy lifestyle, and consequently better cardiometabolic health. There is growing evidence showing that the severity of IR at the tissue level may play a role in the differential responses to lifestyle and pharmacological interventions that aim to increase insulin sensitivity (12-14) in the prevention and control of cardiometabolic diseases. Hence, more insight into various IR phenotypes and the 
underlying biological mechanisms are needed. An important first step is to identify whether these phenotypes are indeed distinct. As we have demonstrated in this thesis, pathway and network analysis with transcriptomics data on the whole blood and adipose tissue can help determine whether IR phenotypes are distinct and elucidate the pathways and mechanisms that are altered in those individuals, which might, in turn, provide leads for novel precision-based prevention and treatment strategies.

Precision-based strategies, either data-driven, knowledge-driven, or a combination of both, have the potential to change the conventional standards of care in human obesity. Nevertheless, even the most advanced precision-based strategies for obesity prevention and treatment are unlikely to be successful under conditions that are obesity-promoting; parallel efforts from governments, policymakers and food industry, for instance, are needed to make environments supportive of healthy eating and physical activity. Simply, making the healthy choice the easy choice.

Suggestions for further research to increase our understanding of the biology of obesity and related diseases:

Usefulness of stratification on IR subgroups. In Chapters 2 and 3, we showed distinct metabolic profiles associated with either adipose tissue, muscle or liver IR, using the surrogate insulin sensitivity indexes ATIRI, MISI and HIRI. These surrogate measures have a great potential in providing relatively easy methods to classify and identify IR subgroups. As we move towards precisionbased prevention and treatment strategies for obesity, modifications in diet and physical activity are very important, and their effectiveness might depend on individual or subgroup pathophysiological factors. Future studies should investigate whether the IR subgroups defined in Chapters 2 and 3 respond differentially to diet or other interventions in order to obtain effective precisionbased prevention and treatment strategies.

(] Single-cell approaches to further elucidate IR phenotypes. In Chapters 4 and 5, we highlight the added value of knowing/determining cell type composition in the context of human obesity and IR. Characterisation of IR phenotypes, as well as characterisation of mechanisms related to adipose tissue dysfunction and plasticity, can offer targets and biomarkers for novel precision-based prevention and treatment strategies for obesity and its complications. The computational deconvolution methods utilised in Chapters $\mathbf{4}$ and $\mathbf{5}$ cannot capture new celltype specific gene expression profiles, nor can they describe cell phenotype information of complex tissues $(47,68)$. Future studies, therefore, should enable single-cell mRNA sequencing for experimentally estimating cell type gene expression profiles and single-cell reference profiles in small cohorts. Furthermore, researchers should be stimulated to deposit their datasets to enable more accurate strategies for estimating cell type gene expression profiles and single-cell reference profiles for in silico tissue dissection.

Further enabling a data reuse culture towards precision-based strategies. In Chapter 6, I have discussed the advantages and disadvantages of public data repositories and data reuse with the aim of advancing scientific knowledge and discovery. In order to achieve effective precision-based prevention and treatment strategies for obesity and related diseases, I believe we need to further re-enforce a well-characterised (sufficient meta-information) data depositing and reuse culture, which will enhance our understanding of the IR phenotypes and provide mechanistic insight into altered biological processes. Unfortunately, these data are not shared in a standardised and constructive manner. Furthermore, even though it is a pre-requirement for European grants to adhere to the FAIR principles, in practise, data deposited in public databases are of controversial quality and there is a great amount of missing meta-information. Finally, data generated with more expensive technologies, such as RNA or single-cell mRNA sequencing, in their majority, are not deposited in public databases. It is apparent that data privacy plays an important role in why certain information is not available, but considering the plethora of data generation compared to the data deposited, there is a clear imbalance.

\section{Conclusions}

The present thesis investigated IR phenotypes in human obesity with transcriptomics data from the adipose tissue and the whole blood and has offered insights that may represent a starting point for future research aimed at identifying novel, more effective precisionbased prevention and treatment strategies of obesity and its complications. The main findings of this thesis are:

In Chapters $\mathbf{2}$ and $\mathbf{3}$ distinct transcriptome and metabolic/clinical profiles were revealed in non-diabetic overweight and obese individuals in relation to muscle, liver and adipose tissue IR. Muscle IR was associated with an increased inflammatory gene expression profile in SAT which may translate into an increased systemic inflammatory profile (Chapter 2). Hepatic IR on the other hand was associated with an increased expression of genes related to extracellular matrix remodelling in the SAT (Chapter 2). Furthermore, adipose tissue IR did not always coincide with muscle IR, and muscle IR could develop despite a relatively insulin sensitive adipose tissue (Chapter 3 )

In Chapters 4 and $\mathbf{5}$, we showed the benefit of reusing publicly available data while we highlight the added value of knowing/determining cell-type composition in the 
context of obesity and/or IR organ dysfunction. An increased inflammatory and reduced metabolic gene expression profile were associated with individuals with high adipose tissue macrophage infiltration, confirming findings from literature and in addition, demonstrating the hidden strength of reusing publicly available data to gain cell-type specific insights into adipose tissue function (Chapter 4). Finally, an interferon related signature characterized the whole blood transcriptome profile of the insulin resistant individuals, independent of their WBC profile. The observed signature indicated increased systemic inflammation possibly due to an innate immune response, nd whole-body insulin resistance, which can be a cause or a consequence of insulin resistance (Chapter 5).

\section{References}

1. Society CotO. Obesity as a disease: the Obesity Society Council resolution. Obesity. 2008;16(6):1151-.

2. Reaven GM. Banting lecture 1988. Role of insulin resistance in human disease. Diabetes. 1988;37(12):1595-

Bluher M. Adipose tissue dysfunction in obesity. Exp Clin Endocrinol Diabetes. 2009;117(6):241-50.

Bluher M. Adipose tissue dysfunction contributes to obesity related metabolic diseases. Best Pract Res Clin Endocrinol Metab. 2013;27(2):163-77.

5. Goossens $\mathrm{GH}$. The role of adipose tissue dysfunction in the pathogenesis of obesity-related insulin resistance. Physiol Behav. 2008;94(2):206-18.

6. Goossens GH. The Metabolic Phenotype in Obesity: Fat Mass, Body Fat Distribution, and Adipose Tissue Function. Obes Facts. 2017;10(3):207-15.

7. Goossens GH, Blaak EE. Adipose tissue dysfunction and impaired metabolic health in human obesity: a matter of oxygen? Front Endocrinol (Lausanne). 2015;6:55

8. Hoffstedt J, Arner E, Wahrenberg H, Andersson DP, Qvisth V, Lofgren P, et al. Regional impact of adipose tissue morphology on the metabolic profile in morbid obesity. Diabetologia. 2010;53(12):2496-503.

9. Kwon H, Pessin JE. Adipokines mediate inflammation and insulin resistance. Front Endocrinol (Lausanne). 2013;4:71.

10. McArdle MA, Finucane OM, Connaughton RM, McMorrow AM, Roche HM. Mechanisms of obesityinduced inflammation and insulin resistance: insights into the emerging role of nutritional strategies. Front Endocrinol (Lausanne). 2013;4:52

11. Stinkens R, Goossens GH, Jocken JW, Blaak EE. Targeting fatty acid metabolism to improve glucose metabolism. Obes Rev. 2015;16(9):715-57.

12. Blanco-Rojo R, Alcala-Diaz JF, Wopereis S, Perez-Martinez P, Quintana-Navarro GM, Marin C, et al. The insulin resistance phenotype (muscle or liver) interacts with the type of diet to determine changes in disposition index after 2 years of intervention: the CORDIOPREV-DIAB randomised clinical trial. Diabetologia. 2016;59(1):67-76

13. Zheng I, Woo SL, Hu X, Botchlett R, Chen L, Huo Y, et al. Metformin and metabolic diseases: a focus on hepatic aspects. Front Med. 2015;9(2):173-86

14. Otten I, Stomby A, Waling M, Isaksson A, Soderstrom I, Ryberg M, et al. A heterogeneous response of liver and skeletal muscle fat to the combination of a Paleolithic diet and exercise in obese individuals with type 2 diabetes: a randomised controlled trial. Diabetologia. 2018;61(7):1548-59.

15. Søndergaard E, Espinosa De Ycaza AE, Morgan-Bathke M, Jensen MD. How to measure adipose tissue insulin sensitivity. The Journal of Clinical Endocrinology \& Metabolism. 2017;102(4):1193-9.

rotard E, Jensen MD. Unique Metabolic Features of Adults Discordant for Indices of nsulin Resistance. J Clin Endocrinol Metab. 2020;105(8).

17. Keller MP, Attie AD. Physiological insights gained from gene expression analysis in obesity and

18. Elbein SC, Kern PA, Rasouli N, Yao-Borengasser A, Sharma NK, Das SK. Global gene expression profiles of subcutaneous adipose and muscle from glucose-tolerant, insulin-sensitive, and insulin-resistant individuals matched for BMi. Diabetes. 201,60(3). $019-29$.

19. Soronen J, Laurila PP, Naukkarinen J, Surakka I, Ripatti S, Jauhiainen M, et al. Adipose tissue gene expression analysis reveals changes in inflammatory, mitochondrial respiratory and lipid metabolic pathways in obese insulin-resistant subjects. BMC Med Genomics. 2012;5:9.

20. Armenise C, Lefebvre G, Carayol J, Bonnel S, Bolton J, Di Cara A, et al. Transcriptome profiling from adipose tissue during a low-calorie diet reveals predictors of weight and glycemic outcomes in obese, nondiabetic subjects. Am J Clin Nutr. 2017;106(3):736-46.

21. Larsen TM, Dalskov S, van Baak M, Jebb S, Kafatos A, Pfeiffer A, et al. The Diet, Obesity and Genes (Diogenes) Dietary Study in eight European countries - a comprehensive design for long-term intervention. Obes Rev. 2010,11(1).76-91.

22. Hertle E, van Greevenbroek MM, Arts IC, van der Kallen CJ, Geijselaers SL, Feskens EJ, et al. Distinct associations of complement $\mathrm{C}_{3}$ and its precursor $\mathrm{C}_{3}$ with atherosclerosis and cardiovascular disease. The CODAM study. Thromb Haemost. 2014;111(6):1102-11.

23. Schram MT, Sep S], van der Kallen CJ, Dagnelie PC, Koster A, Schaper N, et al. The Maastricht Study: 
an extensive phenotyping study on determinants of type 2 diabetes, its complications and its comorbidities. Eur ] Epidemiol. 2014;29(6):439-51.

24. Vogelzangs N, van der Kallen CJH, van Greevenbroek MMI, van der Kolk BW, Jocken JWE, Goossens $\mathrm{GH}$, et al. Metabolic profiling of tissue-specific insulin resistance in human obesity: results from the Diogenes study and the Maastricht Study. Int J Obes (Lond). 2020;44(6):1376-86.

25. Van der Kolk BW, Vogelzangs N, Jocken JWE, Valsesia A, Hankemeier T, Astrup A, et al. Plasma lipid profiling of tissue-specific insulin resistance in human obesity. Int J Obes (Lond). 2019;43(5):989-98.

. Di Meo S, lossa $S$, Venditti P. Skeletal muscle insulin resistance. role of mitochondria and other ROS

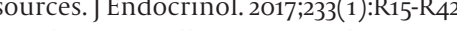

27. Genders AJ, Holloway GP, Bishop DJ. Are Alterations in Skeletal Muscle Mitochondria a Cause or Consequence of lnsuln Resistance? Int J Mol Sci. 2020;21(18).

28. Toledo FG, Goodpaster BH. The role of weight loss and exercise in correcting skeletal muscle mitochondrial abnormalities in obesity, diabetes and aging. Mol Cell Endocrinol. 2013;379(1-2):30-4.

29. Di Meo S, lossa S, Venditti P. Improvement of obesity-linked skeletal muscle insulin resistance by strength and endurance training.J Endocrinol. 2017;234(3):R159-R8.

30. Morino K, Petersen KF, Dufour S, Befroy D, Frattini J, Shatzkes N, et al. Reduced mitochondrial density and increased IRS-1 serine phosphorylation in muscle of insulin-resistant offspring of type 2 diabetic parents. J Clin Invest. 2005;115(12):3587-93.

31. Elgzyri T, Parikh H, Zhou Y, Dekker Nitert M, Ronn T, Segerstrom AB, et al. First-degree relatives of type 2 diabetic patients have reduced expression of genes involved in fatty acid metabolism in skeletal muscle. J Clin Endocrinol Metab. 2012;97(7):E1332-7.

32. DeFronzo RA, Tripathy D. Skeletal muscle insulin resistance is the primary defect in type 2 diabetes. Diabetes Care. 2009;32 Suppl 2:S157-63.

33. Petersen KF, Dufour S, Befroy D, Garcia R, Shulman GI. Impaired mitochondrial activity in the insulinresistant offspring of patients with type 2 diabetes. $\mathrm{N}$ Engl J Med. 2004;350(7):664-71.

34. Koyama Y, Brenner DA. Liver inflammation and fibrosis. J Clin Invest. 2017;127(1):55-64

35. Hotamisligil GS, Shargill NS, Spiegelman BM. Adipose expression of tumor necrosis factor-alpha: direct role in obesity-linked insulin resistance. Science. 1993;259(5091):87-91.

36. Xu H, Barnes GT, Yang $\mathrm{Q}$, Tan G, Yang D, Chou C], et al. Chronic inflammation in fat plays a crucial role in the development of obesity-related insulin resistance. J Clin Invest. 2003;112(12):1821-30.

37. Weisberg SP, McCann D, Desai M, Rosenbaum M, Leibel RL, Ferrante AW. Obesity is associated with macrophage accumulation in adipose tissue. The Journal of clinical investigation. 2003;112(12):1796808 .

38. Lumeng CN, Deyoung SM, Bodzin JL, Saltiel AR. Increased inflammatory properties of adipose tissue macrophages recruited during diet-induced obesity. Diabetes. 2007;56(1):16-23.

39. Lumeng CN, Saltiel AR. Inflammatory links between obesity and metabolic disease. The Journal of clinical investigation. 2011;121(6):2111-7

40. Lenz M, Arts ICW, Peeters RLM, de Kok TM, Ertaylan G. Adipose tissue in health and disease through the lens of its building blocks. Sci Rep. 2020;10(1):10433.

41. Hebels DG, Georgiadis P, Keun HC, Athersuch T], Vineis P, Vermeulen R, et al. Performance in omics biobanks in environmental health research. Environ Health Perspect. 2013;121(4):480-7.

42. Liew CC, Ma J, Tang HC, Zheng R, Dempsey AA. The peripheral blood transcriptome dynamically reflects system wide biology: a potential diagnostic tool. J Lab Clin Med. 2006;147(3):126-32.

43. Teschendorff AE, Breeze CE, Zheng SC, Beck S. A comparison of reference-based algorithms for correcting cell-type heterogeneity in Epigenome-Wide Association Studies. BMC Bioinformatics. 2017;18(1):105

44. de Matos MA, Duarte TC, Ottone Vde O, Sampaio PF, Costa KB, de Oliveira MF, et al. The effect of insulin resistance and exercise on the percentage of $\mathrm{CD} 16(+)$ monocyte subset in obese individuals. Cell Biochem Funct. 2016;34(4):209-16.

45. Poitou C, Dalmas E, Renovato M, Benhamo V, Hajduch F, Abdennour M, et al. CD14dimCD16+ and CD14+CD16+ monocytes in obesity and during weight loss: relationships with fat mass and subclinical atherosclerosis. Arterioscler Thromb Vasc Biol. 2011;31(10):2322-30.

46. Venet D, Pecasse F, Maenhaut C, Bersini H. Separation of samples into their constituents using gene expression data. Bioinformatics. 2001;17(suppl_1):S279-S87.
47. Shen-Orr SS, Gaujoux R. Computational deconvolution: extracting cell type-specific information from heterogeneous samples. Curr Opin Immunol. 2013;25(5):571-8.

48. Qiao W, Quon G Csaszar E, Yu M, Morris Q Zandstra PW. PERT: a method for expression deconvolution of human blood samples from varied microenvironmental and developmental conditions. PLoS Comput Biol. 2012;8(12)::1002838.

49. Elliott RM, de Roos B, Duthie SJ, Bouwman FG, Rubio-Aliaga I, Crosley LK, et al. Transcriptome analysis of peripheral blood mononuclear cells in human subjects following a $36 \mathrm{~h}$ fast provides evidence of effects on genes regulating inflammation, apoptosis and energy metabolism. Genes Nutr. 2014;9(6):432.

50. van der Pouw Kraan TC, Chen WJ, Bunck MC, van Raalte DH, van der Zijl NJ, van Genugten RE, et al. Metabolic changes in type 2 diabetes are reflected in peripheral blood cells, revealing aberrant cytotoxicity, a viral signature, and hypoxia inducible factor activity. BMC Med Genomics. 2015,8.20.

51. DeFronzo RA, Tobin JD, Andres R. Glucose clamp technique: a method for quantifying insulin secretion and resistance. Am J Physiol. 1979;237(3):E214-23.

52. Buchanan TA, Watanabe RM, Xiang AH. Limitations in surrogate measures of insulin resistance. J Clin Endocrinol Metab. 2010;95(11):4874-6,

53. Lorenzo C, Haffner SM, Stancakova A, Laakso M. Relation of direct and surrogate measures of insulin resistance to cardiovascular risk factors in nondiabetic finnish offspring of type 2 diabetic individuals. J Clin Endocrinol Metab. 2010;95(11):5082-90.

54. Rudvik A, Mansson M. Evaluation of surrogate measures of insulin sensitivity - correlation with gold standard is not enough. BMC Med Res Methodol. 2018;18(1):64

55. Otten J, Ahren B, Olsson T. Surrogate measures of insulin sensitivity vs the hyperinsulinaemiceuglycaemic clamp: a meta-analysis. Diabetologia. 2014;57(9):1781-8.

56. Fiorentino TV, Marini MA, Succurro E, Andreozzi F, Sesti G. Relationships of surrogate indexes of insulin resistance with insulin sensitivity assessed by euglycemic hyperinsulinemic clamp and subclinical vascular damage. BMJ Open Diabetes Res Care. 2019;7(1):eooog11.

57. Matthews DR, Hosker IP, Rudenski AS, Naylor BA, Treacher DF, Turner RC. Homeostasis model assessment: insulin resistance and beta-cell function from fasting plasma glucose and insulin concentrations in man. Diabetologia. 1985;28(7):412-9.

58. van der Kolk BW, Goossens GH, Jocken JW, Blaak EE. Altered skeletal muscle fatty acid handling is associated with the degree of insulin resistance in overweight and obese humans. Diabetologia. 2016;59(12):2686-96.

59. Barchetta I, Angelico F, Del Ben M, Di Martino M, Cimini FA, Bertoccini L, et al. Phenotypical heterogeneity linked to adipose tissue dysfunction in patients with Type 2 diabetes. Clin Sci (Lond). 2016;130(19):1753-62.

60. Adams-Huet B, Devaraj S, Siegel D, Jialal I. Increased adipose tissue insulin resistance in metabolic syndrome: relationship to circulating adipokines. Metab Syndr Relat Disord. 2014;12(10):503-7.

61. Mu L, Li R, Lai Y, Zhao Y, Qiao J. Adipose insulin resistance is associated with cardiovascular risk factors in polycystic ovary syndrome. Journal of endocrinological investigation. 2019;42(5):541-8.

62. Lomonaco R, Ortiz-Lopez C, Orsak B, Webb A, Hardies J, Darland C, et al. Effect of adipose tissue insulin resistance on metabolic parameters and liver histology in obese patients with nonalcoholic fatty liver disease. Hepatology. 2012;55(5):1389-97.

63. Jorge-Galarza E, Posadas-Romero C, Torres-Tamayo M, Medina-Urrutia AX, Rodas-Díaz MA, PosadasSánchez R, et al. Insulin resistance in adipose tissue but not in liver is associated with aortic valve calcification. Disease markers. 2016:2016.

64. Abdul-Ghani MA, Matsuda M, Balas B, DeFronzo RA. Muscle and liver insulin resistance indexes derived from the oral glucose tolerance test. Diabetes Care. 2007;30(1):89-94.

65. Repsilber D, Kern S, Telaar A, Walzl G, Black GF, Selbig J et al. Biomarker discovery in heterogeneous tissue samples -taking the in-silico deconfounding approach. BMC Bioinformatics. 2010:11:27.

66. Mohammadi S. Zuckerman N, Goldsmith A, Grama A A critical survey of deconvolution methods for separating cell types in complex tissues. Proceedings of the IEEE. 2016;105(2):340-66.

67. Avila Cobos F, Vandesompele J, Mestdagh P, De Preter K. Computational deconvolution of transcriptomics data from mixed cell populations. Bioinformatics. 2018;34(11):1969-79.

68. Newman AM, Alizadeh AA. High-throughput genomic profiling of tumor-infiltrating leukocytes. Curr Opin Immunol. 2016;41:77-84.

69. Newman AM, Liu CL, Green MR, Gentles A], Feng W, Xu Y, et al. Robust enumeration of cell subsets 
from tissue expression profiles. Nat Methods. 2015;12(5):453-7.

70. Newman AM, Steen CB, Liu CL, Gentles AJ, Chaudhuri AA, Scherer F, et al. Determining cell type abundance and expression from bulk tissues with digital cytometry. Nat Biotechnol. 2019;37(7):773-82. . Racle J, de Jonge K, Baumgaertner P, Speiser DE, Gfeller D. Simultaneous enumeration of cancer and B

72. Bafon M, Veres A, Wolock SL, Faust AL, Gaujoux R, Vetere A, et al. A Single-Cell Transcriptomic Map of the Human and 2016;3(4):346-60 e4.

73. Schelker M, Feau S, Du J, Ranu N, Klipp E, MacBeath G, et al. Estimation of immune cell content in tumour tissue using single-cell RNA-seq data. Nat Commun. 2017;8(1):2032.

74. Yadav VK, De S. An assessment of computational methods for estimating purity and clonality using genomic data derived from heterogeneous tumor tissue samples. Brief Bioinform. 2015;16(2):232-41.

5. Tenopir C, Rice NM, Allard S, Baird L, Borycz J, Christian L, et al. Data sharing, management, use, and reuse: Practices and perceptions of scientists worldwide. PLoS One. 2020;15(3):e0229003.

76. Sielemann K, Hafner A, Pucker B. The reuse of public datasets in the life sciences: potential risks and rewards. PeerJ. 2020;8:e9954.

77. Wilkinson MD, Dumontier M, Aalbersberg IJ, Appleton G, Axton M, Baak A, et al. The FAIR Guiding Principles for scientific data management and stewardship. Sci Data. 2016;3:160018.

78. Open Data in a Big Data World. Chemistry International. 2016;38(2):17-.

9. Duvallet C, Gibbons SM, Gurry T, Irizarry RA, Alm EJ. Meta-analysis of gut microbiome studies identifies disease-specific and shared responses. Nat Commun. 2017;8(1):1784.

8o. Edgar R, Domrachev M, Lash AE. Gene Expression Omnibus: NCBI gene expression and hybridization array data repository. Nucleic Acids Res. 2002;30(1):207-10.

81. Barrett T, Wilhite SE, Ledoux P, Evangelista C, Kim IF, Tomashevsky M, et al. NCBI GEO: archive for functional genomics data sets-update. Nucleic Acids Res. 2013;41(Database issue):D991-5.

82. Kutmon M, van Iersel MP, Bohler A, Kelder T, Nunes N, Pico AR, et al. PathVisio 3: an extendable pathway analysis toolbox. PLoS Comput Biol. 2015;11(2):e1004085.

83. Khatri P, Sirota M, Butte AJ. Ten years of pathway analysis: current approaches and outstanding challenges. PLoS Comput Biol. 2012;8(2):e1002375.

84. Jin L, Zuo XY, Su WY, Zhao XL, Yuan MQ, Han LZ, et al. Pathway-based analysis tools for complex diseases: a review. Genomics Proteomics Bioinformatics. 2014;12(5):210-20.

85. Goeman JJ, Buhlmann P. Analyzing gene expression data in terms of gene sets: methodological issues. Bioinformatics. 2007;23(8):980-7.

86. Martens M, Ammar A, Riutta A, Waagmeester A, Slenter DN, Hanspers K, et al. WikiPathways: connecting communities. Nucleic Acids Res. 2021;49(D1):D613-D21.

87. Slenter DN, Kutmon M, Hanspers K, Riutta A, Windsor J, Nunes N, et al. WikiPathways: a multifaceted pathway database bridging metabolomics to other omics research. Nucleic Acids Res. 2018;46(D1):D661-D7.

88. Muzio G, O'Bray L, Borgwardt K. Biological network analysis with deep learning. Brief Bioinform. 2021;22(2):1515-30

8. Zampieri G, Vijayakumar S, Yaneske E, Angione C. Machine and deep learning meet genome-scale metabolic modeling. PLoS Comput Biol. 2019;15(7):e1007084.

9o. Ng K, Kartoun U, Stavropoulos H, Zambrano JA, Tang PC. Personalized treatment options for chronic diseases using precision cohort analytics. Sci Rep. 2021;11(1):1139.

1. Wilkinson J, Arnold KF, Murray EJ, van Smeden M, Carr K, Sippy R, et al. Time to reality check the promises of machine learning-powered precision medicine Lancet Digit Health. 2020:2(12):e677-e80. 


\section{Summary}

The prevalence of overweight and obesity is increasing worldwide. Obesity is officially recognized as a disease with a great impact on health and well-being. Obesity is associated with insulin resistance (IR), which is a major risk factor for the development of type 2 diabetes and cardiovascular disease. A plethora of evidence suggests that adipose tissue mass and function and the distribution of body fat are the most important contributing factors, determining an individual's risk to develop obesity-associated IR, type 2 diabetes and cardiometabolic disease. Importantly, IR may develop separately in multiple organs and the severity may vary between organs. Sub-typing obese individuals based on their IR phenotype, may lead to a better understanding of the relationship between insulin resistance and type 2 diabetes and cardiometabolic risk. This may give leads to precisionbased prevention and treatment strategies.

The primary goal of this thesis was to investigate IR phenotypes in human obesity with transcriptomic data from the adipose tissue and whole blood. For the purposes of this thesis, we applied data-driven computational approaches (e.g. differential gene expression analysis, biological pathway and network analysis).

In Chapter 2, we investigated abdominal subcutaneous adipose tissue (SAT) gene expression and clinical profiles in individuals with more pronounced IR in skeletal muscle or liver. We demonstrated distinct adipose tissue transcriptome profiles in tissuespecific IR. We showed that an altered ECM gene expression profile in SAT was present in overweight and obese individuals with pronounced hepatic IR. Furthermore, an upregulation of inflammatory gene expression was particularly present in individuals with pronounced muscle IR. We subsequently hypothesized that an increased SAT inflammatorygene expression, as observed in the muscle IR group, may lead to the secretion of pro-inflammatory adipokines in the circulation and a systemic pro-inflammatory profile inducing subsequently peripheral IR. In line with this hypothesis, in two cohorts with similar characteristics, the CODAM and Maastricht Study, we showed that low-grade inflammation scores of plasma inflammatory markers, were inversely associated with muscle insulin sensitivity (MISI), after adjustment for sex and body composition, while we did not observe an association between the systemic low-grade inflammation score and hepatic IR (HIRI).

In Chapter 3, we investigated SAT gene expression, clinical and metabolic profiles of individuals who were discordant for IR in their adipose tissue and skeletal muscle. We found that $40 \%$ of the study participants were discordant for IR in adipose tissue and muscle. Furthermore, we found that adipose tissue IR was characterized by an upregulation of inflammatory and ECM genes, and a worse metabolic and inflammatory profile as compared to adipose insulin sensitive individuals, regardless of concurrent presence of muscle IR. On the other hand, within individuals with a relative insulin sensitive adipose 
tissue and no major alterations in adipose tissue gene expression and systemic metabolic profile, a considerable group of individuals did develop muscle IR.

The data presented in Chapter $\mathbf{2}$ and 3, open new exciting avenues showing distinct IR subgroups in overweight and obese individuals in the development of type 2 diabetes and cardiovascular disease. Our findings could help identify functional subgroups of obese individuals with different risk profiles, which may represent a starting point for future research aimed at identifying novel, more effective precision-based prevention and treatment strategies of obesity and its complications.

In Chapter 4, using a publicly available collection of seven adipose tissue transcriptomics datasets and the bioinformatics tool TissueDecoder we presented an approach to assess the contribution of macrophages to the overall subcutaneous adipose tissue gene expression. We observed lower frequencies of adipocytes and higher frequencies of adipose stem cell in individuals characterised by high macrophage frequencies. Adipose tissue of individuals with high macrophage frequencies had a higher expression of genes involved in complement activation, chemotaxis, focal adhesion and oxidative stress. Similarly, we observed a lower expression of genes involved in lipid metabolism, fatty acid synthesis and oxidation and mitochondrial respiration. We hypothesized that increased macrophage and adipose stem cell percentage and the decreased percentage of adipocytes reflects adipose tissue inflammation and impaired pre-adipocyte differentiation, possibly reflective of a limited capacity for hyperplasia and adipose tissue dysfunction that contributes to an unfavourable metabolic profile.

In Chapter 5, we presented an approach to investigate the whole blood transcriptome of insulin resistant and insulin sensitive individuals, independent of white blood cell (WBC) profile. We showed the relative amount of monocytes to be significantly greater in the insulin resistant compared to the insulin sensitive participants. We demonstrated a distinct blood transcriptome profile in insulin resistance, independent of WBC profile. We observed that, the expression of interferon-stimulated genes(ISGs) in the whole blood was higher in insulin resistant as compared to insulin sensitive individuals. We hypothesised that this interferon related signature might indicate increased systemic inflammation possibly due to an innate immune response and whole-body insulin resistance, which can be a cause or a consequence of IR. We additionally observed a lower expression of genes involved in cellular differentiation in the whole blood of insulin resistant individuals. Hence, we think that the systemic inflammation in combination with the downregulation of cellular differentiation and remodelling of actin cytoskeleton we observed in the whole blood of the insulin resistant individuals may reflect obesity and/or insulin resistance related organ dysfunction, such as adipose tissue or gut.
Collectively in Chapters 4 and 5, we have shown the additive value of integrating publicly available datasets in combination with the useful application of cell-type composition in SAT gene expression (Chapter 4) and whole blood transcriptome analysis of IR (Chapter 5). In addition to identifying functional subgroups of obese individuals with different risk profiles, the contribution of macrophage frequencies and other cell types to organ/tissue dysfunction and plasticity, can offer targets and biomarkers for novel precision-based prevention and treatment strategies of obesity and its complications.

In conclusion, the present thesis investigated IR phenotypes in human obesity with transcriptomics data from the adipose tissue and the whole blood, and have offered insights which may represent a starting point for future research aimed at identifying novel, more effective precision-based prevention and treatment strategies of obesity and its complications. Future research should investigate the usefulness of stratification on IR phenotypes, single-cell approaches to further elucidate IR phenotypes and finally enable a data reuse culture. Precision-based strategies, either data-driven, knowledge-driven, or a combination of both, have the potential to change the conventional standards of care in human obesity. Nevertheless, parallel efforts from governments, policy makers and food industry are needed to make environments less obesity-promoting and more supportive of healthy eating and physical activity. Simply, making the healthy choice the easy choice. 


\section{Impact paragraph}

Cardiometabolic diseases are the number one cause of death globally. Among them, is cardiovascular disease (CVD) (e.g., heart attack, stroke, thrombosis) and diabetes mellitus (e.g., type 2 diabetes). Persons with type 2 diabetes have a two times higher chance to develop CVD, and it is the main cause of death in persons with type 2 diabetes (1). Cardiometabolic risk describes a person's chance of having a cardiovascular event when one or more risk factors are present. Both obesity and overweight are associated with insulin resistance (IR), which is a risk factor for the development of type 2 diabetes and cardiovascular disease. On that note, a plethora of evidence indicates the importance of adipose tissue mass and function and body fat distribution as important factors determining an individual's risk to develop obesity-associated cardiometabolic diseases, IR and type 2 diabetes.

The World Health Organization (WHO) defines obesity and overweight as "abnormal or excessive fat accumulation that presents a risk to health", and it is recognised as a disease. A body mass index (BMI) over 25 is considered overweight, and over 30 is obese (2). Obesity is an epidemic, with over 4 million people dying each year because of being overweight or obese, based on the WHO. It is therefore understandable, that treating obesity is very important. In successfully treating obesity, the primary course of action is to reduce weight, as losing weight is associated with a considerable improvement in risk factors associated with obesity. There are several ways to address obesity, from nutritional interventions (e.g., healthier eating habits, diets) to bariatric surgery. In the Netherlands, bariatric surgery, even though an effective treatment, is the last resort in combating severe (BMI over 35) and morbid obesity (BMI over 40) (3).

Nutritional interventions, on the other hand, are non-invasive strategies, which include personalised advice based on general guidelines for a healthy diet and physical activity. They are effective in the reduction of body weight or diabetes risk but are not effective in longterm weight maintenance for the majority of overweight and obese persons. Furthermore, nutritional interventions might improve glucose metabolism, insulin sensitivity and obesity-related health risks despite moderate weight loss, and these effects might be driven by the differential response of a certain subgroup (e.g. based on IR phenotype) to a diet composition. There is growing evidence showing that the severity of IR at the tissue level may play a role in the differential responses to lifestyle and pharmacological interventions that aim to increase insulin sensitivity (4-6). Hence, the effectiveness of an intervention might depend on individual or subgroup pathophysiological factors. This emphasises the need of identifying functional subgroups of obese individuals with different risk profiles, which might lead to a better understanding of the relationship between IR and type 2 diabetes and cardiometabolic risk. This may represent a starting point for future research aimed at identifying novel, more effective precision-based prevention and treatment strategies of obesity and its complications, contrary to the population-based strategies. 
Relevance of our results towards precision-based prevention and treatment strategies

In this thesis, we have used network and pathway analysis with transcriptomics data as a means to help elucidate the pathways and mechanisms that are altered in human overweight and obese IR phenotypes. We have provided mechanistic insight that the IR phenotypes discussed in this thesis are distinct (Chapter 2 and 3), which could help identify functional subgroups of obese individuals with different risk profiles. Furthermore, surrogate insulin sensitivity indexes MISI, HIRI and ATIRI (Chapters $\mathbf{2}$ and 3), are measures that have a great potential in providing relatively easy methods to classify and identify IR phenotypes. This is particularly important when suggesting nutritional intervention strategies for treating or preventing obesity-associated complications, as their effect on an individual might depend on the IR phenotype. In addition to identifying functional subgroups, we have highlighted the added value of knowing/determining cell type composition in the context of human obesity and IR (Chapters 4 and 5).

Collectively, our results might represent a starting point for future research aimed at identifying novel, more effective precision-based prevention and treatment strategies of obesity and its complications, contrary to the population-based strategies. Notably, future research is needed to first demonstrate that the IR phenotypes respond differentially to diet composition or other interventions. Subsequently, the implications of our findings and the fact that these IR phenotypes may respond differentially to food products or pharmacological agents might be interesting for the nutritional and pharmaceutical industry as it may give leads for product development. Furthermore, the results presented in this thesis may also may be relevant for prevention and give leads for health professionals for guidelines on how to stimulate a healthier lifestyle that will offer a societal benefit in reversing the obesity epidemic. Finally, our results represent a form of knowledge utilization and might be of interest for health professionals and scientists. They have been presented in relevant scientific meetings for obesity and diabetes and have been (or will be) published in academic peer-reviewed journals.

\section{Enabling data sharing and reuse to enhance scientific research}

In the era of "Big Data", with increasing costs for data generation, storage and computation, precision-based strategies come with high promises and the potential to be more effective with better understanding of individual factors that predict response. The "Big Data" revolution has enabled the scientific community to recognise the advantages of open and reusable data, while data sharing and reuse are becoming an important part of research, particularly in life sciences. On that note, the scientific community has established guidelines to improve and facilitate data reusability, known as "FAIR data principles" (7); sharing data has undeniable benefits, including minimising costs.
Throughout this thesis, we have used computational tools freely available and accessible to all the scientific community, which provide helpful insights for future research, warrant novel scientific discoveries, reduce costs but most importantly enable a research community of accountability and reproducibility. Furthermore, the computational approaches presented in this thesis hold great potential and have provided us with comprehensive and insightful information representing a starting point for future research aimed at identifying precision-based prevention and treatment strategies for obesity and its complications.

As an example, for pathway analysis, we used PathVisio (8) and the human-curated collections from WikiPathways (9), a continuously evolving and growing open community, where researchers can create and curate biological pathways. For network analysis, we used Cytoscape (10), which is an open-source platform for visualizing complex networks and integrating these with any type of attribute data. Importantly, these tools are user friendly, well documented and do not necessarily require experience in programming, therefore they can be useful to scientists without a computational background. Additionally, these tools offered powerful data representation by illustrating complex biological information, in the context of obesity and IR, in an intuitive way, which might represent a starting point for future research aimed at identifying precision-based prevention and treatment strategies.

In Chapter 4, we highlight the benefit of publicly available data reuse, which provided helpful mechanistic insight in the context of human obesity and IR. In addition, we have illustrated how other researchers can benefit from our proposed approach. In this way, data sharing and reuse also offers a form of knowledge utilization, which can be beneficial to the scientific community. Furthermore, in Chapters 4 and 5, we used two computational algorithms TissueDecoder (11) and EpiDISH (12) to perform computational deconvolution as an alternative to wet-lab experimental approaches for estimating cell type composition. Similarly to other university departments and scientists that mainly use computational we did not have access, sufficient funds, or as a matter of fact expertise to use wet-lab experimental approaches. Nevertheless, the proposed approaches and tooling offered us the opportunity to highlight the added value of knowing/determining cell type composition in the context of human obesity and IR. In those circumstances, publicly available datasets and computational deconvolution can tackle these hurdles and enable researchers without access to wet-lab experimental approaches to develop valid and useful computational approaches and tools that provide comprehensive and insightful information, as we have demonstrated in this thesis. 


\section{References}

1. Abdul-Ghani M, DeFronzo RA, Del Prato S, Chilton R, Singh R, Ryder REJ. Cardiovascular Disease and Type 2 Diabetes: Has the Dawn of a New Era Arrived? Diabetes Care. 2017;40(7):813-20.

2. Kelly T, Yang W, Chen CS, Reynolds K, He J. Global burden of obesity in 2005 and projections to 2030. Int J Obes (Lond). 2008;32(9):1431-7.

3. Verdam FJ, de Jonge C, Greve JW. [Practice guideline for the treatment of morbid obesity]. Ned Tijdschr Geneeskd. 2012;156(23):A4630.

4. Blanco-Rojo R, Alcala-Diaz JF, Wopereis S, Perez-Martinez P, Quintana-Navarro GM, Marin C, et al. The insulin resistance phenotype (muscle or liver) interacts with the type of diet to determine changes in disposition index after 2 years of intervention: the CORDIOPREV-DIAB randomised clinical trial. Diabetologia. 2016;59(1):67-76.

5. Otten J, Stomby A, Waling M, Isaksson A, Soderstrom I, Ryberg M, et al. A heterogeneous response of liver and skeletal muscle fat to the combination of a Paleolithic diet and exercise in obese individuals with type 2 diabetes: a randomised controlled trial. Diabetologia. 2018;61(7):1548-59.

6. Zheng J, Woo SL, Hu X, Botchlett R, Chen L, Huo Y, et al. Metformin and metabolic diseases: a focus on hepatic aspects. Front Med. 2015;9(2):173-86.

7. Wilkinson MD, Dumontier M, Aalbersberg IJ, Appleton G, Axton M, Baak A, et al. The FAIR Guiding Principles for scientific data management and stewardship. Sci Data. 2016;3:160o18.

8. Kutmon M, van Iersel MP, Bohler A, Kelder T, Nunes N, Pico AR, et al. PathVisio 3: an extendable

pathway analysis toolbox. PLoS Comput Biol. 2015;11(2):e1004085.

9. Martens M, Ammar A, Riutta A, Waagmeester A, Slenter DN, Hanspers K, et al. WikiPathways:

connecting communities. Nucleic Acids Res. 2021;49(D1):D613-D21.

10. Shannon P, Markiel A, Ozier O, Baliga NS, Wang JT, Ramage D, et al. Cytoscape: a software environment for integrated models of biomolecular interaction networks. Genome Res. 2003;13(11):2498-504.

11. Lenz M, Arts ICW, Peeters RLM, de Kok TM, Ertaylan G. Adipose tissue in health and disease through the lens of its building blocks. Sci Rep. 2020;10(1):10433.

12. Teschendorff AE, Breeze CE, Zheng SC, Beck S. A comparison of reference-based algorithms for correcting cell-type heterogeneity in Epigenome-Wide Association Studies. BMC Bioinformatics. 2017;18(1):105. 


\section{Acknowledgements}

One of my favourite poems, which you can find in the first pages of this thesis is called "Ithaka" by Constantine Cavafy (Greek poet). "Ithaka" describes a long journey, the return of Odysseus to his homeland Ithaka (island on the Ionian Sea) after the end of the Trojan War. This poem symbolises the journey of every man through life and suggests that each person is looking for his own Ithaca, their personal supreme goal. However, in the end, it is not the goal but the journey that matters, because this journey makes us wise and gives people the richest good: experience, knowledge, and maturity. In a way that's how I have experienced my PhD and its many challenges (e.g. punished by Zeus and Poseidon, captivated by the lotus-eaters and the Sirens, fought with a cyclops and had encounters with witches and monsters). In this journey, I was not alone; I had companions that either lifted or disheartened my spirits, and both in their way helped me to reach my own "Ithaka".

Ilja and Chris, thank you for giving me the opportunity to start a PhD and for the time you put 4 years in my supervision. A big thank you to all the people that helped me continue my PhD with the Department of Human Biology. Thank you Prof. de Vries for inviting me to your office, listening to me and offering me the opportunity to continue my $\mathrm{PhD}$ and for arranging the collaboration with Prof. Blaak. Anna, what an amazingly positive person you are! Thank you for listening to me, actively helping me, talking sense to me, hugging me, taking for coffee/lunch and checking up on me. You went above and beyond for me and I am truly grateful! Marloes, thank you for guiding me though the proceedings and even translating for me! Gerk, thank you for all your legal advice and the interest you took in my case!

A big thank you to my promotor and co-promotors. Ellen, thank you for accepting me in your group and picking up my PhD project. From our brief encounters before I joined Human Biology, I remember that you were always very kind to me, very helpful and genuinely interest in my research. We started our collaboration in March 2020 and you have been a truly amazing supervisor, guiding me when it is necessary and giving me space. Most importantly, you have been a mentor and you have supported me as a person. I will never forget your kind messages, either to congratulate me about a presentation or to reassure me that I can finish this PhD.

Marleen, thank you your kindness, for showing so much interest in my project, for providing clear and extremely fast feedback (and correcting all my typos and those commas I add for no particular reason), and finally thank you for working full-time with me this past year! Before our direct collaboration, I remembered how supportive you were with Birgitta, guiding and helping her especially towards the end of her PhD project, and of course your insightful thoughts and comments in all those "Sub-typing obesity" meetings.

Martina, you were one of the first persons I talked to when I applied for the PhD position 
in the department of Bioinformatics. Even though we had a skype call (without video), I remember that I liked you and I was happy to work with someone with your background. The past 5 years that we have known each other, you have always complimented my technical skills and respected me as colleague, treated me as a peer. In the many times that my PhD project was falling apart, you were there for me, actively helping me. Thank you for the M4G project - which is finally accepted and published! You have so many good qualities, by being extremely bright to extremely kind and respectful.

Finally, Michiel, our collaboration started in the second year of my PhD (September 2016). You have been my daily supervisor, a mediator and in a way my personal phycologist; a bit more than you most probably bargained for. Even though my PhD project was far from ideal or well planned (I cannot begin to count the difficulties we have faced), to the day, I honestly believe that if you were not my daily supervisor I would have quitted this $\mathrm{PhD}$ in 2016. You were and are a very charismatic and gifted person, a good mentor. I want to make very clear that I am extremely thankful to you for all the countless hours you have devoted to my PhD project.

A big thank you to my reading committee, Prof. Dr. Mariman, Dr. ir. Moerland, Prof. Dr. Shiri-Sverdlov, Prof. Dr.ir. Willems van Dijk, and Dr. Wouters for taking the time to read and evaluate my thesis.

A big thank you to my paranymphs Elisa and Lauren. I have chosen you as my paranymphs because you have been in this journey with me from the beginning and in your way you have kept me sane and helped me in some very difficult moments. You both have vibrant personalities and I have so many memories with you!

Elisa, you are all the colours of a rainbow! You are kind, dedicated, smart, energetic and positive! You taught me how to use PathVisio and Cytoscape, you have introduced me to RSG Netherlands and you have on-boarded me as a project manager at The Hyve. It was hard to see you go from the PhD office, but life brought us together again as colleagues at The Hyve! You have been a truly amazing colleague and a friend, and I wish you, Wael, Nadine, Mila and Zein all the best!

Laurena, you are kind, funny, smart, energetic and devoted! You were one of the first people I met when I moved to Maastricht. Even though I was the reason you were voted out the post-doc office (sorry not sorry, muhaha), I was happy to have you as a colleague at BiGCaT! No matter what people call you these days (Doctor Dupuis or Lady Doctor Dupuis), thank you for introducing me to Vivino, although I will never be able to match your drinking talent! Finally, thank you for being a good friend and I do wish you all the best in your life!
BiGCaTs: Jonathan, Nuno, Anwesha, Ryan, Denise, Marvin, Nasim, Amadeo, Egon, a big thank you for being nice colleagues! A special thank you to Freddie, the cake and wine master for organizing very nice gatherings! Susan thank you for introducing me to the Sinteklaas dice game and Lars, thank you for taking me to my first carnival experience and for helping me with statistics especially during my first year!

MaCSBio: Thank you all for the nice dinners, borrels and at times extremely dreadful lunch conversations! A special thank you to Samar; it has been a pleasure to work with you, thank you for teaching me how to use Inkscape, for sending me your thesis all the way from the UK and for never forgetting my birthday! Finally, Gokhan and Michael thankyou for your contribution to the $\mathrm{M}_{4} \mathrm{G}$ project and your helpful feedback.

Human Biology colleagues and Fat PhDs (Kelly, Ines, Dilemin, Thirza, Lina, Michelle, Kenneth, Lars, Jacco (also known as Tzako), Rens, Ioannis, Adriyan and Manuel) thank you! It has been an absolute honour working with all of you. Even though our collaboration was mostly online due to the corona virus, I could not have wished for better colleagues. You made me feel like home! Birgitta, although we were not in Human Biology at the same time, together we share a beautiful chapter in this thesis and through you I met Ellen. Thank you for all your help and for your tips on how to format my thesis!

IDE: Thank you for the nice workshops and chats! Especially, Linda (former BiGCaT) it was a pleasure meet you in San Francisco! Amrapali, rest in peace. Thank you for your enthusiasm and positivity and for helping us with the RSG semantic web workshop.

RSG Netherlands: Elisa, Joske, Gosia and Kyoko thank you for the nice events and collaboration!

To my Amsterdam friends: $\Sigma \tau \tilde{\varepsilon} \hat{\varepsilon} \lambda \boldsymbol{\lambda} \boldsymbol{\alpha}$ and Marcin we have countless memories from our time together in Amsterdam! $\Sigma \tau \varepsilon \lambda \lambda \boldsymbol{\alpha}_{\mathbf{\alpha}} \mathbf{k}$, thank you for your always visiting me in Maastricht, for always getting bags for me, and of course for being a good friend all these years! Hopefully

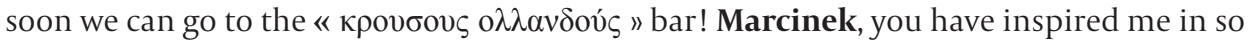
many ways and I am very grateful to have you in my life. Thank you for all the nice travels, beautiful conversations and professional advice. One day I might become a worthy friend and learn Polish as you have learned Greek. Till that day, I will stick to the basics: Jestem Mirella, kurwa, ssij mi chuja, na zdrowie!

To my many friends in Maastricht: Serena, you have been a role model! Thank you truly for being there for me in my darkest moments and for insisting on continuing my PhD. Petra, it was a pleasure to hang out with you, have long walks, nice conversations and Candiero ice cream! Sterrenplein has given me another friend for life (including Dries and Sigrid)! 
Carey \& Luke, Marcello \& Lina, Bruna, Timme thank you for all the nice moments we shared together! Carey \& Luke looking forward to seeing you in Australia one day! Camiel \& Sanne, thank you for all the fun times we had together (especially in La Rioja), the professional tips, nice conversations accompanied by wine and music that worsens as the alcohol increases!

Sergiy, I am so glad to have met you! Thank you for all our nice psychology conversations, walks, dinners and movie nights together. You are one of the sweetest people I know!

Dries (former MaCSBio) and Sigrid, I am so happy to have you in my life (and the "neutral kanaal")! Dries, thank you for all the Dutch Donderdags, for talking about the weather and not politics during the MaCSBio lunches. Thank you for being a very good friend, the dinners, walks, talks, movies and parties! I wish you all the best with your life in Sweden and your PhD. My nagging clearly did not convince you in not doing one! I have no doubt you will do an amazing job! Sigrid, what a pleasure it has been to hang out with you! Thank you for all the nice walks and conversations we had. Looking forward in seeing you both in Sweden (where Dries can fall yet again in the mud)!

Hazel, you are my family and our lives have been aligned from day one. I could not have completed this PhD without your friendship. Our "arranged" friendship has been a blessing in my life in Maastricht. You are an amazing woman, a leader, a force of nature and I am fortunate to have you in my life! I wish you and Erik all the happiness in the world. You deserve the best!

To my Greek friends: Eגívo, we have known each other from high school and our friendship has grown as much as we have. Words cannot describe how much you mean to me. I consider myself very lucky to have you in my life. You are always there for me. You are also there to drive me around, as you are my personal chauffeur all these years, since we all

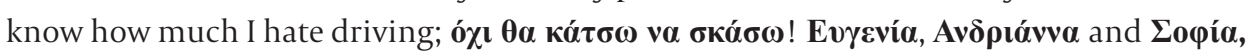

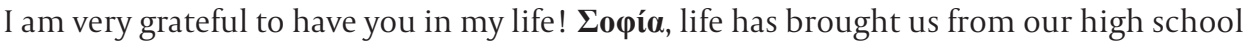
years in Piraeus to our adult life in the Netherlands. I will always look back at the photo I took when you arrived in Eindhoven or the fact that you wanted to have raki for breakfast! I know that it was not easy for you in the beginning but I am very happy that you have joined me in this journey!

To Joël's family: Marjo \& Joep, Hans \& Moniek, Aniek \& Ronald, thank you for all your support the last 3 years! Especially to Marjo and Hans, thank you for creating a beautiful, supportive and respectful man.

To my family: Thank you, $\Gamma \mathbf{\imath} \omega \boldsymbol{\tau} \boldsymbol{\alpha}$ for listening to me and constantly spamming me with cat photos! Be proud of what you have achieved; a business of your own, from scratch against

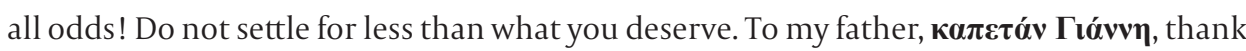
you for giving me the opportunity to study abroad and seeing to my education. To my

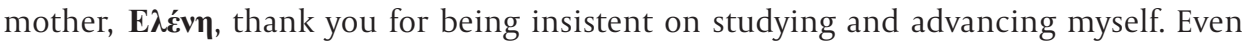

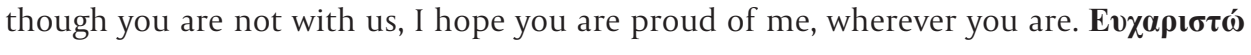

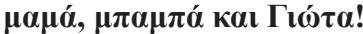

Joël, I would have not completed this PhD without you. Apart from extremely smart, supportive, loving, sweet, caring, honest, you have stood by me through my absolute worst. You have given me a place to call home, two cat children and you make me happy every day! Thank you for being the truly amazing person that you are, and most importantly thank you for loving and accepting me for who I am. Artemis and Apollo, my supreme, wonderful cat children, mama thanks you so much for being the two little bundles of joy that you are. Your purring and meowing has helped mama a lot. You have been a joyful distraction, gracefully destroying everything that we have!

I would also like to thank Candiero for providing me with delicious pistachio ice cream! I can honestly say that this $\mathrm{PhD}$ would not have been completed without your ice cream. I was very sad that you closed and I was forced to get ice cream from La Luna Rosa. This $\mathrm{PhD}$ would not have been completed without you as well paracetamol; so many times you have supported me and have taken my headache away.

Finally, finalising a PhD during Covid-19 was not ideal; nevertheless, I was very fortunate to be able to work from home and conclude my research without (major) delays. Covid-19 in a way was a blessing which reminded me to appreciate and focus on the things that matter and are truly important; therefore, I am truly thankful to have my health, a place to live, a place to work and love in my life. 


\section{About the author}

Mirella was born in Athens, Greece on June $24^{\text {th }} 1988$. In the early 200o's Mirella moved from her beloved port city of Piraeus to the south suburbs of Athens (Glyfada). While still living in Glyfada, for 3 years she travelled every day to Piraeus to attend gymnasium at the "Ionideios Model High School of Piraeus", where she graduated in 2003. After 2003, travelling back and forth from Glyfada to Piraeus was not an option anymore so she enrolled at the $6^{\text {th }}$ Glyfada Lyceum, where she graduated in 2006. In 2007 after taking the national Greek exams, she started her bachelor studies in Computer Science at the Athens University of Economics and Business (AUEB), where she graduated in 2013. During these studies, she discovered her interest in Bioinformatics after completing a 4-month internship at the Institute of Informatics and telecommunications (NCSR Demokritos) in Athens, where she developed a method to identify and classify areas of nucleosome binding DNA sequences from the species S.cerevisiae.

In August 2013, Mirella moved to Amsterdam for her master studies in Bioinformatics and Systems Biology at Vrije Universiteit Amsterdam. During these studies, she completed two internships (minor and major), where she worked for the first time in a wet-lab. In her minor internship she worked for the Department of Bioinformatics and Systems Biology (Vrije Universiteit) and she optimized PCR conditions and transformation protocols in order to construct a promoter library for E.coli. Furthermore, for her major internship she worked at the Department of Advance Analytical Discovery in Danone Nutricia Research (Utrecht), where she developed a bioinformatics method and experimental skills on protein profiling using LC-MS/MS to analyse the infant faecal microbiome.

In 2015, Mirella completed her master's studies and moved to Maastricht for her PhD. She started her PhD at the Department of Bioinformatics and Maastricht Centre in Systems Biology. In March 2020, she joined and completed her PhD at the Department of Human Biology under the supervision of Prof. Blaak, Dr. van Greevenbroek, Dr. Adriaens and Dr. Summer-Kutmon. In her PhD research she investigated human obesity and insulin resistance with transcriptomics data from adipose tissue and peripheral blood with datadriven approaches. She hopes that her research can provide helpful insights for precisionbased prevention and treatment strategies for obesity and cardiometabolic diseases. In March 2021 Mirella started working as a project manager at the "The Hyve" (Utrecht) where she contributes to the company's mission in enabling open science for better health care. Mirella enjoys long distance running (marathon finisher Rome 2018), cooking, and yoga and loves cats. 


\section{List of publications}

WikiPathways: a multifaceted pathway database bridging metabolomics to other omics research

Denise N Slenter, Martina Kutmon, Kristina Hanspers, Anders Riutta, Jacob Windsor, Nuno Nunes, Jonathan Mélius, Elisa Cirillo, Susan L Coort, Daniela Digles, Friederike Ehrhart, Pieter Giesbertz, Marianthi Kalafati, Marvin Martens, Ryan Miller, Kozo Nishida, Linda Rieswijk, Andra Waagmeester, Lars M T Eijssen, Chris T Evelo, Alexander R Pico, and Egon L Willighagen

Nucleic Acids Research, Volume 46, Issue D1, 4 January 2018, Pages D661-D667, https://doi. org/10.1093/nar/gkx1064

Subcutaneous Adipose Tissue and Systemic Inflammation Are Associated With Peripheral but Not Hepatic Insulin Resistance in Humans

Birgitta W. van der Kolk*, Marianthi Kalafati*, Michiel Adriaens, Marleen M.J. van Greevenbroek, Nicole Vogelzangs, Wim H.M. Saris, Arne Astrup, Armand Valsesia, Dominique Langin, Carla J.H. van der Kallen, Simone J.P.M. Eussen, Casper G. Schalkwijk, Coen D.A. Stehouwer, Gijs H. Goossens, Ilja C.W. Arts, Johan W.E. Jocken, Chris T. Evelo ${ }^{\S}$, and Ellen E. Blaak ${ }^{\S}$

*shared first authors, ${ }^{\S}$ shared last authors

Diabetes Volume 68, December 2019, https://doi.org/10.2337/db19-056o

Assessing the contribution of macrophage frequencies to subcutaneous adipose tissue

Marianthi Kalafati, Michael Lenz, Gökhan Ertaylan, Ilja C.W. Arts, Chris T. Evelo, Marleen M.J. van Greevenbroek, Ellen E. Blaak, Michiel Adriaens* and Martina Kutmon *

*Shared last authors

Frontiers in Nutrition and Metabolism, May 2021, https://doi.org/10.3389/fnut.2021.675935

An interferon related signature characterizes the whole blood transcriptome profile of insulin resistant individuals - The CODAM study

Marianthi Kalafati, Martina Kutmon, Chris T. Evelo, Carla J.H. van der Kallen, Casper G.

Schalkwijk, Coen D.A Stehouwer, Ellen E. Blaak, Marleen M.J. van Greevenbroek*, and Michiel Adriaens*

*Shared last aur

Under review in Genes and Nutrition

Metabolic features and differential gene expression analysis in individuals discordant for adipose tissue and muscle insulin resistance

Marianthi Kalafati, Martina Kutmon, Michiel Adriaens, Arne Astrup, Armand Valensia, Dominique Langin, Marleen M.J. van Greevenbroek, Ellen E. Blaak

Manuscript in preparation 


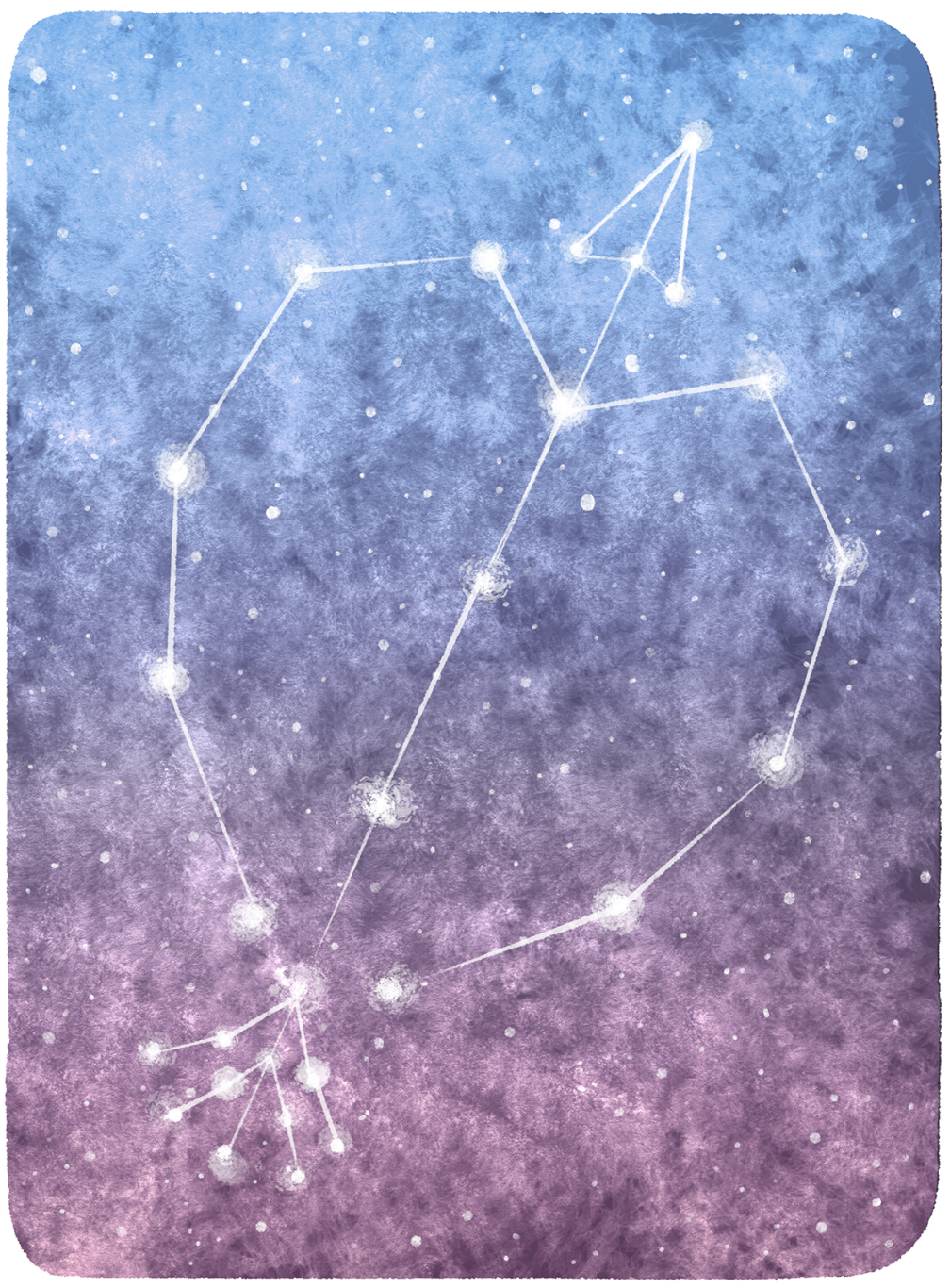

